\title{
Sistema celular evolutivo para reconhecimento de padrão invariante
}

\author{
Guillermo Cámara Chávez
}

Orientador:

Prof. Dr. Zhao Liang

Dissertação apresentada ao Instituto de Ciências Matemáticas e de Computação ICMC-USP, como parte dos requisitos para obtenção do título de Mestre em Ciências de Computação e Matemática Computacional.

$$
\begin{gathered}
\text { USP - São Carlos } \\
\text { Dezembro/2002 }
\end{gathered}
$$

\section{"VERSÃO REVISADA APÓS A DEFESA"}


Aos meus pais,

Rodolfo e Laura 


\section{Agradecimentos}

A Deus e a Mãezinha por estar sempre comigo.

Ao meu orientador, Prof. Dr. Zhao Liang, pelo esforço, dedicação e amizade. Espccialmente pela troca de idéias e pelo apoio nos momentos certos.

À minha família porque, ainda que longe, souberam ajudar-me a superar os diversos obstáculos e demonstraram-me sempre muito carinho.

Aos colegas e compatriotas pelo apoio nos momentos difíceis, eles atuaram como minha família, em especial ao Ernesto de quem recebi muitos conselhos c pelo apoio brindado.

Ao pessoal administrativo do ICMC. em especial à Beth, Laura, Ana Paula e Marília, pela disposição e atenção que sempre demonstraram.

Aus novos amigos que fiz em São Carlos e que ajudaram a sentir-me como se estivesse em casa.

À CNPq pelo apóio financeiro.

Guillermo 


\section{Resumo}

O reconhecimento de padrões tem provocado um grande interesse nas últimas décadas. Como consequiência. numerosas aplicações foram desenvolvidas. Entre as mais importantes podem-se citar as seguintes: ajuda ao diagnóstico médico, análise automática de sinais, inspeção automática de produtos industriais, sistemas de vigilância automática, busca automática de informação digitalizada, etc. A complexidade de um sistema de reconhccimento de padrões é alta, devido ao fato de que padrǒes reais se apresentam com grande variedade, sofrendo transformações e deformações não-lineares. Este trabalho tem como objetivo desenvolver um sistema celular evolutivo, para reconhecimento de padröes invariantes à rotação, bascado em mecanismos fundamentais de Autômatos Celulares, os quais foram usados com sucesso para modelagem e simulação de problemas complexos. O modelo proposto neste trabalho extrai eficientemente características globais invariantes à rotação de padrões, a partir das interações locais das células. 
Paltern recognition has provoked a great interest in the last decades. As a consequence, numerous engineering applications have been developed, such as medical diagnosis aiding, automatic signal analysis, industrial inspection, automatic monitoring systems, automatic digital information searching. etc. The complexity of a pattern recognition system is high because real patterns present in forms of large extent of varieties. suffering from linear transformations even nonlinear deformations. The objective of this work is to develop a evolutive cellular system for rotational invariant pattern recognition based on the fundamental mechanism of cellular automata, which has been successfully used to model and simulate complex problems. The proposed model extracts efficiently global features invariant to pattern rotation by local interactions among cellulars. 


\section{Índice}

1 Introdução 1

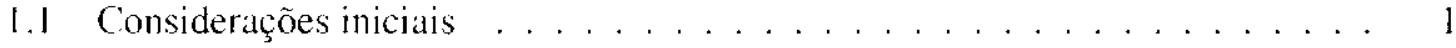

1.2 Objetivos . . . . . . . . . . . . . . . . . . . . . . . 4

1.3 Motivação . . . . . . . . . . . . . . . . . . . . 4

1.4 Estrutura do documento . . . . . . . . . . . . . . 5

2 Reconhecimento de Padrões Invariantes 6

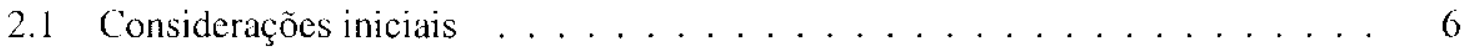

2.2 Terminologia e conceitos básicos . . . . . . . . . . . . . 6

2.2 .1 Coordenadas cartesianas e polares . . . . . . . . . . 7

2.2 .2 Momentos estatísticos . . . . . . . . . . . . . . . . . . 9

2.3 Monentos e momentos invariantes . . . . . . . . . . . . . . . . I0

2.3.I Momentos regulares invariantes . . . . . . . . . . . . . 10

2.3 .2 Momentos de Hu . . . . . . . . . . . . . . . . . . . . . . I I

2.4 Momentos ortogonais radiais . . . . . . . . . . . . . . . . . . . 13

2.4.1 Momentos de Zernike . . . . . . . . . . . . . . . . . . . 14

2.4.2 Momentos ortogonais Fourier-Mellin . . . . . . . . . . . . . 19

2.5 Momentos de Legendre . . . . . . . . . . . . . . . . . . . . . . . . . . 22

2.6 Monentos de Tchebichef . . . . . . . . . . . . . . . . . . . . . . . . . 23

2.7 wavelets . . . . . . . . . . . . . . . . . . . 26

2.7.1 Transformada de Wavelets . . . . . . . . . . . . . . . 27

2.7 .2 Momentos de Wavelets . . . . . . . . . . . . . . . . . 32

2.8 Redes de pulso acoplado . . . . . . . . . . . . . . . . . . . . . 35

2.8 .1 Rede de pulso acoplado seqüencial . . . . . . . . . . . . . . 38

2.9 Consideraçōes finais . . . . . . . . . . . . . . . . . . . . 42

3 Autômatos Celulares $\quad \mathbf{4 3}$

3.1 Considerações iniciais . . . . . . . . . . . . . . . . . 43

3.2 Introdução . . . . . . . . . . . . . . . . . . . . . . . . . . 43

3.2 .1 Notação e formalismo . . . . . . . . . . . . . . 44

3.3 Classificação do ACs . . . . . . . . . . . . . . . . . . . 46

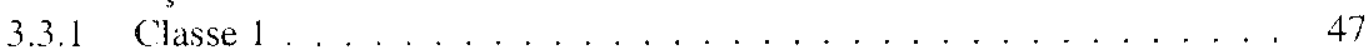

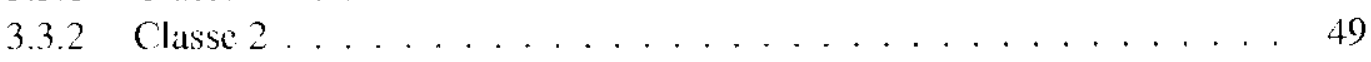




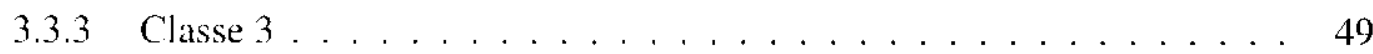

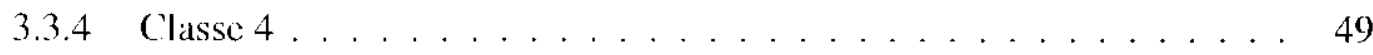

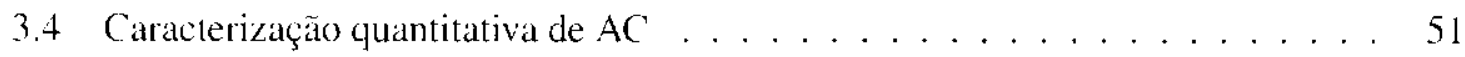

3.5 Comportamento dinâmico dos ACs . . . . . . . . . . . . 53

3.6 Capacidades computacionais dos ACs . . . . . . . . . . . . . . . . . . . 54

3.7 Construção de fractais utilizando $\mathrm{AC} \ldots \ldots \ldots$. . . . . . . . . . . . . . . . 55

3.8 Aplicaçôes dos ACs . . . . . . . . . . . . . . . . . . . . . 57

3.9 Extração de bordas de imagens utilizando AC . . . . . . . . . . . . . . 58

3.10 Consideraçòes tinais . . . . . . . . . . . . . . 58

4 Adaptive Resonance Theory (ART) 59

4.1 Considerações iniciais . . . . . . . . . . . . . . . . . 59

4.2 Introdução . . . . . . . . . . . . . . . . . . . . . . . . . . . . . . 59

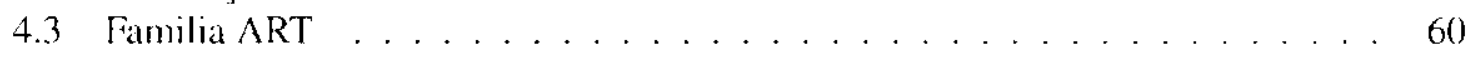

4.3 .1 ART1 ........................... 61

$4.3 .2 \quad$ Fuzy ART . . . . . . . . . . . . . . . . . . . . . 65

4.4 Consideraçōes finais . . . . . . . . . . . . . . . . . . . . 68

5 Sistema Celular Evolutivo para extração de características invariantes $\quad 69$

5.1 Considerações iniciais . . . . . . . . . . . . . . . . . . . . . 69

5.2 Modelo proposto . . . . . . . . . . . . . . . . . . 70

5.3 Resultados de classificação . . . . . . . . . . . . . . . . . . . 76

5.4 Considerações linais . . . . . . . . . . . . . . . . 78

6 Conclusões e Trabalhos Futuros $\quad 79$

6.1 Considerações iniciais . . . . . . . . . . . . . . . . . . . 79

6.2 Conclusöes . . . . . . . . . . . . . . . . . . . . . . . . . 79

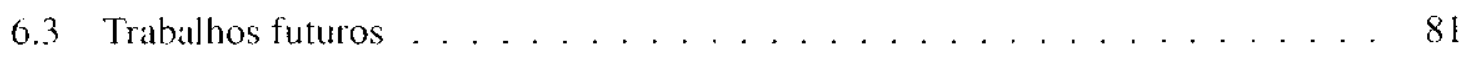

$\begin{array}{lr}\text { Referências Bibliográficas } & \mathbf{8 1}\end{array}$ 
1.1 O esquema geral para sistemas de reconhecimento de padrões. . . . . . . . . . 2

2.1 Representação de uma imagem através da função $f(x, y)$, tal que a função representa intensidade do pixel posicionado nas coordenadas $(x, y) \ldots \ldots 7$

2.2 Eixos das coordenadas polares. . . . . . . . . . . . . . . . 8

2.3 (a) Imagem de um caracter chinês a ser transformada em coordenadas polares,

(b) Círculos concêntricos e ângulos eqüidistantes. . . . . . . . . . . 8

2.4 (a) Círculos concêntricos desenhados na imagem, (b) Imagem transformada em coordenadas polares. . . . . . . . . . . . . . . . . 9

2.5 Mapeamento em coordenadas polares da imagem dentro do círculo unitário. . . 9

2.6 Transformaçōes geométricas da imagem "morcego" sendo rotacionada em $0^{\circ}$, $20^{\circ}, 45^{\circ}, 90^{\circ}$ e $120^{\circ}$ respectivamente. . . . . . . . . . . . 12

2.7 Os sete momentos de Hu extraídos das imagens "morcegos". . . . . . . . . . . 13

2.8 Polinômios de Zernike de diferentes ordens, (a) de ordem 2, (b) ordem 4. (c) de ordem 6, (d) de ordem 8. (e) de ordem $R_{p,|10|}(\rho)$. (f) de ordem $20 . \ldots 16$

2.9 Os momentos de Zernike de ordem 8 extraídos das imagens "morcegos". . . . . 17

2.10 Reconstruçôes de imagens a partir de seus próprios momentos. De esquerda para a direita e de cima para baixo, as ordens dos momentos são de 15,20, 30 e 40, respectivamente. . . . . . . . . . . . . . . . 18

2.11 Momentos Ortogonais Fourier-Mellin $R_{p}(\rho) \ldots \ldots \ldots \ldots \ldots \ldots$

2.12 Os momentos de Fourier-Mellin de ordem 5 extraídos das imagens "morcegos" (ver Figura 2.6 ). . . . . . . . . . . . . . . . . . . . . . . . 21

2.13 Polinômio de Legendre. . . . . . . . . . . . . . . . . . . . . . 22

2.14 Polinômio de Tchebichef. . . . . . . . . . . . . . . . . . . . . . 26

2.15 Reconstruçôes de imagens a partir de seus próprios momentos. (a) mostra a imagem original. A imagem é reconstruída através dos seus momentos de or-

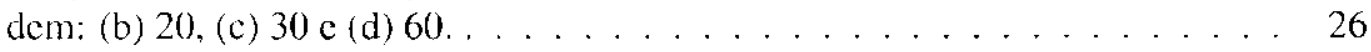

2.16 Sistema de Haar, wavelet primaria. . . . . . . . . . . . . . . 30

2.17 Multi-resolução usando as wavelets de Haar. A primeira é a imagem original, a segunda é a multi-resolução através das wavelets de Haar e a terceira é a reconstrução da imagem através das wavelets e dos detalhes. . . . . . . . . . . . .

2.18 Famílias de wavelets de Daubechies. Correspondentes funções de escala c wanelets primárias; $N=203$ (Lima, 2002). 
2.19 Multi-resolução das wavelets de Daubchies de ordem 2. . . . . . . . . . 32

2.20 Padrões semelhantes " 1 " e "l" que pertencem a classes diferentes. . . . . . . 32

$2.21 \wedge$ wavelet mãe B-spline cúbica. . . . . . . . . . . . . . . . . . 33

2.22 Representação gráfica das 4 diferentes dilataçōes que sofre as wavelets $\mathrm{B}$-spline cúbicas para $m=0, m=1, m=2$ e $m=3$ respectivamente. . . . . . . 34

2.23 Momentos das wavelets B-spline cábicas cxtraídos das imagens "morcegos" (ver Figura 2.6).

2.24 O modelo consta de três partes: a árvore de sinapse, o enlace e o gerador de pulsos. A árvore de sinapse é dividida em dois canais, enlace e alimentação. As entradas são pulsos provenientes de outro neurônios e a saída é um pulso. A entrada de enlace modula a entrada de alimentação. Quando o pulso acontece durante a entrada de enlace, este faz incrementar rapidamente a energia interna total $U_{j}$ e faz com que o neurônio dispare ao mesmo tempo. . . . . . . . . . . . .

2.25 A figura mostra como um elemento dispara sob condições de um pulso de sáída.

2.26 Vizinhança de von Neumann (a) c Moore (b) do elemento i.

2.27 (a)lmagem "Lenna" c (b) Vetor de somatório de pulsos da imagem em (a) e suas versões rotacionadas em $2\left(0^{\circ}, 15^{\circ} \mathrm{e} 90^{\circ}\right.$ respectivamente. . . . . . . . . 38

2.28 Grade de codificação. . . . . . . . . . . . . . . . . . . . . 40

2.29 (a) Codificador de grade com unidades ativadas (escuras). (b) Codificador de grade com unidades ativadas (escuras) para um contorno rotacionado. (c) Ilustração da função do codificador de grade: pulsos correspondentes às varreduras horizontais e verticais de(a). (c) Ilustração da função do codificador de grade: pulsos correspondentes às varreduras horizontais e verticais de (b). . . . . . . .

2.30 Representação do diagrama de blocos do modelo proposto por Rishikesh. . . .

3.1 Exemplos da classificação de Wolfram. onde $r$ representa o raio e $k$ o número de estados. A classe 1, independentemente da contiguração inicial, o AC tende a um estado global espacialmente homogêneo; a classe 2, atinge um estado estável formado por estruturas espaciais periódicas estáveis: a classe 3, têm um comportamento caótico, a maioria de ACs da classe 3 gera padrões fractais e; a classe 4, podem ser geradas estruturas estacionárias, periódicas ou fractais. As estruturas persistentes podem ser simples, também crescentes e complexas. . .

3.2 ACs da classe 2, atingem um estado estável formado estruturas espaciais per-

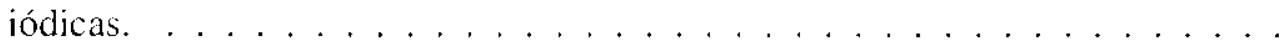

3.3 ACs da classe 3, não apresentam estrutura alguma, tendo um comportamento caótico; isto ocorre por causa de seu comportamento imprevisível. . . . . . . .

3.4 ACs da classe 4, aparecem estruturas complicadas, as vezes localizadas e outras transladando-se pelo espaço celular. Tem-se conjeturado que os ACs desta classe são capazes de processar informação ao estilo das máquinas de Turing. (a) ACs com estruturas crescentes que evoluem a estados "nulos", (b) ACs com estruturas persistentes (Wolfram, 1984).

3.5 Estruturas persistentes encontradas nas evoluções dos ACs da classe 4 desde estados iniciais diferentes de zero (Wolfram, 1984) . . . . . . . . . 51

3.6 Estado inicial . . . . . . . . . . . . . . . . . . . . . . 55

3.7 Depois de várias iterações a célula vai evoluindo, formando o fractal especificado nas regras do exemplo $1 . \ldots \ldots \ldots 5$ 
3.8 Fractal gerado a partir das regras do exemplo $1 . \ldots \ldots \ldots 6$

3.9 Fractal formado pelas regras descritas no Exemplo 2. . . . . . . . . . . . 56

3.10 Extração de bordas de imagens binárias e em níveis de cinza. . . . . . . . . . 58

4.1 Arquitetura simplificada da ART1 . . . . . . . . . . . . . . 61

4.2 Uma outra visão da arquitetura ART 1. . . . . . . . . . . . . . . 62

4.3 Arquitetura da fuzz ART . . . . . . . . . . . . . . 66

5.1 Matriz de pesos para três camadas de vizinhos com distribuição gaussiana. . . . 71

5.2 Atividade interna das células, pode-se ver que apresentam um comportamento periódico. . . . . . . . . . . . . . . . . . 71

5.3 Transformações geométricas das imagens "araras" e "cachorro", sendo rotacionadas em $00^{\circ}, 37^{\circ}, 45^{\circ}$ e $90^{\circ}$ respectivamente. . . . . . . . . . 72

5.4 Vetores de estado e de pulsos do sistema respectivamente. . . . . . . . . . . 72

5.5 Vetores de estados para a imagem (a) "araras" e (b) "cachorro" com rotações de

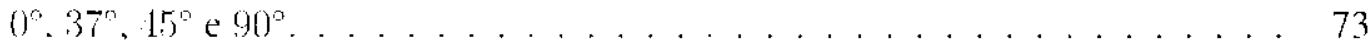

5.6 Vetores de pulsos para as imagens (a) "araras" c (b) "cachorro", com rotações

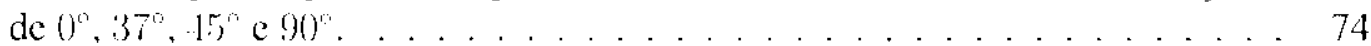

5.7 Diferença entre o vetor da imagem "cachorro" original com suas transformações cm $37^{\circ}, 15^{\circ}$ e $90^{\circ}$. (a) trata-se dos vetores de estados e (b) trata-se dos vetores de pulsos. . . . . . . . . . . . . . . . . . . . . . .

5.8 A formação de padrão. A primeira linha mostra a formação de padrão por estados celulares e a segunda linha mostra a formação de padrão por pulsos. (a) a formação de padrão depois de 5 iterações. (b) depois de 8 iterações, (c) 20 iterações e (d) 50 iterações. . . . . . . . . . . . . . . . . . . . .

5.9 Padrões adicionais usados para testar as técnicas e serem classificados posteriormente, (a) Lenna, (b) lince c (c) leão. . . . . . . . . . . . . . . . . . 75

5.10 Vetores de estados das imagens originais das Figuras 5.3 e 5.9. (a) Mostra os vetores completos, cada um com 200 iterações e (b) mostra uma seção do vetor.

5.11 Imagens com ruído. Começando de esquerda para direita e de cima para baixo apresentam-se versões com ruído, tendo uma porcentagem de ruído de $5,10,20$

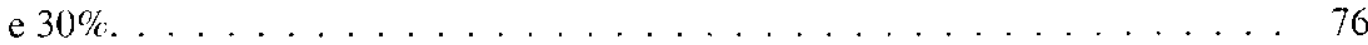

5.12 (a) Vetores de estados das imagens com diferentes porcentagens de ruído. (b)Diferença (distância) entre o vetor da imagem original com os vetores com porcentagens de ruído de $5,10,20,30 \%$. As imagens com ruído são ạjuelas que vemos na

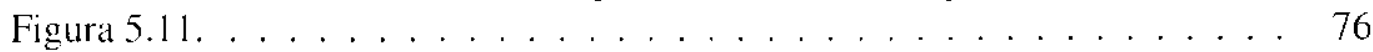




\section{Lista de Tabelas}

4.1 Analogia entre ARTI e fuzzy ART . . . . . . . . . . . . . . . . . 66

5.1 Valores dos parâmetros para a rede fuzzy ART. . . . . . . . . . . . . . . . 77

5.2 Resultado de classificação por diversas técricas de extração de características invariantes. . . . . . . . . . . . . . . . . 77 


\subsection{Considerações iniciais}

O reconhecimento de padrões é o estudo de como as máquinas observam o entomo, aprendem a distinguir padrões de interesse e tomam decisões razoáveis sobre as categorias dos padrões (Jain et al., 2000). Um padrão é uma descrição de um objeto que pode ser classificado como: concretos (espaciais: caracteres, imagens; e temporais: formas de onda, séries. etc) e abstratos (raciocínio, soluções a problemas, etc) (Watanabe, 1985). Um computador consegue reconhecer padrões. convertendo-os em sinais digitais e comparando-os com outros sinais já armazenados na memória.

O reconhecimento de padrão abrange sub-disciplinas tais como: processamento de imagens, extração de características, estimação de crro, análise de clusters c classificação de dados, ete. As técnicas de reconhecimento de padrões podem ser aplicadas $\mathrm{cm}$ vários domínios, dentre os quais podemos mencionar a bioinformática, mineração de dados, automação industrial, etc (Jain et al.. 2000). Mais especificamente, podemos encontrar aplicações desta tecnologia como reconhecimento de caracteres de escrita manual, reconhecimento de voz, robótica, etc.

O uso intensivo de computadores, outros dispositivos eletrônicos $\mathrm{c}$ avanços da tecnologia têm impulsionado o estudo e aplicação de técnicas de reconhecimento de padrões. 
Embora a aplicabilidade das técnicas se mostre, a priori, muito ampla: năo existe um método que seja a panacéia. Diversas razões fazem com que os sistemas de reconhecimento de formas sejam específicos para cada problema a resolver: A natureza dos padrões (caracteres escritos. símbolos, desenhos, imagens biomédicas, objetos 3D, assinaturas, etc); os requerimentos do sistema, cspecialmente em tempo de resposta, fazem com que alguns métodos de reconhecimento, mesmo superiores em qualidade, não sejam aplicáveis na prática por serem inferiores no tempo de resposta; $\mathfrak{c}$ fatores econômicos. um sistema equipado com diferentes sensores $\mathrm{c}$ equipamentos de processamento muito potentes podem dar resultados muito satisfatórios. mas não podem ser adquiridos pelos usuários (Cortijo, 2000).

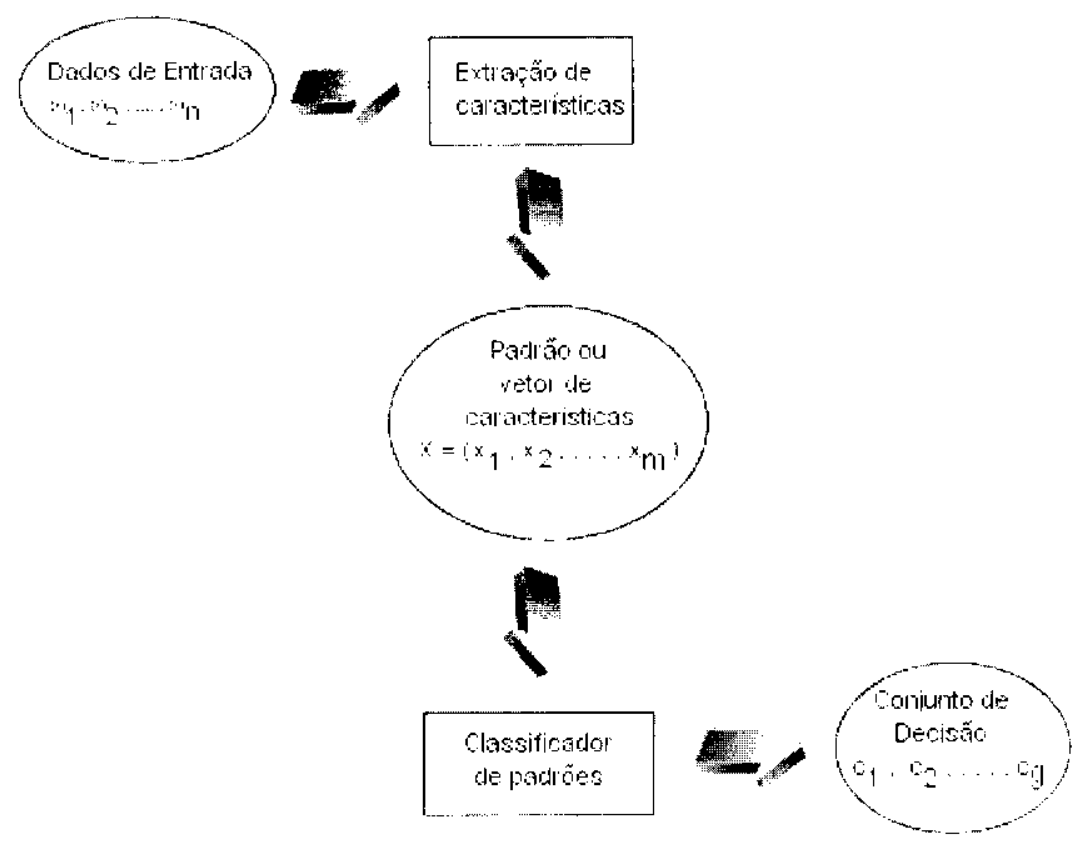

Figura 1.1: O esquema geral para sistemas de reconhecimento de padrões.

Uln sistema de reconhecimento geralmente compreende três componentes principais: préprocessamento, extração de características e classificação. ver Figura 1.1. Na etapa de pré-processamento, os dados de entrada são manipulados por uma variedade de métodos que fazem operações, tais como remoção de ruído, segmentação e melhoramento da qualidade dos mesmos. Na extração de características, o objetivo é representar os dados de entrada em termos de medidas quantificáveis que possam ser utilizados facilmente na etapa de classificação. Em geral, acredita-se que um problema de reconhecimento de padrões bem definido e restrito (com pequenas variações intra-classe e grandes variações inter-classes), permitirá uma representação compacta dos padrões e uma estratégia de decisão simples. Mas nem sempre os padrões a serem reconhecidos possuem essas características. Nesse fato reside a importância de algorit- 
mos de extração e seleção de características. Na classificação, os padrões são agrupados em lunçâo das características comuns entre eles.

O problcma do reconhecimento de padrões ć reconhecer padrões que sejam, em algum sentido, "os mesmos" apesar de ter experimentado uma variedade de transformações permitidas. Os padrões de imagens na vida real apresentam transformações gcométricas lineares (rotaçã̃o, escala e translação), deformações não lineares e variância de iluminação e background, etc. Este tipo de reconhecimento pode ser uma tarefa simples para os seres humanos e para os animais, mas converte-se em um grande problema se tentamos realizá-lo através de um computador. Os métodos tradicionais de reconhecimento de padrôes carecem da habilidade para reconhecer o mesmo padrão com certo tipo de variância. Portanto, a pesquisa c o desenvolvimento de técnicas e sistemas de Reconhecimento de Padrão Invariante (RPI) são importantes tanto para fins teóricos quanto na prática. Atualmente, as principais abordagens de RPI são realizadas através de extração de características invariantes antes da classificação. Algumas dessas técnicas se cnvolveram procurando representações do padrão em novos espaços diferentes do original (espaço cartesiano, na maioria dos casos). tal que a representação no novo espaço é invariante sob as transformações. Também existem outras técnicas para a análise dos padrões como os momentos estatísticos, as transformadas de Fourier, as transformadas de wavelets, o casamento de grafos e redes neurais como as redes de pulso acoplado.

O autômato celular foi proposto por Von Neumann como um modelo formal para simular organismos auto-reprodutivos (Sarkar, 2000). Esta técnica é uma alternativa poderosa para resolver problemas onde existe incertezas ou ruídos. Esta técnica tem tomado várias idéias $\mathrm{c}$ conceitos da psicologia sobre o aprendizado e a forma como este se realizá no homem. Também. tem se tomado alguns comportamentos observados em seres vivos e na sua adaptação ao meio. Durante muito tempo, foi complicado modelar este tipo de sistema.

Os autômatos celulares não só estão baseados no comportamento dos sistemas biológicos, mas também capturam muitas características essenciais do comportamento auto-organizado (cooperação e competição) observado em outros sistemas naturais. Esta auto-organização vai evoluindo, desde a interação local das células com seus vizinhos, até gerar um efeito global.

Os autômatos celulares fornecem vários modelos não só para pesquisa teórica, como um modelo puramente matemático; mas também para resolver muitos problemas reais. Entre as aplicações podemos encontrar: processamento de imagens (Tzionas, 2000), (Viher et al., 1998), modelamento de redes de computadores (Zhiliang et al., 2002), modelamento de sistemas biológicos (dos Santos e Coutinho, 2001). Neste trabalho, ilustra-se que os autômatos celulares também podem ser uma ferramenta útil para reconhecimento de padrões invariantes. 
Neste capítulo, são discutidos o contexto, as motivaçōes, a relevância do temá da Dissertação dentro da área da Inteligência Artificial e os objetivos cspecíficos a serem atingidos. $\Lambda$ organização da Dissertação é apresentada na última seção deste capítulo.

\subsection{Objetivos}

No presente trabalho objetiva-se investigar autômatos celulares para extração de características invariantes à rotação do padrão.

Esse objetivo geral contém dois objetivos específicos a serem atingidos:

1. Estudar e analisar os métodos representativos de extração de características invariantes com o foco de métodos bascados em momentos estatísticos, a fim de comparar os desempenhos dos mesmos frente a transformações geométricas e deformações não lineares. Além dos momentos, também serão cstudadas redes de pulso acoplado paralelas c seqüenciais. as quais serviram como inspiração para o presente trabalho.

2. Descnvolver um modelo baseado $\mathrm{cm}$ idéias fundamentais de autômato celular. que permitam extrair características invariantes à rotação e que possuam certo nível de tolerância ao ruído.

\subsection{Motivação}

As motivações deste trabalho são originadas pelas necessidades práticas de um sistema de reconhecimento de padrões invariantes à rotaçâo e as características do autômato celular, tais como:

1. Reconhecimento automático de um objeto em uma cena, sem levar em consideração a posição e orientação. Entre estas aplicações têm-sc: inspeção c empacotamento de partes para manufatura, classificação de cromossomos, identificação de alvos, análise de cenas, etc.

2. Os métodos para extração de características invariantes existentes possuem certas limitações, sendo a principal a tolerância baixa ao ruído. Também temos como outra limitação o alto custo computacional da maioria das técnicas. Por exemplo, os momentos de alta ordem precisam de um elevado número de iterações. 
3. Os autômatos celulares possuem uma estrutura simples, mas são capazes de simular sistemas complexos. Trabalhos recentes mostram a capacidade e potêncial destes modelos, assim como a grande diversificação de áreas em que são usados.

4. Os autômatos celulares bi-dimensionais possuem uma cstrutura semelhante à organização natural de padrões a serem reconhecidos, tais como imagens, i.e., existe uma correspondência direta entre uma célula e um pixel de uma imagem, facilitando a representação de padrões originais.

\subsection{Estrutura do documento}

Este trabalho está organizado como segue: No capítulo 2, serão apresentadas as técnicas de reconhecimento de padrões invariantes assim como os conceitos fundamentais dos mesmos. No capítulo 3, serão descritos os autômatos celulares seguindo a classificação feita por Wolfram. No capítulo 4, serão apresentadas as redes neurais artificiais ARTI e fuzzy ART, esta última será utilizada como classificador de vetores de características extraídos pelos métodos apresentados neste trabalho. No capítulo 5, será apresentado o modelo proposto por nós. Nesse capítulo, descrever-se-ão as diferentes regras de transição usadas neste projeto e finalmente no capítulo 6, serão apresentadas as conclusões e futuros trabalhos. 


5

Reconhecimento de Padrões

Invariantes

\subsection{Considerações iniciais}

Neste capítulo, serão apresentadas as principais técnicas existentes de extração de caracteríslicas invariantes à translação, escala c rotação, tais como os momentos estatísticos, transformada de Fourier, transformada de wavelets, redes de pulso acoplado paralelas e sequienciais. Primeiro, apresentar-se-ão diferentes espaços de representação de imagens c conceitos básicos de momentos estatísticos. Depois disso, vários momentos serão apresentados, destacando sua utilidade. Especificamente, são os momentos de Hu, de Zernike, de Fourier-Mellin, de Legendre, de Tchebichef e momentos de wavelets. Finalmente. serão descritas as redes de pulso acoplado em suas duas versões, paralelas e sequienciais, as quais serviram como inspiração para o modelo proposto neste trabalho.

\subsection{Terminologia e conceitos básicos}

Esta seção servirá para ter uma noção elementar sobre coordenadas cartesianas e polares (sistema de coordenadas sobre as quais estão bascados os momentos em sua maioria, atingindo 
desta forma a invariância à rotação), assim como uma breve introdução sobre os momentos estatísticos.

\subsubsection{Coordenadas cartesianas e polares}

Uma imagem é definida como uma função linear por partes $\int(x, y)$, portanto limitada, no plano $x y$ isto é, $f(x, y)$ representa a intensidade (níveis de cinza) do pixel posicionado nas coordenadas $(x, y)$ de uma imagem. No caso de imagem digital, esta função intensidade contém valores discretos. A Figura 2.1 mostra uma imagem $\mathrm{de} N \times N$ pixels, onde as coordenadas $r \mathrm{c}$ $y$ vão de 0 a $N-1$. Cada pixel $(x, y)$ tem uma intensidade $f(x, y)$.

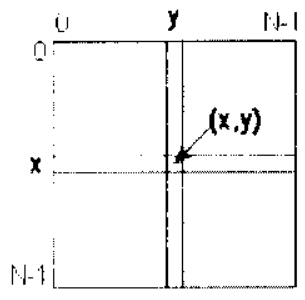

Figura 2.1: Representação de uma imagem através da função $f(x, y)$, tal que al função representa intensidade do pixel posicionado nas coordenadas $(x, y)$.

As coordenadas cartesianas bi-dimensionais são coordenadas retilíneas. as quais também são chamadas de coordenadas retangulares. Os dois cixos das coordenadas cartesianas bi-dimensionais denotam os eixos das abscissas $(x)$ e das ordenadas $(y)$, sendo estas lineares e mutuamente perpendiculares.

As coordenadas polares bi-dimensionais são coordenadas constituidas por $p$ (coordenada radial) e $\theta$ (coordenada angular), ver Figura 2.2, estas estão definidas $\mathrm{cm}$ termos das coordenadas cartesianas:

$$
\begin{aligned}
& x=\rho \cos \theta \\
& y-\rho \operatorname{sen} \theta .
\end{aligned}
$$

onde $p$ é a distância radial desde a origem, e $\theta$ é o ângulo em sentido anti-horário desde o eixo $r$. Em termos de $x$ e $y$.

$$
\begin{aligned}
& \rho=\sqrt{x^{2}+y^{2}} \\
& 0=\lg ^{-1}(y / x)
\end{aligned}
$$




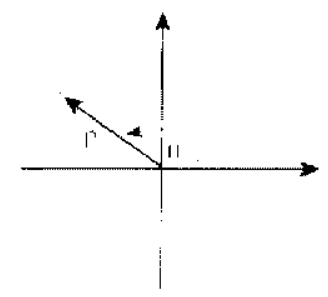

Figura 2.2: Eixos das coordenadas polares.

A seguir apresenta-se uma técnica de transformaçăo de coordenadas cartesianas em polares, tal que o padrão seja invariante à translação, usada nas seguintes seções. A invariância à translação pode ser atingida encontrando o centróide da imagem $\left(x_{c}, y_{c}\right)$, sendo este a origem das coordenadas polares. Seja $d=\max _{f(x, y ; \neq 0} \sqrt{\left(x-x_{c}\right)^{2}+\left(y-y_{c}\right)^{2}}$ a maior distância desde a origem $(x, y)$ ao ponto $(x, y)$ dentro da imagem.

Então, devemos desenhar $N$ círculos concêntricos imaginários centralizados $\mathrm{em}\left(x_{n}, y_{r}\right)$ com um raio $(d \times i) / N, i=1.2, \ldots, N$. Também, vamos gerar $N$ vetores radiais equiidistantes no ângulo $\theta$ partindo desde $\left(x_{c}, y_{c}\right)$ com ângulos de $2 \pi / N$. Podemos ver nas Figuras 2.3 e 2.4 o processo que foi feito para poder transformar a imagem em coordenadas polares. Na Figura 2.3 (a) deve-se calcular o centróide da imagem, o qual será a origem das coordenadas polares, em (b) círculos concêntricos imaginários são desenhados tomando como a origem o centróide achado em (a).

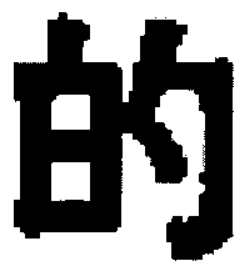

(a)

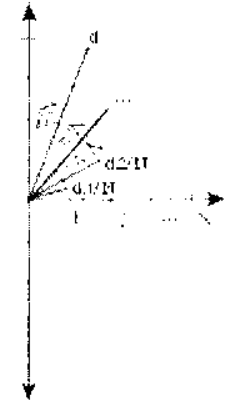

(b)

Figura 2.3: (a) Imagem de um caracter chinês a ser transformada em coordenadas polares, (b) Círculos concêntricos e ângulos equidistantes.

Na Figura 2.4 (a) já vemos os círculos desenhados sobre a imagem, cada ponto definido pelo raio $\rho$ e o ângulo $\theta$ será mapeado para poder encontrar o valor correspondente em coordenadas polares, em (b) temos a imagem desenhada em coordenadas polares.

As descrições dos parágrafos anteriores mostram como transformar uma imagem completa em coordenadas polares, mas também podemos transformar somente uma parte dela, aquela que seja de interesse para nós. Esta outra forma seria achar uma caixa que circunscreva 


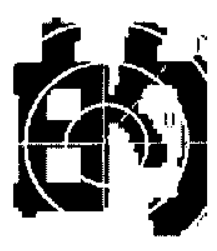

(a)

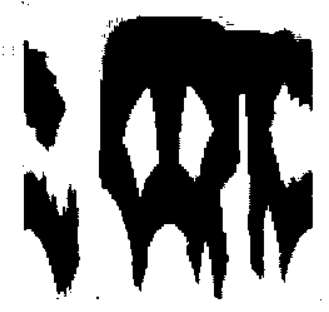

(b)

Figura 2.4: (a) Círculos concêntricos desenhados na imagem, (b) Imagem transformada em coordenadas polares.

o padrão de interesse $(f(x, y) \neq 0)$. logo deve-se encontrar o centróide, que, como no caso anterior, também será a origem. A partir do centróide deve-se achar o rajo de maior comprimento desde a origem até um dos vértices da caixa. Como desejamos mapear a imagem dentro do ćŕculo unitário (condição necessária para os momenıos radiais). este raio será de comprimento 1. Para achar o raio vamos nos valer das componentes retangulares do raio $\rho$, onde $\rho=\sqrt{\left(x-x_{c}\right)^{2}+\left(y-y_{c}\right)^{2}}$ e o ângulo $\theta=\arctan (\Delta y / \Delta x)$. Na Figura 2.5 podemos ver de forma gráfica como encontrar o raio $\rho$ e o ângulo $\theta$.

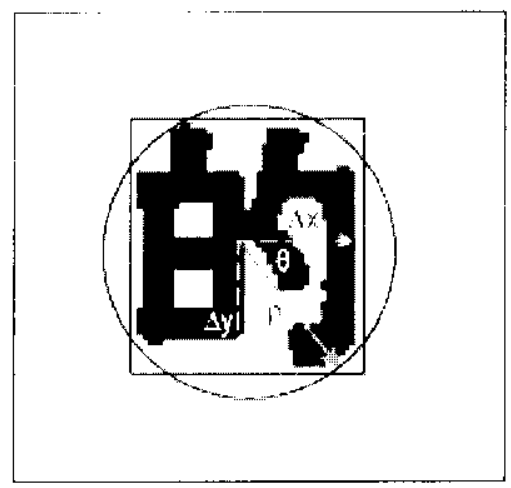

Figura 2.5: Mapeamento em coordenadas polares da imagem dentro do círculo unitário.

\subsubsection{Momentos estatísticos}

As funções de momentos são usadas como descritores de formas em uma grande variedade de aplicações. como reconhecimento visual de padrôes (Belkasim, 1991),(Flusser, 1993), classificação de objetos, template matching (Goshtasby, 1985), deteç̧ão de bordas (Ghosal e Mehrotra, 1993) e compressão de imagens (Hsu, 1993). Em todas estas aplicações. os momentos desempenharam uma função importante na descrição de formas de imagens, e na extração de características que são invariantes às transformações geométricas. 
Teague (Teague, 1980) sugeriu o uso de momentos ortogonais para recuperar a imagem desde os próprios momentos, baseado na teoria de polinômios ortogonais, e introduziu os momentos de Zernike, que permitem que os momentos invariantes independentes sejam construídos facilmente. Os momentos de Zernike e Legendre foram estudados extensivamente no passado recente, e novas técnicas cvoluíram baseadas nos momentos ortogonais como detector de características. Em (Boyce e Hossack, 1983), os momentos rotacionais são usados para estender a definição dos momentos invariantes em uma ordem arbitrária de uma forma que assegurem que as magnitudes não diminuam significativamente com o incremento da ordem. A noção de momentos complexos (Abu-Mostafa e Psaltis, 1984) foi introduzida como uma maneira simples e direta de derivar os momentos invariantes.

\subsection{Momentos e momentos invariantes}

A idéia de usar momentos em reconhecimento de padrões ganhou proeminência cm 1961 quando Hu derivou um conjunto de momentos invariantes usando a teoria dos invariantes algébricos (Hu, 1961).

\subsubsection{Momentos regulares invariantes}

Os momentos mais usados são os momentos regulares, eles estão definidos em termos das integrais de Reimann como (Hu, 1961):

$$
m_{p q}=\int_{-\infty}^{\infty} \int_{-\infty}^{\infty} x^{p} y^{q} f(x, y) d x d y \quad \text { parap }, q=0,1,2, \ldots
$$

$m_{z w}$ é o momento 2D para a função $f(x, y)$. A ordem do momento é $(p+q)$.

Existem momentos de todas as ordens, e a sequiência de momentos $m_{m_{l}}$ é unicamente determinada pela lunção $f(x, y)$. De modo oposto a sequiência $m_{p q}$ determina unicamente a $f(x, y)$. isso é possível por que a imagem é espacialmente discreta (Hu, 1961).

Os momentos centrais $\mu_{p q}$ estão definidos como:

$$
\mu_{q_{q}}=\int_{-\infty}^{\infty} \int_{-\infty}^{\infty}\left(x-x_{c}\right)^{p}\left(y-y_{c}\right)^{q} f(x, y) d x d y, \quad p, q=1,2, \ldots
$$

onde o ponto $\left(x_{c}, y_{c}\right)$ é o centróide da imagem. 
Os momentos de primeira ordem são usados para encontrar o centróide $(x, y)$ da imagem:

$$
r_{r}=\frac{m_{10}}{m_{00}}, \quad y_{r} \cdot-\frac{m_{01}}{m_{00}}
$$

onde $m_{00}$ representa a massa ou área da imagem, $m_{10}$ é $m_{01}$ são as projeções $\mathrm{cm} x$ e $y$ respectivamente.

Os momentos centrais são equivalentes aos momentos regulares de uma imagem que foi deslocada tal que o centróide $\left(x_{n}, y_{c}\right)$ da imagem coincida com a origem. Como resultado, as características extraídas através dos momentos centrais são invariantes à translação.

Os momentos centrais normalizados, denotados por $\eta_{\mu_{q}}$ estão definidas por:

$$
\eta_{p q}=\frac{\mu_{p q}}{m_{00}^{(p+q) / 2+1}}
$$

Pode ser demonstrado que os momentos centrais normalizados são invariantes à escala (Hew, 1996).

\subsubsection{Momentos de Hu}

Usando a teoria dos momentos algébricos de Hu (Hu. 1961) deriva-se o seguinte conjunto de polinômios de momentos:

$$
I_{p-r, r}=\sum_{l=0}^{r}\left[(\cdots)^{l}\left(\begin{array}{c}
p-2 l \\
l
\end{array}\right) \sum_{k=0}^{r}\left(\begin{array}{l}
\mathrm{r} \\
\mathrm{k}
\end{array}\right) \mu_{p-2 k-l .2 k+1}\right] \text {, }
$$

onde $p$ e $r$ determinam a ordem dos momentos. tal que $p-2 r>0, i=\sqrt{-1}$, e

$$
I_{p / 2, p / 2}=\mu_{p 0}+\left(\begin{array}{c}
p / 2 \\
1
\end{array}\right) \mu_{p-2,2}+\left(\begin{array}{c}
p / 2 \\
2
\end{array}\right) \mu_{p-4.4}+\ldots+\mu_{0, p}
$$

sendo $p$ número par. Para maior simplicidade podemos definir $I_{p-r, r}$ como (Belkasim. 1991):

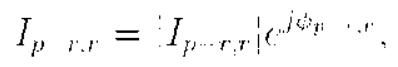

onde

$$
\dot{\varphi}_{p-r, r}=\lg ^{-1}\left(\frac{\operatorname{Re}\left(I_{p-r, r}\right)}{\operatorname{Im}\left(I_{p-r, r}\right)}\right) .
$$

onde $R c$ é a parte real e $\mathrm{Im}$ a parte imaginária de um número complexo. 
Os momentos invariantes descritos acima podem ser usados dirctamente para identificação de padrões invariantes à rotação. Se esses momentos invariantes são combinados com os momentos centrais normalizados, logo a identificação de padrões invariantes pode ser feita, independentemente da posição, tamanho e orientação.

Para os momentos de segunda e terceira ordem, temos os seguintes momentos, conhecidos como os sete momentos de Hu (Hu. 1961), também são invariantes à escala, translação e rotação:

$$
\begin{aligned}
\varphi_{1}= & \eta_{20}+\eta_{02} \\
\varphi_{2}= & \left(\eta_{20} \cdots \eta_{02}\right)^{2}+4 \eta_{11}^{2} \\
\varphi_{3}= & \left(\eta_{30}-3 \eta_{12}\right)^{2}+\left(3 \eta_{21}-\eta_{03}\right)^{2} \\
\varphi_{4}= & \left(\eta_{30}+\eta_{12}\right)^{2}+\left(\eta_{21}+\eta_{03}\right)^{2} \\
\varphi_{5}= & \left.\left(\eta_{30}-3 \eta_{12}\right)\left(\eta_{30}+\eta_{12}\right)\left(\eta_{30}+\eta_{12}\right)^{2}-3\left(\eta_{21}+\eta_{03}\right)^{2}\right]+ \\
& +\left(3 \eta_{21}-\eta_{033}\right)\left(\eta_{21}-\eta_{03}\right)\left[3\left(\eta_{30}+\eta_{12}\right)^{2}-\left(\eta_{21}+\eta_{03}\right)^{2}\right] \\
\varphi_{6}= & \left(\eta_{20}-\eta_{02}\right)\left[\left(\eta_{30}+\eta_{12}\right)^{2} \cdots\left(\eta_{21}+\eta_{03}\right)^{2}\right]+ \\
& -4 \eta_{11}\left(\eta_{30}+\eta_{12}\right)\left(\eta_{21}+\eta_{03}\right) \\
\varphi_{7}= & \left.\left(3 \eta_{21}-\eta_{30}\right)\left(\eta_{30}+\eta_{12}\right)\left(\eta_{30}+\eta_{12}\right)^{2}-3\left(\eta_{21}+\eta_{03}\right)^{2}\right]+ \\
& +\left(3 \eta_{12}-\eta_{30}\right)\left(\eta_{21}+\eta_{033}\right)\left[3\left(\eta_{30}+\eta_{12}\right)^{2}-\left(\eta_{21}+\eta_{033}\right)^{2}\right.
\end{aligned}
$$

A Figura 2.6 mostra a imagem "morcego" e suas respectivas rotações de $0^{\circ}, 20^{\circ}, 45^{\circ}, 90^{\circ}$ e $120^{\circ}$. Estas imagens serão usadas para testar as seguintes técnicas de reconhecimento de padrâo invariante a serem desenvolvidas nas próximas seções. Na Figura 2.7, mostram-se os sete momentos de Hu da Figura 2.6. A similaridade entre os diferentes vetores de momentos é grande.

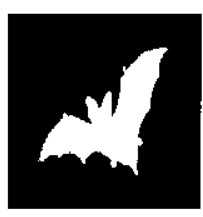

$\left(0^{\circ}\right.$

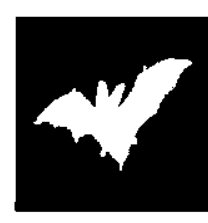

$20^{\circ}$

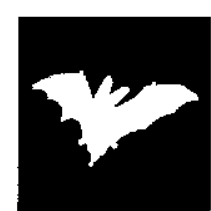

$45^{\circ}$

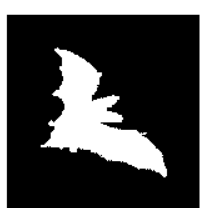

$90^{\circ}$

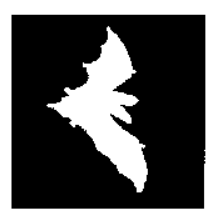

$120^{\circ}$

Figura 2.6: Transformações geométricas da imagem "morcego" sendo rotacionada em $0^{\circ}, 20^{\circ}$, $15^{\circ}, 90^{\circ}$ e $120^{\circ}$ respectivamente. 


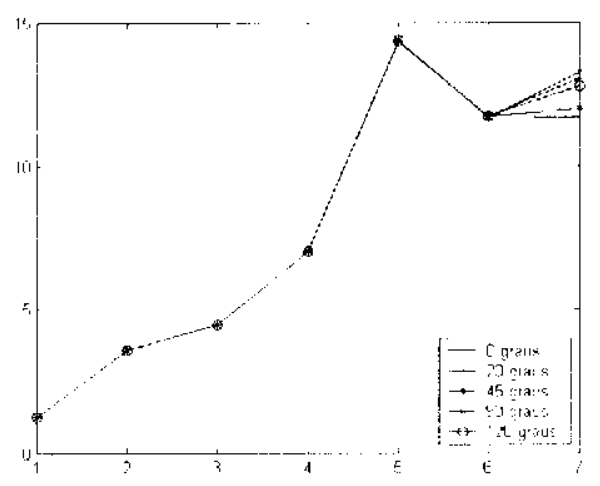

Figura 2.7: Os sete momentos de Hu extraídos das imagens "morcegos".

\subsection{Momentos ortogonais radiais}

Existe uma grande variedade de conjuntos completos de polinómios que são invariantes à rotação e ortogonais mapeados em um círculo unitário. Para obter os momentos invariantes à rotaçũo, geralmente a seguinte expressão é usada (Shen e Ip, 1999)

$$
F_{p q}=\iint f(\rho, \theta) x_{p}(\rho) c^{j q^{\theta}} \rho d \rho d \theta
$$

onde $F_{\eta_{l}}$ ć o momento de ordem $p q, G_{p}(p)$ é a função da variável radial $\rho, p$ e q são parâmetros inteiros, representando a ordem do momento. Nâo é difícil demonstrar que o valor $\left|F_{z w}\right| \mid$ é invariante à rotação, onde ||$x \mid=\sqrt{x \cdot x^{*}}$ é a norma Euclideana e símbolo $*$ representa a conjugada de um numero complexo.

Considera-se a rotação do ângulo $\alpha$ de uma imagem. Se a imagem rotacionada ć denotada por $f^{r}(\rho, \theta)$, a relação entre a imagem original c a rotacionada é como segue:

$$
f(p, \theta) \cdot f(0, \theta-\theta)
$$

Os momentos radiais da imagem seriam:

$$
F_{p q}^{r}=\iint f(\rho \cdot \theta-\alpha) G_{p}(\rho) e^{j q^{\theta}} \rho d \rho d \theta
$$

Trocando a variável $\theta_{1} \cdots \theta-\alpha$

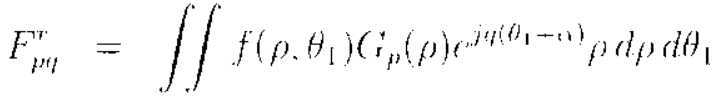

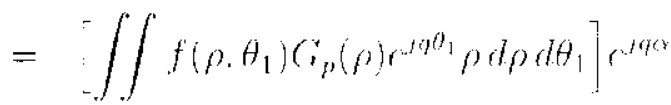




$$
=F_{p q} e^{j \varphi c}
$$

Podemos ver que na Equação (10) mostram-se como os momentos radiais têm propricdades de transformação radial simples; cada momento adquire uma fase de deslocamento na rotação. Esta simples propriedade leva concluir que as magnitudes dos momentos radiais mantêm-se idênticas aquelas antes de acontecer a rotação.

Com o propósito de reduzir o problema de extração de características de um objeto imagem 2D a uma sequiencia ID, a Equação (9) pode ser re-cscrita como segue:

$$
F_{p q}=\int S_{q}(\rho) \cdot G_{p}(\rho) \rho d \rho
$$

onde $S_{q}(\rho)=\int f(\rho, \theta) e^{j q^{\theta}} d \theta$. Note que $S_{g}(\rho)$ é agora uma seqüência $1 \mathrm{D}$ da variável $\rho$.

A Equação (11) define um esquema geral para extrair características invariantes. Os momentos de wavelets são instâncias desse esqucma.

\subsubsection{Momentos de Zernike}

Os Momentos de Zernike (MZ) pertencem à classe dos momentos ortogonais, invariantes à rotação. Outra propriedade interessante dos MZ é a reconstruçẫo da imagem original através de seus próprios momentos (Khotanzand e Lu, 1990).

Os MZ definem uma projeção da imagem original nestas funções base ortogonais (Khotanzand e Lu, 1990). Os MZ definem-se como:

$$
Z_{p, q}=\frac{p+1}{\pi} \int_{0}^{2 \pi} \int_{0}^{1} f(\rho, \theta) V_{p q}^{*}(\rho, \theta) \rho d p d \theta
$$

onde $\rho, \theta$ da função $f$ são coordenadas polares da imagem o símbolo $*$ representa a conjugada de um numero complexo. Também é importante notar que $Z_{p, q}^{*}=Z_{p,-q}$

Os polinômios de Zernike $V_{p q}$ de ordem $p$ com $q$ repetições, representam a dependência angular, sâo definidos nas coordenadas polares $(\rho, \theta)$ dentro de um círculo unitário (Khotanzand e Lu, 1990).

$$
V_{p q}(\rho, \theta)=\Gamma_{p q}(\rho) c^{i q \theta}
$$

onde $V_{\eta_{q}}$ denota um conjunto completo de polinômios complexos e ortogonais em duas variáveis $p \mathrm{e} \theta$. $p$ é um numero inteiro positivo ou zero, q é um numero inteiro positivo ou 
negativo tal que $p-|q|$ é um número par e $q \mid \leq p, j=\sqrt[2]{\cdots-1}$ e $l_{p m}(p)$ representa um conjunto de polinômios ortogonais dentro do círculo unitário cuja definição é como segue:

$$
R_{p q q}(\rho)=\sum_{s=0}^{p \cdot|q| / 2}(-1)^{s} \cdot \frac{(p-s) !}{s !\left(\frac{p-q \mid}{2}-s\right) !\left(\frac{p-|q|}{2} \ldots s\right) !} \rho^{p-2 s}
$$

note que $R_{p,-\imath l}(\rho)=R_{p, q}(\rho)$.

Fistes polinômios são ortogonais e satisfazem (Hew, 1996):

$$
\int_{0}^{2 \pi} \int_{0}^{1}\left[V_{m q}(\rho, \theta)\right]^{*} V_{m k}(\rho, \theta) \rho d \rho d \theta=\frac{\pi}{p+1} \delta_{m m} \delta_{q k}
$$

onde $\delta_{a b}$ é conhecidá como a função delta de Kronecker tal que:

$$
\delta_{n b}, \cdots \begin{cases}1, & \text { se } a=b \\ 0, & \text { em outros casos }\end{cases}
$$

Os MZ são apenas invariantes à rotação, para que possam ser invariantes à escala c translação a imagem deve ser normalizada (Khotanzand e Lu. 1990). Logo, a imagem deve ser transformada a coordenadas polares e mapeada dentro de um círculo unitário e finalmente extrair as características invariantes a rotação dessa nova imagem.

Os polinômios de Zernike são muito conhecidos $\mathrm{c}$ amplamente usados na análise de sistemas ópticos de visão (descriçẫo de superficies ópticas). Atualmente, eles estâo sendo usados para reconstruçăo de formas e sugeridos para reconhecimento de padrões (Belkasim, 1991).

Para calcular os MZ de uma dada imagem, o centro da imagem é tomado como a origem e as coordenadas dos pixels são mapeadas dentro do círculo unitário. Aqueles pixels que ficam fora do círculo não são usados nos cálculos.

Os MZ têm um conjunto de polinômios radiais ortogonais para cada diferente ordem circular q. Os polinômios dos momentos de Zernike. $R_{\eta, q}(\rho)=0$, têm $\frac{(p-\mid q)}{2}$ zeros duplicados, além de $R_{p, q}(0) \cdots 0$. Assim, podemos ver através da Figura 2.8(e) que os valores zero de $R_{p . q}(\rho)$ estão localizados na região de maior distância radial $\rho$ desde a origem. Assim. ć conhecido que o número de zeros dos polinômios radiais correspondem à capacidade dos polinômios de descrever componentes de altas freqüências espaciais da imagem. Isto é, os MZ focalizam-se nas características globais (Kan e Srinath, 2002). Na Figura 2.8 mostram-se polinômios de Zernike de diferentes ordens. 


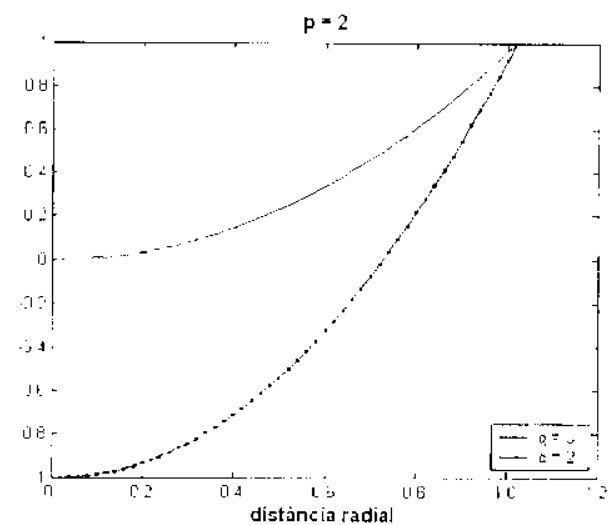

(a)

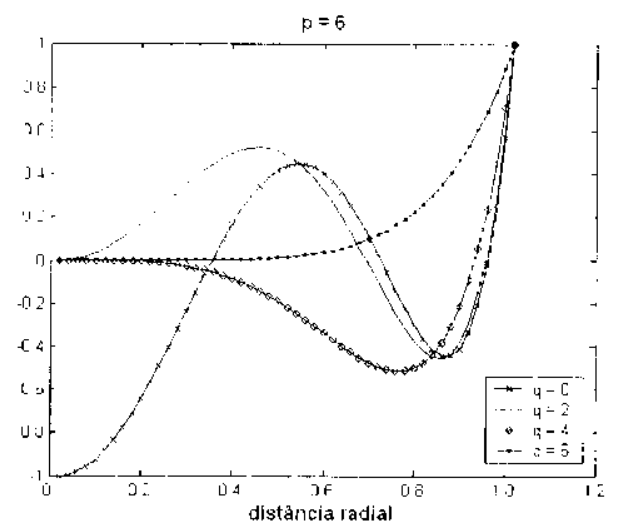

(c)

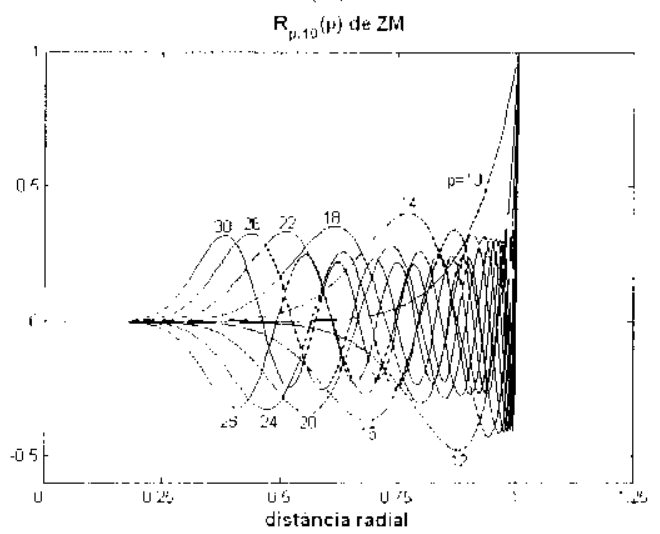

(e)

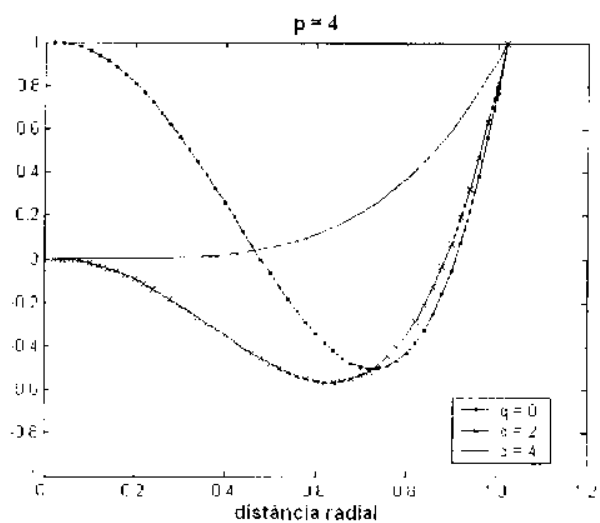

(b)

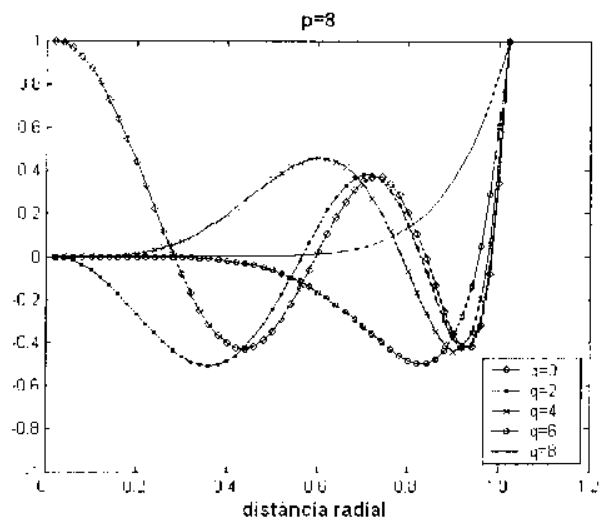

(d)

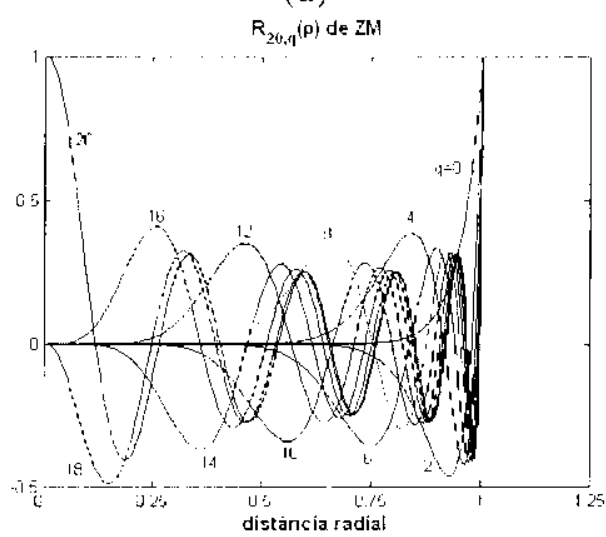

(f)

Figura 2.8: Polinômios de Zernike de diferentes ordens, (a) de ordem 2, (b) ordem 4, (c) de ordem 6. (d) de ordem 8. (e) de ordem $R_{p, \mid 10}(\rho)$. (f) de ordem 20.

A Figura 2.9 mostra os momentos de Zernike de ordem 8 das imagens mostradas na Figura 2.6. Podemos ver nesta figura que os momentos de cada imagem resultam ser muito parecidos. Podemos concluir que os momentos de Zernike efetivamente são invariantes à rotação. 


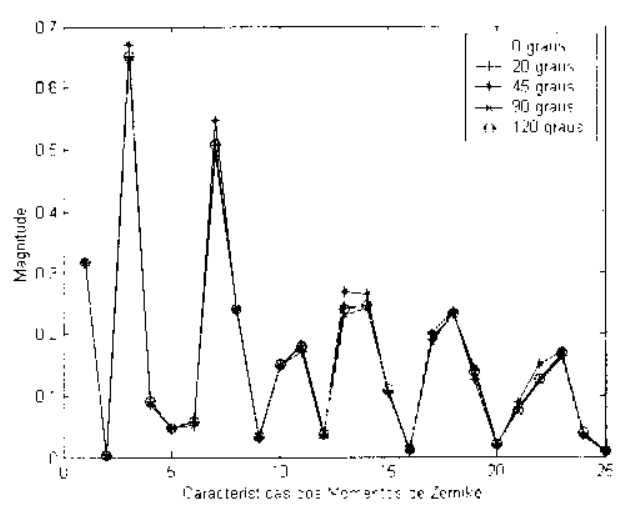

Figura 2.9: Os momentos de Zernike de ordem 8 extraídos das imagens "moreegos".

\subsubsection{Reconstrução de images através dos momentos de Zernike}

Suponha-se que se conhece todos os momentos $Z_{p^{\prime}}$ de $f(x, y)$ até uma ordem dada $p_{m m, r}$. Para poder reconstruir a função discreta $f(x, y)$ onde os momentos dela casam exatamente com os momentos de $f(x, y)$ até uma ordem $p_{m a x . x}$. Os MZ são os coeficientes da expansão da imagem dentro dos polinômios ortogonais de Zernike. Pela ortogonalidade da base de Zernike

$$
\hat{f}(x, y) \quad \sum_{p=0}^{r \cdots a t} \sum_{q} Z_{p, q} V_{p q}(p, \theta)
$$

q com as mesmas restrições que na Equação (13). Note que a medida que $p_{\text {max }}$ se aproxima ao infinito $f(x, y)$ se aproxima a $f(x, y)$ (Khotanzand e Lu. 1990). Na Figura 2.10, vemos a reconstrução feita através dos próprios momentos.

Para comprovar a Equação (16) vamos expandir $V_{p q}^{*}(\rho, \theta)=V_{p,-q}(\rho, \theta)$

$$
\begin{aligned}
& \hat{f}(x, y)=\sum_{p} \sum_{q<0} Z_{p, q} V_{p q}(p, \theta)+\sum_{p} \sum_{q \geq 0} Z_{p q q} V_{p q}(p: \theta) \\
& =\sum_{p} \sum_{q \rho 0} Z_{p \cdot q} V_{p \cdot q q}(\rho \cdot \theta)+\sum_{p} \sum_{q \geq 0} Z_{p \mu_{q}} V_{p+q}(\rho \cdot \theta) \\
& =\sum_{p} \sum_{q>0)} Z_{p q q}^{*} V_{p q}^{*}(\rho . \theta)+\sum_{p} \sum_{q>0)} Z_{p \mu_{i}} V_{p q}(\rho . \theta) \\
& =\left[\sum_{p^{\prime}} \sum_{q>0}\left[Z_{p q}^{*} V_{p q}^{*}(\rho, \theta)+Z_{p q q} V_{T^{*} q}(\rho, \theta)\right]\right]+Z_{p, 0} V_{p 0}(\rho, \theta) \\
& =\left[\sum_{p} \sum_{q>0}\left\{\left[R e\left[Z_{p q}\right]-j I m \mid Z_{p q}\right]\right] R_{p q}(\rho)\right. \\
& \cdot[\cos q \theta-j \sin q \theta]+\left[R c\left[Z_{p q} \div j \ln \left[Z_{p q}\right]\right] \Gamma_{p q}(p)\right.
\end{aligned}
$$




$$
\begin{aligned}
& [\cos q \theta+j \sin q \theta]\}]+\left[\operatorname{Re}\left[Z_{p 0}\right]+j \operatorname{Im}\left[Z_{p^{0}}\right]\right] R_{p^{0} 0}(\rho) \\
& \hat{f}(x, y)=\sum_{p} \sum_{q>0}\left(C_{p q}^{\gamma} \cos q \theta+S_{p q} \sin q \theta\right) R_{p q}(p)+\frac{C_{p 0}(0)}{2} R_{p, 0}(\rho) \\
& C_{p q}^{r}=2 R e\left(Z_{p q}\right) \quad-\frac{2 p+2}{\pi} \iint_{x^{2}, y^{2} \leq 1} f(x, y) \cdot R_{p q}(\rho) \cos q \theta d x d y
\end{aligned}
$$

onde

$$
S_{p q}=-2 \operatorname{Im}\left(Z_{p^{m}}\right)=\frac{-2 p-2}{\pi} \iint_{x^{2}+y^{2}<1} f(x, y) \cdot R_{\eta^{\prime}}(\rho) \sin q \theta d x d y
$$

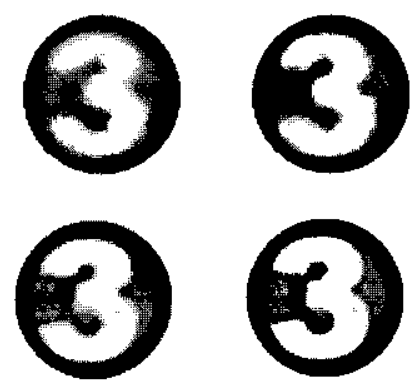

Figura 2.10: Reconstruções de imagens a partir de seus próprios momentos. De esquerda para a dircita e de cima para baixo, as ordens dos momentos são de 15,20,30 e 40, respectivamente.

Os momentos de Zernike têm as seguintes propriedades (Whoi-Yul e Yong-Sung, 2000):

1. Invariância à rotação: a magnitude dos momentos de Zernike tem a propriedade de invariância à rotação. Essa é uma consequiência direta do esquema geral detinido pela Equação 10 , onde $C_{p}(p)$ é substituído pelo polinômio radial $V_{p q}$.

2. Robustez: São robustos ao ruído e a variaçōes mínimas na forma (Khotanzand e Lu, 1990), (Yong-Sung e Whoi-Yul, 1998).

3. Eficiência na expressão: existe menor quantidade de informação redundante, em comparação com momentos não ortogonais (Teh e Chin, 1988).

4. Efetividade: uma imagem pode ser melhor descrita através de um conjunto pequeno de momentos de Zernike que com os momentos geométricos, momentos de Legendre, momentos rotacionais e momentos complexos (Teh e Chin, 1988).

5. Representação multi-resoluçâo: um conjunto relativamente pequeno de momentos de Zernike pode caracterizar efetivamente a forma global do padrão (Teh e Chin, 1988).

Momentos de baixa ordem representam a forma global do padrão e momentos de alta ordem representam os detalhes. 
Teh c (hin (Teh e Chin, 1988) examinaram a sensibilidade ao ruído e a redundância de informação dos momentos de Zcrnike junto com outros 5 tipos de momentos. Eles concluíram que os momentos de alta ordem são mais sensíveis ao ruído. Também mostraram que os momentos ortogonais, incluindo os momentos de Zernike, são melhores do que os outros tipos de momentos cm términos de redundância de representação da imagem.

\subsubsection{Momentos ortogonais Fourier-Mellin}

A transformada de Fourier circular define-se como:

$$
F_{q}(\rho)=\frac{1}{2 \pi} \int_{0}^{2 \pi} f\left(\rho_{i} \theta\right) e^{j q^{\theta}} d \theta
$$

onde a função $f(\rho . \theta)$ está definido em coordenadas polares $(\rho, \theta), F_{q q}$ é uma função que somente depende do raio e $q$ é um inteiro.

Seja $f(\rho)$ uma funçâo positiva real. A transformada de Mellin de $f$ está denotada pela seguinte equação

$$
F(u)=\int_{0}^{\infty} f(\rho) \rho^{u-1} d \rho
$$

onde $u$ é um número complcxo.

Seja a função $f(\rho, \theta)$ definida em coordenadas polares $(\rho, \theta)$. Aplicando a transformada de Fourier circular (Equação 18 ) em $f$ podemos obter uma função de $\rho$ e a variável $q$. A esla nova função podemos aplicar a transformada de Mellin radial (Equação 19) dando como resultado a transformada de Mellin radial e de Fourier circular (Transformada de Fourier-Mellin)(Li. 1992) detinida como

$$
F_{p q}=\int_{0}^{2 \eta 1} \int_{0}^{\infty} \rho \mu^{p} \int(\rho, 0) e^{-j q^{\prime}} \rho d \rho d \theta
$$

onde $q=0 . \pm 1, \pm 2 \ldots$ é a ordem harmônica circular da transformada de Fourier e a ordem da transformada de Mcllin radial é um inteiro $p$ tal que $p \geq 0$. Também. é conhecido que através de uma adequada normalização, as transformadas de Mcllin são invariantes à escala e o módulo da transformada de Fourier circular é invariante à rotação, então os momentos Fourier-Mcllin são invariantes à rotação, escala e translação (Kan c Srinath. 2002). Lembremos que sempre transformaremos a imagem em coordenadas polares, tomando como a origem o centróide da imagem, portanto é invariante à translação. Agora vamos introduzir o polinômio $Q_{p}(\rho)$ definido em (Sheng c Shen. 1994) como

$$
Q_{p}(\rho)=\sum_{k=0}^{\prime \prime} \alpha_{k} \rho^{k}
$$


onde

$$
c_{p k}=(-1)^{p+k} \frac{(p+k+1) !}{(p-k) ! k !(k+1) !}
$$

Pode-sc vcrificar que o conjunto $Q_{p}(\rho)$ é ortogonal $(\mathrm{Hew}, 1996)$ dentro do círculo unitário :

$$
\int_{0}^{1} Q_{p}(\rho) Q_{p^{\prime}}(\rho) \rho d \rho=c_{p} \delta_{p p^{\prime}}
$$

Logo as funções ortogonais Fourier-Mellin de ordem $p, q$ denotada como $V_{p q q}$ são definidas como

$$
U_{p \psi}(\rho, \theta)=Q_{p}(\rho) \epsilon^{j q^{\theta}}
$$

e os momentos ortogonais Fourier-Mellin $O_{p q}$ são definidos como

$$
O_{p q}=\frac{1}{2 \pi} \int_{0}^{2 \pi} \int_{0}^{1} f(\rho, \theta) U_{p q}(\rho, \theta) \rho d \rho d \theta .
$$

$\Lambda$ versão discreta dos momentos Fourier-Mellin e os momentos ortogonais Fourier-Mellin podem ser expressadas em coordenadas cartesianas $(x, y)$ como

$$
\begin{aligned}
& F_{p q}=\sum_{x} \sum_{y} f(x, y) p^{\mu} e^{-j q q^{\theta}} \Delta x \Delta y, \\
& O_{m_{l}}-\frac{p+1}{\pi} \sum_{x} \sum_{y} f(x, y) Q_{\psi}(\rho) \epsilon^{-j q^{\prime}} \Delta x \Delta y \\
& u^{2}+y^{2} \leq 1, \quad x=\beta \cos \theta, \quad y=\rho \sin \theta .
\end{aligned}
$$

$Q_{\mu}(p)$ contém potências naturais $1, \rho: \rho^{2}, \ldots, \rho^{n}$, a equação $Q_{p}(\rho): 0$ tem $p$ raízes distintas e distribuída uniformemente dentro do círculo unitário. Lembremos que a quantidade de zeros de um polinômio radial corresponde à capacidade para descrever componentes de altas freqüências espaciais da imagem. Portanto, para representar uma imagem dentro de um mesmo nível de qualidade, a ordem de $p$ momentos orlogonais Fourier-Mellin sempre é menor à ordem de outros momentos. Como os momento de alta ordem são mais sensiveis ao ruído e às variações, portanto, esta é uma das vantagens dos momentos ortogonais Fourier-Mellin. Como podemos ver na Figura 2.11, o número de zeros está distribuído uniformemente sobre o círculo unitário (Kan e Srinath, 2002).

A Figura 2.12 mostra os momentos de Fourier-Mellin de ordem 5 das imagens mostradas na Figura 2.6. Assim como aconteceu com os momentos de Hu e de Zerike, os vetores de mo- 


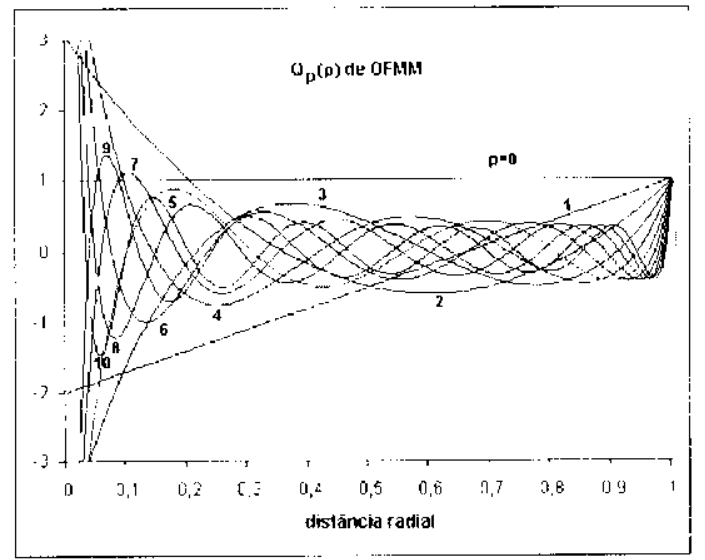

Figura 2.11: Momentos Ortogonais Fourier-Mellin $R_{p}(\rho)$.

mentos de Fourier-Mellin também são parecidos. Isto é. podemos concluir que são invariantes à rotação.

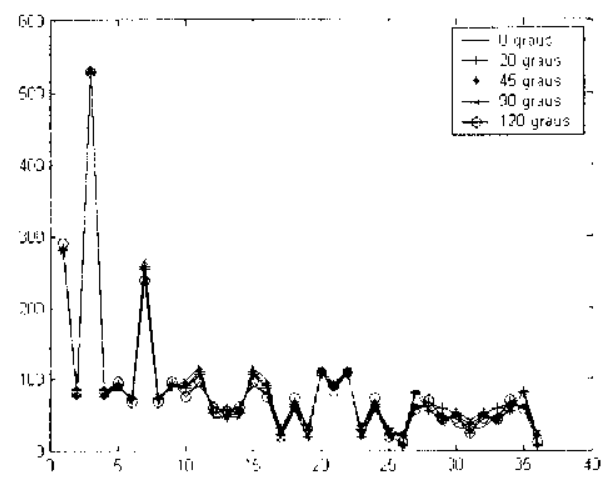

Figura 2.12: Os momentos de Fourier-Mellin de ordem 5 extraídos das imagens "morcegos" (ver Figura 2.6).

$\Lambda$ reconstrução da imagem pode ser obtida através de:

$$
\hat{f}(x, y)=\sum_{p-0}^{N} \sum_{q=-N}^{N} O_{m, q} Q_{p}(\rho) r^{j q}
$$

onde $N$ é a ordem máxima dos momentos usados para reconstruir a imagem. 


\subsection{Momentos de Legendre}

Os momentos de Legendre (Teh e Chin, 1988) de ordem $(p+q)$ estão definidos por

$$
\lambda_{p q}=\frac{(2 p-1)(2 q+1)}{1} \int_{\alpha}^{x} \int_{\infty}^{x} P_{p}(x) P_{q}(y) f(x, y) d x d y
$$

onde $p . q=0.1,2, \ldots, \propto$. Os polinômios de Legendre $P_{n},(x)$ formam uma base ortogonal dentro do intervalo $[-1,1]$ :

$$
\int_{1}^{1} P_{p}(x) P_{q}(y)=\frac{2}{2 p+1} \delta_{p q}
$$

os momentos de Legendre são um caso especial dos polinômios ortogonais de Jacobi (Hew, 1996), ondc a função de ponderação é 1 .

A fómula de Rodrigues (Koekoek e Swarttouw, 1998) fornece a função geradora do polinômio de Legendre de ordem $p$

$$
P_{p}(x)=\sum_{j=0}^{p} a_{p j} x^{j}=\frac{1}{2^{p} p !} \frac{d^{p}}{d x^{p}}\left(x^{2}-1\right)^{p} .
$$

que produz depois da expansão

$$
P_{i}(x)=\frac{1}{2^{p}} \sum_{k=0}^{\lfloor p / 2\rfloor} \frac{(-1)^{k}(2 p-2 k) !}{k !(p-k) !(p-2 k) !} x^{p-2 k}
$$

Na Figura 2.13 são plotados os polinômios de Legendre, pode-se apreciar que os polinômios cstão definidos dentro do intervalo $[-1,1]$.

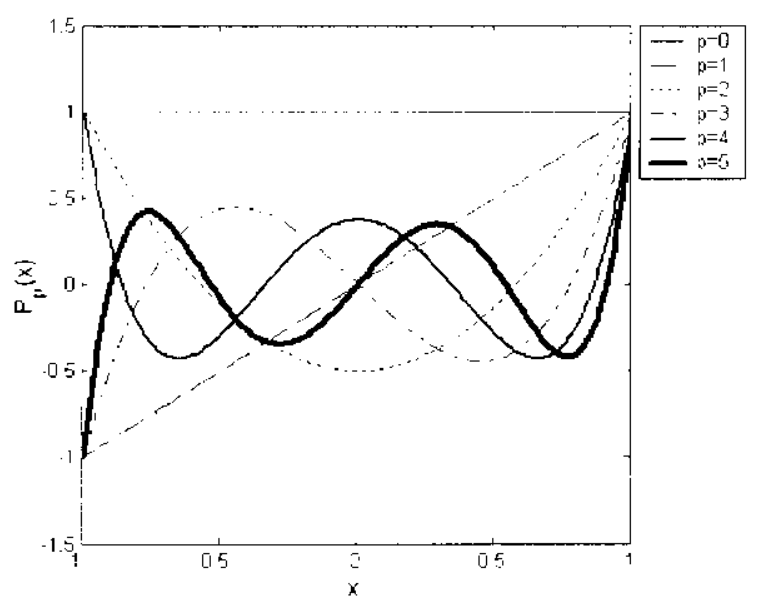

Figura 2.13: Polinômio de Legendre. 
Pelo principio de ortogonalidade, a função imagem $f(x, y)$ pode ser escrita como uma séric de expansão finita $\mathrm{cm}$ termos dos polinômios de Legendre dentro do quadrado $\{-1 \leq x, y \leq 1$ :

$$
f(x, y)=\sum_{p=0}^{\infty} \sum_{q-0}^{\infty} \lambda_{p q} P_{p}(x) P_{q}(y)
$$

onde os momentos de Legendre são calculados dentro do mesmo quadrado. Se somente os momentos de Legendre de ordem $N$ são dados, então a função $f(x, y)$ pode ser aproximada por:

$$
f(x \cdot y)=\sum_{p=0}^{N} \sum_{q=0}^{p} \lambda_{p-q, q} P_{p},(x) P_{q}(y) .
$$

\subsection{Momentos de Tchebichef}

Os momentos, como os momentos radiais. são definidos por integrais que usualmente são aproximadas através de somatórios para imagens digitais. Este processo nāo só pode ocasionar erros nos cálculos dos momentos, também afetam as propriedades analíticas. como at invariância. ortogonalidade, etc (Mukundan et al., 2001).

As bases ortogonais, normalmente, têm um espaço de domínio diferente do espaço do padrão original. Por exemplo, os polinômios de Legendre são válidos somente no intervalo $[-1,1]$. enquanto os polinômios radiais de Zernike estão definidos dentro do círculo unitário. As aplicações de tais polinômios orlogonais requerem a transformação do espaço da imagem original para o domínio dos polinômios (Mukundan et al., 2001).

Pelos problemas já descritos surge a necessidade de considerar o uso de polinômios ortogonais discretos com domínio igual ao espaço da imagem original. Assim. pode-se evitar o processo de normalização da imagem, que resulta em perda de informação em caso geral. Como a implementação dos momentos ortogonais discretos não envolvem aproximações numéricas. as bases ortogonais satisfazem exatamente a propriedade de ortogonalidade: portanto, geram resultado superior de reconstrução de imagens. Considere um sistema ortogonal discreto $f_{n}(i)$, onde $a \leq i \leq b$. A propriedade de ortogonalidade pode ser descrita como:

$$
\sum_{i=u}^{b} u(i) f_{p}(i) f_{u}(i) \cdots \rho(p, a, b) \delta_{\mu q}
$$

onde $u(i)$ é a função de ponderação $c \rho($.$) é a norma quadrada. A função de ponderação$ dos polinômios de Tchebichef é 1. e o domínio de definição adapta-se idealmente às imagens quadradas de tamanho $N \times N$ pixels (Mukundan et al., 2001). 
As funções-base dos momentos de Tchebichef $l_{p}(x)$ são polinômios discretos ortogonais que satisfazem

$$
\sum_{r=0}^{N-1} t_{p}(x) t_{q}(x)=\rho(p, N) \delta_{p q} \quad 0 \leq p, q \leq N-1
$$

onde

$$
\rho(p, N)=\sum_{i=0}^{N}\left\{t_{p}(x)\right\}^{2}
$$

Os polinômios clássicos de Tchebichef estão dados por (Yap ct al.. 2001)

$$
t_{p}(x)=p ! \sum_{k=0}^{p}(-1)^{p-k}\left(\begin{array}{c}
\mathrm{N}-\mathrm{l}-\mathrm{k} \\
\mathrm{p}-\mathrm{k}
\end{array}\right)\left(\begin{array}{c}
\mathrm{p}+\mathrm{k} \\
\mathrm{p}
\end{array}\right)\left(\begin{array}{l}
\mathrm{x} \\
\mathrm{k}
\end{array}\right)
$$

e

$$
\begin{aligned}
\rho(p, N) & =\frac{N\left(N^{2}-1\right)\left(N^{2}-2^{2}\right) \ldots\left(N^{2}-p^{2}\right)}{2 p+1} \\
& =(2 p) !\left(\begin{array}{c}
\mathrm{N}+\mathrm{p} \\
2 \mathrm{p}+1
\end{array}\right): \quad p-0,1, \ldots, \ldots N-1
\end{aligned}
$$

e têm a seguinte relação de recorrência (Mukundan et al., 2001):

$$
(p+1) t_{p+1}(x)-(2 p+1)(2 x, \quad N+1) t_{p}(x)+p\left(N^{2}-p^{2}\right) t_{p} \cdot 1(x)=0, p=1,2, \ldots, N-1
$$

Os momentos de Tchcbichef de ordem $(p+q)$ estão definidos como (Yap et al., 2001)

$$
T_{p \mu q}=\frac{1}{\rho(p, N) p(q, N)} \sum_{x=0}^{N-1} \sum_{y=0}^{N-1} l_{p}(x) l_{q}(y) f(x, y) \quad p, q=0,1,2, \ldots, N-1
$$

onde $t_{w}(x)$ está determinado pela Equação (38).

Podemos perceber através das Equações (38) e (41) que a ordem dos momentos de $T_{F^{\prime}}$ é muito alta para $N$ grande. Por isso não é conveniente para ser usado em aplicações reais. Para evitar esse problema, foram introduzidos os polinômios escalados de Tchebichef (Mukundan et al., 2001).

Definimos os polinômios escalados de Tchebichef como

$$
t_{n}(x) \cdots \frac{t_{n}(x)}{\beta(n, N)}
$$


onde $\beta(n . N)$ é uma constante adequada de normalização independente de $x . \Lambda$ norma quadrada dos polinômios escalados é modificada conforme a fórmula:

$$
\rho(n, N)=\frac{\rho(n, N)}{\beta(n, N)^{2}}
$$

Agora definimos os momentos escalados de Tchebichef como

$$
T_{p q}=\frac{1}{\rho(p, N) \rho(p, N)} \sum_{x=0}^{N-1} \sum_{y=0}^{N-1} \tilde{t}_{p}(x) i_{q}(y) f(x, y) \quad p, q=0,1,2, \ldots, N-1 .
$$

O fator de escala $\beta(n, N)$ ć uma função de $N$ que cresce em $N^{n}$. As fórmulas descritas para obtenção dos polinômios escalados de Tchebichef e os momentos associados a cle. garantem que não devem existir grandes variações no intervalo dinâmico dos valores dos momentos. também não haverá instabilidades numéricas para valores de $N$. A eleição mais simples para (j(n,N) é

$$
B(n, N)=N^{n}
$$

nesse caso, temos a seguinte fórmula de recorrência para $t_{p}(x)$

$$
i_{n}(x)=\frac{(2 n-1) f_{1}(x) \tilde{l}_{n-1}(x)-(n-1)\left(1-\frac{(n-1)^{2}}{N^{2}}\right) \tilde{l}_{n-2}(x)}{n}, \quad n=2,3, \ldots, N-1
$$

onde $\tilde{t}_{0}-1, \tilde{t}_{1}(x)=(2 x+1-N) / N \mathrm{e}$

$$
\hat{\rho}(n . N) \cdot \frac{N\left(1-\frac{1}{N^{2}}\right)\left(1-\frac{2^{2}}{N^{2}}\right) \ldots\left(1 \cdots \frac{n^{2}}{N^{2}}\right)}{2 n+1} \quad n=0,1, \ldots, N-1
$$

Na Figura 2.14 os polinômios de Tchebichef são plotados para $N-20$.

A transformação inversa dos momentos é usada para reconstruir a imagem e está dada por (Yap ct al., 2001)

$$
f(x, y)=\sum_{x=0}^{N-1} \sum_{y, n-0}^{N-1} T_{p q} t_{p}(x) t_{q}(y)
$$

A Figura 2.15 mostra a reconstrução de uma imagem a partir de seus próprios momentos de Tchebichef. Usaram-se diferentes ordens para reconstruir as imagens. A imagem reconstruída com os momentos de Tchebichef de ordem 60 resulta ser similar à original. 


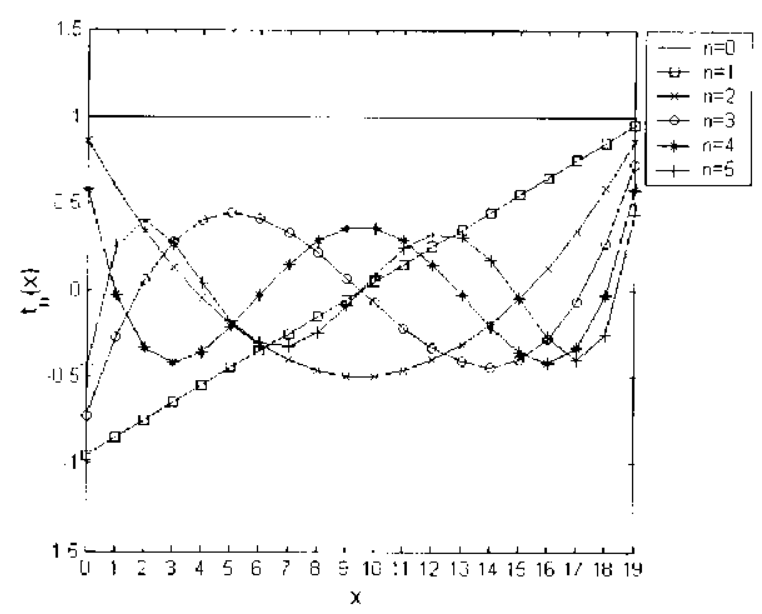

Figura 2.14: Polinômio de Tchebichef.

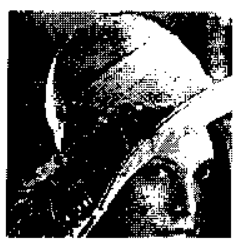

(a)

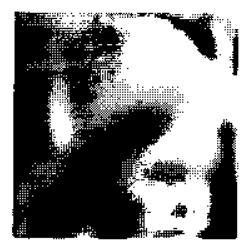

(b)

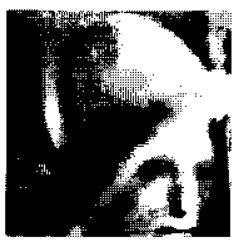

(c)

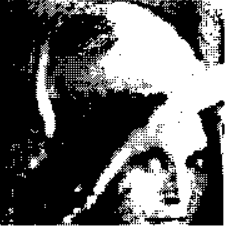

(d)

Figura 2.15: Reconstruções de imagens a partir de seus próprios momentos. (a) mostra a imagem original. A imagem é reconstruída através dos seus momentos de ordem: (b) 20. (c) 30 e (d) 60 .

\subsection{Wavelets}

No dia-i-dia, interagimos com diferentes tipos de sinais, tais como: sinais de rádio, áudio, fala humana, dados financeiros, imagens, entre outros. No caso de pessoas e animais, os sinais do meio, que são captados através dos órgãos do sentido, são transformadas em sinais nervosos palla depois ser processados pelo cérebro.

Assim como acontece com o cérebro, o processamento automático de sinais precisa contar com ferramentas que permitam transformar os sinais para um novo domínio. Neste domínio, será possível detectar singularidades ou características para ser aproveitadas posteriormente. A ferramenta matemática mais usada são as transformadas de Fourier, a qual fornece informação sobre as trequiências dos sinais, dentro de um intervalo de tempo, por exemplo, se temos uma música e aplicamos as transformadas de Fourier poderemos conhecer as notas musicais.

Em muitas aplicações, além de conhecer as freqüências, também é necessário saber em que intervalos de tempo aconteceram. Consideremos o exemplo dado, além de conhecer que notas musicais estão presentes na música, é necessário determinar em que intervalo de tem- 
po ocorreram. As transformadas de Fourier estão impossibilitadas de responder esta última questão, por não estar localizadas no domínio do espaço, surgindo as transformadas de wavelets como ferramentas alternativas. Deste modo, muda o paradigma de representação ao transformar um sinal de tempo em outro domínio de tempo-escala. Isto é possível através do uso das funções-base de wavelets em lugar das funções senoidais de Fourier (Gutierrez e Beltran, 2002). A primeira referencia às wavelets pode ser encontrada na tese de Haar (1909). quem propôs uma nova base que a denomino como a base de Haar (Guticrrez e Beltran, 2002).

Em 1984 o físico Grossmann (Grossmann e Morlet, 1984) formalizou a teoria das wavelets, depois, em 1992 através da publicação de Daubechics (Daubechies, 1992) a aplicação desta técnica cresecu rapidamente. Nas últimas duas décadas. a analise das wavelets tem mostrado ser uma ferramenta útil em vários campos do conhecimento como a Física, a Matemática, a Engenharia, a Medicina e na última década a Estatística. a Economia e o Processamento de Imagens. Como antecessora das wavelets temos as transformadas de Fourier, a qual usa bases senoidais.

\subsubsection{Transformada de Wavelets}

A definição de uma transformada de wavelets considerando um sinal contínuo é dada por :

$$
F(a, b)=\int_{-\infty}^{-\infty} f(t) r_{a, b}(t) d t, \quad a, b \in \mathbb{R}
$$

as funções $\psi_{a, k}$ são denominadas wavelets e definidas da seguinte forma :

$$
\psi_{a, b}(t)=\frac{1}{\sqrt{a}} 2\left(\frac{1-b}{a}\right)
$$

A transformada de wavelets para sinais discretos é delinida como:

$$
F_{m, n}(a, b)=a_{0}^{-m / 2} \int_{-\infty}^{\cdots \times} f(t) z_{1}\left(a_{0}^{-m} t-n b_{0}\right)
$$

onde $a \mathrm{e} b$ representam a dilatação (escala) e translação (tempo), respectivamente. A função 2) recebe o nome de wavelet-mãe. Em ambos os casos. essa wavelet mäe, deve satisfazer a propriedade :

$$
\int_{i x}^{+x}(t) d l=0
$$


As transformadas discretas de wavelets escolhe um subconjunto de escalas e localizações sobre as quais os cálculos serão feitos, reduzindo assim a quantidade de cálculos.

Segundo Daubechies (Daubechies, 1992) existem duas abordagens dentro da transformada discreta de wavelets : sistemas redundantes discretos (frames) e ortonormal (e outras bases de wavelets). A segunda abordagem considera a estratégia de análise de multi-resolução, desenvolvida por Mallat (Mallat, 1989).

\subsubsection{Análise de multi-resolução}

A análise de multi-rcsolução foi formulada em 1986 por Mallat e Meyer. Ela permite estudar um sinal ou uma função em diferentes escalas. Uma analogia de utilidade é considerar a observação de um objeto a diferentes distâncias. Se o objeto for visto desde uma grande distância, a representação percebida é em alta cscala; na qual é possível distingüir somente a informação global. Assim também, um sinal pode ser analisado em diferentes escalas. Escalas maiores tratam com da informação global, que implicam na representação de informação em baixo nível. Escalas menores fornecem uma representação de sinal mais detalhada e menos compacta.

O elemento central da análise central multi-resolução é a função $\phi(t)$, denominada como função escalar, cujo objetivo é representar um sinal em diferentes escalas. A função $\phi(t)$ atua como uma função filtro, no sentido de que o produto interno de $\phi(t) \mathrm{com}$ um sinal representa uma espécic de valor médio da função sobre o suporte (extensão) de $\phi(t)$. A fim de poder atingir esta propricdade, a função escalar deve possuir suporte compacto, propriedade na qual o domínio é diferente de zero em uma extensão finita e igual a zero no resto.

A análise multi-resolução representa um sistema de espaços $\left\{\ldots, V_{-2}, V_{-1}, V_{0}, V_{1}, V_{2}, \ldots\right\}$ que satisfitzem as seguintes condições:

- Os espaços $V$ estão contidos um dentro do outro, i.e.. que $V_{m+1}$ está contido $\mathrm{cm} V_{m}$, o qual esta incluído em $V_{m-1}$ e assim por diante.

- Quando $m \rightarrow \infty$ os espaços $V_{m}^{r}$ são mais grosseiros e tendem a zero no limite. No sentido contrario, quando $m \cdots \cdots \times, V_{m}$ é mais detalhado e chega ser $L^{2}(\mathbb{R})$ no limite. Em outras palavras, em uma estrutura de análise de multi-resolução, sempre é possível obter uma aproximação, a qual é arbitrariamente próxima à verdadeira função, através do decrescimento da escala.

- Cada espaço tem duas vezes a quantidade de informação que o próximo espaço grosseiro. Isto significa que as funções pertencentes ao $V_{m-1}$ são duas vezes mais detalhadas que aquelas pertencentes ao $V_{m}$ 
- Existe uma função o(t) cujas translações inteiras formam uma base ortogonal no espaço $V_{0}$. Por cxtensão, as translações no passo $2^{m}$ da função $\phi_{m}(t)=2 \frac{m}{2} \phi\left(2^{-m} l\right)$ formam uma base ortogonal no espaço $V_{m}$

Agora examinemos a relação entre a análise multi-resolução e as wavelets. Sabendo que os espaços $V_{m}$ estão todos contidos um dentro do outro, por excmplo. $V_{0}$ é um subconjunto de $V_{1}$, mas o contrário não é verdadeiro. O espaço $V_{-1}$ contem a $V_{6}$ mais alguns outros dados, denominada $H_{-1}$. Pode-se generalizar e definir uma nova família de espaços. mas precisamente. define-se o espaço $W_{m}$ como o complemento de $V_{m}$ em $V_{m-1}$. De fato $V_{m-1}$ é mais detalhado que $V_{m}$, e $W_{m}$ contém os detalhes perdidos de $V_{m}^{r}$ com respeito a $V_{m, 1}$.

A relação com as wavelets radica no fato de que os espaços $W_{m}$ são gerados mediantc dilatações e translações da função $\psi(l)$, a qual satisfaz a condição de admissibilidade, portanto é uma wavelet. As translações da função $\psi_{m}(l)=2^{\frac{n_{m}}{2}} \psi\left(2^{-m} t\right)$ formam uma base ortonormal no espaço $W_{m}$.

A continuação vamos desenvolver duas das wavelets mais conhecidas: Haar e Daubechies.

A wavelet de Haar (ver Figura 2.16) é definida como

$$
\begin{gathered}
h(x):= \begin{cases}1, & x \in[0,1), 5) \\
-1, & x \in[0.5,1) \\
0, & \text { caso contrario }\end{cases} \\
h_{n(x)} \quad 2^{j / 2} h\left(2^{j} x-h\right)
\end{gathered}
$$

onde $n=2^{\jmath}+k \cdot k \in\left[0,2^{\jmath}\right), x \in\left[k \cdot 2^{-j}:(k+1) 2^{-\mathrm{i}}\right)$.

Existem limitações no uso da construção de Haar. Estas não têm uma boa localização tempo-frequiencia: a sua transformada de Fourier decai muito lentamente (Lima, 2002). Como as funções-base de Haar são funções de passos descontínuos, não sấo muito adequadas para a análise de funções estáveis com derivações contínuas. Visto que as imagens geralmente contêm regiões estáveis, a transformada wavelets de Haar não fornece resultados satisfatórios em muitas aplicaçôes com imagens (Wang, 2001).

A Figura 2.17 mostra a multi-resolução conseguido através das wavelets de Haar. A primeira imagem mostra a figura original de quem se pretende extrair as wavelets, na segunda imagem são extraídas as wavelets somente até o primeiro nível, podemos ver a imagem em uma resolução inferior e os detalhes da mesma que servirá para reconstruir a imagem original e finalmente, na terceira temos a imagem reconstruída sem perda de informação. Para poder atingir uma reconstruçầo perfeita foram usados todos os detalhes contidos em $W$. 


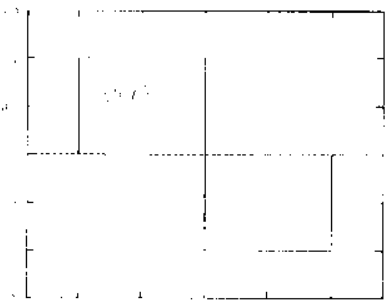

Figura 2.16: Sistema de Haar, wavelet primaria.
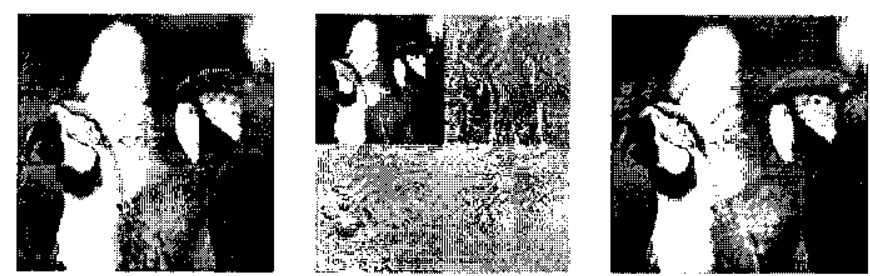

Figura 2.17: Multi-resolução usando as wavelets de Haar. A primeira é a imagem original, a segunda é a multi-resolução através das wavelets de Haar e a terceira é a reconstrução da imagem através das wavelets e dos detalhes.

As wavelets de Daubechies (Daubechies, 1992) formam sistemas completos de funções ortonormais. Para cada inteiro $r$, a base ortonormal para $L^{2}(\mathbb{R})$ está definida como

$$
\phi_{r, j, k}(x)=2^{j / 2} \phi_{r}\left(2^{j} x-k\right), j, k \in \mathbb{Z}
$$

onde a funçăo $\dot{\phi}_{r}(x)$ em $L^{2}(\mathbb{R})$ tem a propriedade que $\phi_{r}(x \cdots k)$, tal que $k \in \mathbb{Z}$, é uma base seqü̈encial ortonormal $\mathrm{cm} L^{2}(\mathbb{R})$. Aqui. $j$ é o índice de escala, $k$ é o índice de translação c $r$ é o índice de filtragem.

Então a tendência $f_{j}$ na escala $2^{-j}$ de uma função $f \in L^{2}(R)$ está definida como

$$
f_{j}(x)=\sum_{k}<f: \phi_{r, j, k}>\phi_{r, j, k}(x)
$$

onde o símbolo $<\ldots .>>$ representa a produto interno.

Os detalhes ou flutuaçōes estão definidas por

$$
d_{j}(x)-f_{j+1}(x)-f_{j}(x)
$$

Para analisar estes detalhes en uma dada escala, define-se uma base ortonormal $\psi_{r}(x)$ com propriedades similares às de $\dot{\phi}_{r}(x)$ descritas anteriormente. 
As funções $\phi_{r}(x)$ e $t_{r}(x)$, denominadas por wavelet-pai e wavelet-mäe respectivamente (ver Figura 2.20), são as funções wavelets protótipo necessárias para a análise de wavelets. A figura 2.20 mostra algumas wavelets mães c pais. As famílias de wavelets. como aquelas definidas na equação 55, são geradas a partir da wavelet pai ou da mãe mudando a escala e translação no tempo (ou espaço em processamento de imagens).
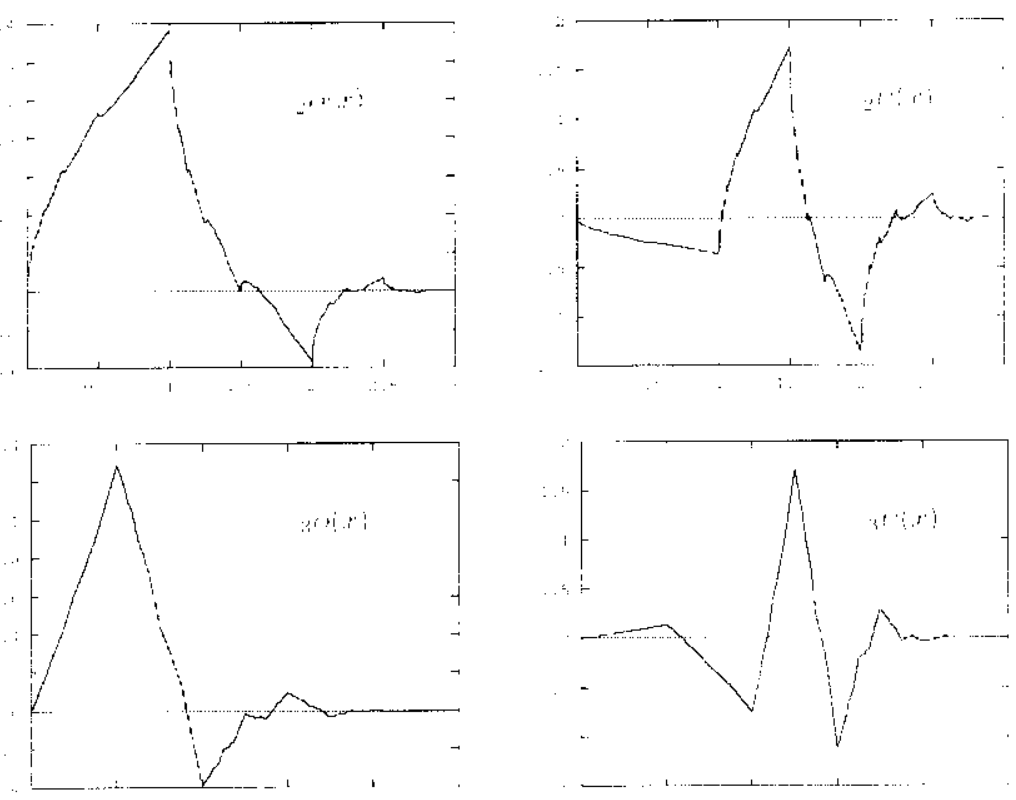

Figura 2.18: Famílias de wavelets de Daubechies. Correspondentes funções de escala e wavelets primárias: $N=20.3($ Lima, 2002).

A base ortonormal de Daubchies tem as seguintes propriedades:

- $\psi$ tem o intervalo de suporte compacto $[0,2 r+1]$ :

- $\ell$ tem ao redor de $1 / 5$ derivações contínuas:

- $\int_{-\infty}^{\infty} b_{r}(x) d x=\ldots=\int_{\infty}^{\infty} x^{r} t_{r}(x) d x=0$.

A Figura 2.19 mostra as wavelets de Daubechies exıraídas da imagem "araras", usada lambém para as wavelets de Haar. Neste caso. chegamos até o nivel dois de resolução. da mesma forma que acontece com as wavelets de Haar podemos reconstruir a imagem através da imagem menor $\mathrm{c}$ dos detalhes.

A transformada wavelets de Haar é um caso especial da wavelets Daubechics com $r::$, a qual é denominada como transformada wavelets Daubechies-2 (Lima. 2002). 


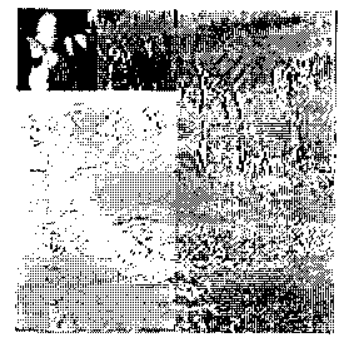

Figura 2.19: Multi-resolução das wavelets de Daubechies de ordem 2.

\subsubsection{Momentos de Wavelets}

Os momentos de Zernike, de Fourier-Mellin, de Hu usam transformadas globais, que apresentam problemas de classificação de objetos distintos com pequenos diferenças. Suponha que temos dois objetos similares, ver Figura 2.20 e os momentos correspondentes deles sejam $\left\|F_{p q}\right\|$ e $\left\|F_{m i}^{\prime}\right\|$, respectivamente. Sendo similares, então na ausência de ruído estas podem ser relacionadas como:

$$
\left\|F_{p q}\right\|+\cdots \mid F_{p q}^{\prime} \|+\Delta_{p q}
$$

onde $\Delta_{p q}$ é um desvio pequeno. Se há existência de algum tipo de ruído, então a relação deve incluir o termo de ruído:

$$
\begin{array}{ll}
\left\|F_{m}\right\|=\left\|F_{m}\right\| \\
1
\end{array}
$$

Figura 2.20: Padrões semelhantes " 1 " e " $\mid$ " que pertencem a classes diferentes.

Como os dois objetos são parecidos, $\Delta_{p q}$ é pequeno. No entanto, a magnitude ruido $p q$, que está integrada dentro do espaço da imagem, pode ser maior que a magnitude $\Delta_{p q}$. Conseqüentemente, os valores de $\left|F_{p q}\right| \mid$ e $\| F_{p q}^{\prime}||$ vão se sobrepor e os dois objetos serão dificilmente separados (Shen e Ip, 1999).

Se a função de transformação $G_{p}(p)$ da Equação (9) é delinida localmente, então $\| F_{\prime^{\prime \prime}} !$ e ||$F_{p q}^{\prime} \|$, serão extraídas desde áreas locais do espaço da imagem e a diferença, $\Delta_{p q}$, entre as características correspondentes de diferentes formas será maior. Similarmente, o efeito do ruído ruido $p_{m}$ será calculado localmente, sendo este valor menor. Provavelmente, os valores de $\| F_{p q} \mid$ e $\left|F_{p q}^{\prime}\right|$ não se sobreporão (Shen e Ip, 1999). Para isso, as wavelets serão usadas em lugar de $\left(G_{p}(p)\right.$. Nas simulaçōes nesta seção, as wavelets B-spline cúbicas (Unser et al., 1992) serão utilizadas, as quais estão localizadas de forma ótima no espaço de frequiência. A wavelet mãe 
B-spline cúbica t( $(\rho)$ pode ser definida como (Unser et al., 1992):

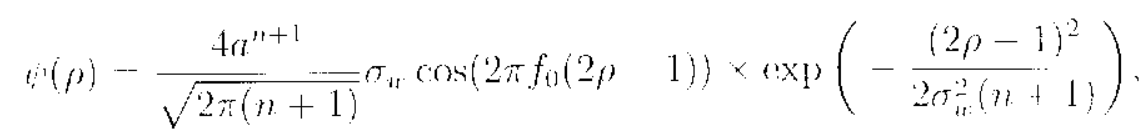

onde $n=3, a=0.697066, f_{0}=0.409177 \mathrm{e} \sigma_{u}^{2}=0.561145$. Esta função é plotada na Figura 2.21 .

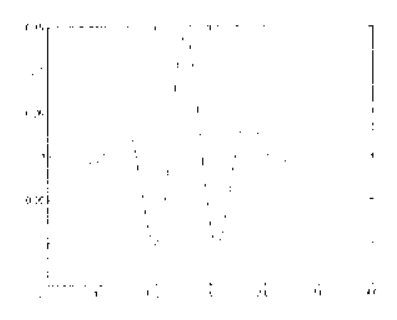

Figura 2.21: $\Lambda$ wavelet mãe B-spline cúbica.

A Equação (50) pode ser expressada em coordenadas polares, trocando o valor $x$ pelo raio $\rho$, onde $\varphi(\rho)$ satisfaz. a Equação 58 . Sclecionando os valores dos parâmetros $a$ e $b$ como segue (Kan e Srinath, 2001):

$$
\begin{array}{ll}
\text { a } \quad 0.5^{m}, & m=0.1, \ldots, M \\
b=n \cdot 0.5 \cdot 0.5^{m} & n=0,1, \ldots, 2^{m+1}
\end{array}
$$

Então, a Equação 50 pode ser reescrita como

$$
\psi_{m, n}(\rho)=2^{m / 2} \omega\left(2^{m} \rho-0.5 n\right)
$$

e os momentos das wavelets B-spline cúbicas estão definidos como (Shen e Ip, 1999):

$$
F_{m, n, q_{2}}=\iint f(\rho, \theta) r_{m, n}(\rho) t^{-j q q^{\prime}} \rho d \rho d \theta
$$

A magnitude dos momentos das wavelets B-spline cuibicas é invariante à rotaçâo e pode ser usado para reconhecimento invariante. Os momentos das wavelets B-spline cribicas para umal imagem digital $f(\rho, \theta)$ pode se definir como (Kan e Srinath, 2001)

$$
F_{m, n, q}=\sum_{x} \sum_{y} f(x, y) k_{m, n}(\rho) r^{-j n t)} \Delta x \Delta y
$$

já vimos na seção 2.1 como encontrar os valor de $\rho$ e $\theta$. 
Os momentos das wavelets $B$-spline cúbicas podem extrair informações locais em diferentes escalas de resolução e translação, onde a função $\xi_{m, n}(\rho)$ varre todas as rolações angulares para calcular os momentos (Kan e Srinath, 2001). Especificamente, para um valor fixo de $\rho$, $\int f(\rho, \theta) \odot{ }^{j q^{\theta}}$ representa a q-ésima característica de frequiência da imagem $f(\rho, \theta)$ no espaço de domínio $0 \leq \theta \leq 2 \pi$. Além disto, usando diferentes índices de resolução $m$ e índices de deslocamento $h$, asseguramos que a wavelet $i_{m, n}(\rho)$ consiga se extender no domínio radial $0 \leqslant \rho \leq 1$ (Shen c Ip. 1999). Então, os momentos invariantes de wavelets $F_{m, n, q}$ podem prover informação sobre os detalhes do objeto $f(\rho, \theta)$ em diferentes níveis de resolução e translação.

Na Figura 2.22 podemos comparar 4 diferentes dilatações de $m$ que sofrem as wavelets $B$-spline cúbicas.
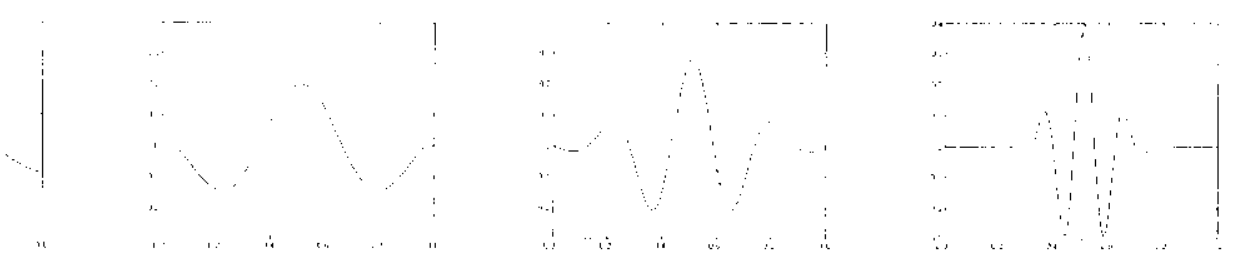

Figura 2.22: Representação gráfica das 4 diferentes dilatações que sofre as wavelets $B$-spline cúbicas para $m \ldots 0, m \ldots 1, m=2$ e $m=3$ respectivamente.

A Figura 2.23 mostra os momentos das wavelets B-spline cúbicas das imagens da Figura 2.6. Assim como aconteceu com os momentos de Hu, de Zernike e Fourier-Mellin, os vetores dos monentos das wavelets B-spline cúbicas também são parecidos. O que nos leva a concluir que são invariantes à rotação e que a qualidade dos dados extraídos é ótima.

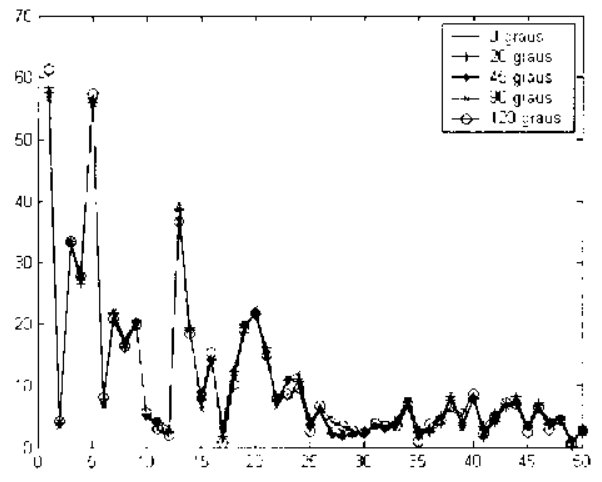

Figura 2.23: Momentos das wavelets B-spline cuibicas extraídos das imagens "morcegos" (ver Figura 2.6). 


\subsection{Redes de pulso acoplado}

Os sistemas biológicos. tais como cérebros de mamíferos, usam um sistema de alta ordem que é consideravelmente mais complexo e poderoso (Eckhorn et al. 1990). Redes neurais de pulso acoplado (PCNN: Pulse-Coupled Neural Network) são justamente motivadas pela investigações do córtex visual de gatos (Eckhorn et al., 1990), a que pretende emular as atividades de umá porção do cérebro e foram aplicadas como técnicas cficientes de processamento de imagens (Berthe e Yang, 2001).

A PCNN recebe estímulos (e.g. intensidade do pixcl) assim como um enlace inibitório. Esses dois sinais são combinados em um sistema de atividade interna, que acumula o sinal até que seja maior a um certo threshold. resultando em uma saída. Este modifica o threshold assim como as propriedades dos neurônios de enlace e de alimentação. Nos seguintes parágrafos se verá com maior detalhe o funcionamento da mesma.

Como podemos ver na Figura 2.24, esta consta de três partes: uma árvore de sinapse. a modulação de enlace e um gerador de pulsos (Johnson, 1994).

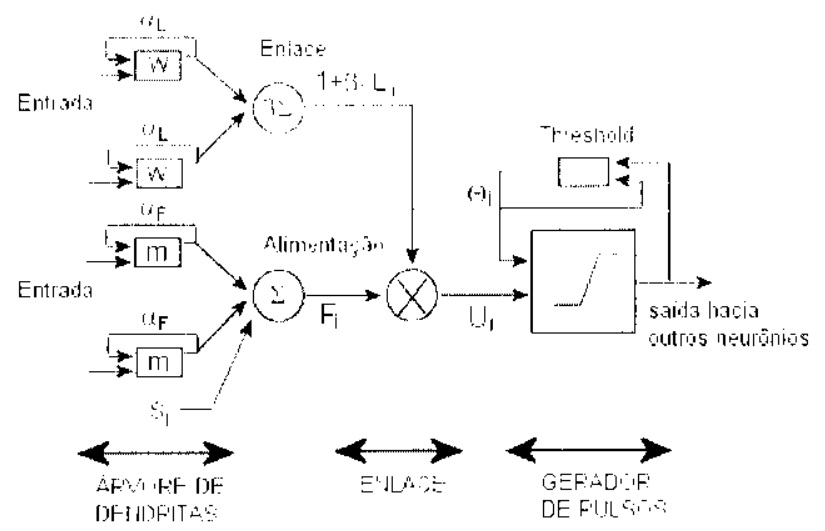

Figura 2.24: O modelo consta de três partes: a árvore de sinapse, o enlace e o gerador de pulsos. A árvore de sinapse é dividida $\mathrm{cm}$ dois canais, enlace e alimentaçâo. As entradas são pulsos provenientes de outro neurônios e a saída é um pulso. A entrada de cnlace modula a entrada de alimentação. Quando o pulso acontece durante a entrada de enlace, este faz incrementar rapidamente a energia interna total $U_{j}$ e faz com que o neurônio dispare ao mesmo tempo.

A PCNN produz uma serie temporal de pulsos. Dependendo do tempo assim como dos parâmetros. csta saída dinâmica contém informação. que permite restaurar imagens (Xiaodong et al., 2000), segmentar (Skourikhine et al., 2000). reconhecimento de alvos (Waldemark et al.. 1997), clusterização (Rhouma e Frigui. 2001) e executar outros tipos de extraçầo de características. Gera uma sequiência de imagens binárias contendo segmentos e bordas da cena de entrada. O algoritmo é executado através de iterações continuas dits seguintes equações: 


$$
\begin{aligned}
& F_{i j}[n]=e^{-\alpha_{l}} F_{i j}[n-1]+S_{i j}+V_{F} \sum_{k l l} m_{i j ; k l} Y_{k l}[n-1] \\
& L_{i j}[n]=e^{-a_{L}} L_{i j}[n-1]+V_{l} \sum_{k: l} w_{i j ; k l} Y_{k l l}[n-1] \\
& \left.U U_{i j} n\right]=F_{i j} n\left\{1+3 L_{i j}[n j\}\right. \\
& Y_{i j}[n]=\left\{\begin{array}{l}
\left.\left.1, \text { se } U_{i j} \mid n\right]>\Theta_{i j_{2}} n\right] \\
0, \text { em outro caso }
\end{array}\right. \\
& \left.\Theta_{i j}[n]=e^{-\alpha_{\Theta}} \Theta_{i j}[n-1]+V_{\Theta} Y_{i j} n\right]
\end{aligned}
$$

onde $S$ é o estimulo de entrada (e.g. a intensidade do pixel $i, j$ ). $m_{i j}$ ć a matriz de pesos para as entradas de alimentação $(F), u_{i j}$ as matrices de pesos das sinapse para as entradas de enlace $\left(I_{i}\right)$, estas matrices podem ser iguais a tim de reduzir o custo computacional. $F_{i j}$ é a entrada de alimentação, $L_{r j}$ a entrada de enlace. $U_{i j}$ a atividade interna total, $Y_{i j}$ a saída, $\Theta_{i j}$ o threshold, c $B$ o parâmetro de enlace. Existem três potências $V$ e três constantes de tempo $\alpha$ associadas $\operatorname{com} F, L \mathrm{e} \Theta$.

O gerador de pulsos está constituído por um formador de pulso e uma variável threshold (ver Figura 2.24) que depende do pulso anterior emitido pelo formador de pulsos. O neurônio cmite um pulso quando a primeira condição da Equação 65 é satisfeita $\mathrm{e} Y_{i j}=1$, i.e., quando a energia interna $U_{i j}$ do neurônio é maior que seu threshold $\Theta_{i j}$. Este pulso leva o valor threshold do mesmo elemento para o nível máximo, inibindo geração de pulsos contínuos. Em seguida, o threshold decai exponencialmente (veja a Equação 66 e a Figura 2.25). Com chegada dos novos pulsos dos elementos vizinhos e a decaída do threshold, o elemento pode gerar um novo pulso, e assim por diante para lodos os elementos da rede.

Veja a Figura 2.25, quando a entrada de enlace $L_{i j}$ atinge a zona de captura (um intervalo de tempo), o elementos dispara um pulso. Nesta mesma zona, se os elementos vizinhos também disparam pulsos, todos eles serão sincronizados, no sentido de que eles vão gerar pulsos ao mesmo tempo.

A taxa de pulsos disparados está definida pela seguinte equação (Xiaodong et al., 2000):

$$
f_{j}=\frac{a_{j}^{T}}{\ln \left(1+\frac{v_{j}^{T}}{v_{y}}\right)}
$$

O intervalo da zona de captura é (Xiaodong et al., 2000)

$$
T_{j}^{\prime}=\frac{1}{\alpha_{j}^{T}} \ln \left(1+\beta_{j} L_{j}\right)
$$




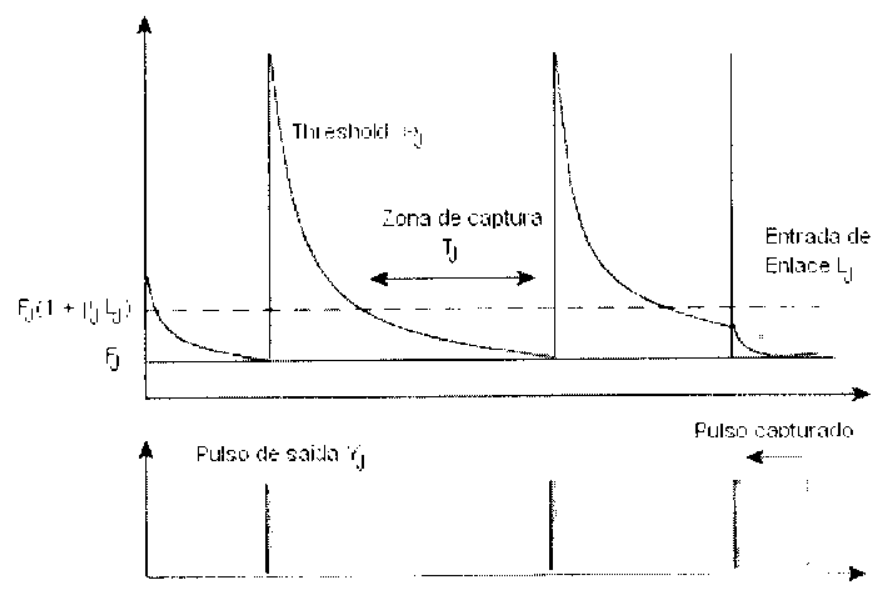

Figura 2.25: A figura mostra como um elemento dispara sob condições de um pulso de saída.

A forma de acoplamento entre cada elemento e seus vizinhos é um outro aspecto importante em redes de pulso acoplado. Cada elemento se acopla com os vizinhos através de uma matriz de pesos $m_{i j k l l}$ e $w_{y, k l l}$. A forma de acoplamento dos elementos pode ser feita de duas maneiras:

1. Vizinhança de Von Neumann:

$$
n_{k N}=\left\{\left(\mathbf{n}_{j}=\left(i_{1 j}, \ldots, i_{d j}\right) / i_{k j} \in\{1,0,1\} \text { para } \quad k \quad 1, \ldots, d \bullet \sum_{k=1}^{d}\left|i_{k j} \leq 1\right|\right\}\right.
$$

Neste caso. o clemento i está conectado com todos os clementos que estâo a uma distância de raio 1, isto é, com seus 4 vizinhos mais próximos, como podemos ver na Figura 2.26 (a).

2. Vizinhança de Moore:

$$
n_{M}=\left\{\mathbf{n}_{j}=\left(i_{1 j}, \ldots, i_{d j}\right) / i_{k j} \in\{-1.0,1\} \text { para } k=1 \ldots d\right\}
$$

Neste caso o elemento i está conectado com todos os clementos que estão a uma distância de raio 1 em qualquer direção (i.e. as conexốes diagonais são permitidas. ver Figura2.26 (b) )

Imagens parecidas geram sequiencias de pulsos similares. Esta característica das redes de pulso acoplado permite usá-las como extratores de características invariantes.

A Figura 2.27 (a) mostra a imagem "Lenna" que será usada para avaliar o desempenho da rede de pulso acoplado e (b) mostra os vetores de pulsos da imagem em (a) e suas versões rotacionadas em $20^{\circ}, 45^{\circ}, 90^{\circ}$. Podemos ver que os diferentes vetores de pulsos são similares. 


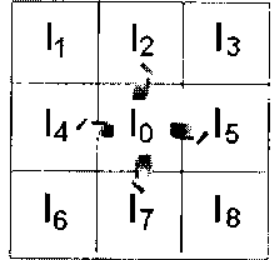

(a)

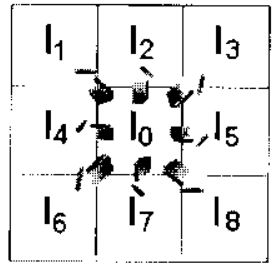

(b)

Figura 2.26: Vizinhança de von Neumann (a) e Moore (b) do elemento i.

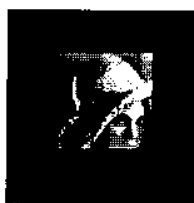

(a)

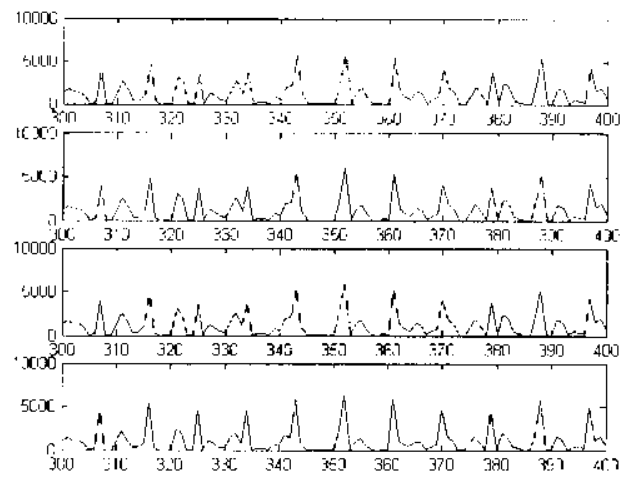

(b)

Figura 2.27: (a)Imagem "Lenna" e (b) Vetor de somatório de pulsos da imagem em (a) e suas versões rotacionadas em $20^{\circ}, 45^{\circ}$ e $90^{\circ}$ respectivamente.

\subsubsection{Rede de pulso acoplado seqüencial}

Em PCNNs, os elementos evoluem de forma paralela. Existe urna outra forma de geração de pulsos, onde os pulsos são transmitidos seqüencialmente (horizontal ou vertical). Esse tipo de redes é chamado como Rede de pulso acoplado seqüencial, proposto por Dodwell (Rishikesh e Venkatesh, 2001).

A rede de pulso acoplado seqüencial só gera pulsos invariantes à translação. Para obter características invariantes à rotação e escala, o mapeamento do logaritmo complexo(CLM) será aplicado para a imagem de entrada. Logo, usa-se uma rede de pulso acoplado seqüencial afim de atingir a invariância à rotação, cscala c translação. 


\subsubsection{Mapeamento do logaritmo complexo}

O CLM é descrito por $w=\log z$ ou $w \cdots \log \rho+j(\theta+2 k \pi)$ onde $w \mathrm{e} z=\rho^{(0+2 k x)}$ são variáveis complexas, $\rho$ e $\theta$ denotam as coordenadas polares de $z$, e $k$, um inteiro. Esta detinição indica que a rotação e escala no domínio de $z$ significam deslocamentos ao longo do eixo $\theta$ e o eixo $\log \rho$. Essas propriedades do CLM somente são atingidas quando o mapeamento da origem está bem definida com respeito às bordas. O centróide do padrão é usado como a origem do mapeamento, desta forma se consegue garantir a invariância com respeito aos deslocamentos das posições da borda.

\subsubsection{Esquema de codificação do Dodwell}

O modelo do Dodwell inclui uma matriz bi-dimensional de unidades, estas unidades estäio conectadas em cadcias de tal forma que uma unidades tem como máximo dois vizinhos. De um deles recebe a excitação, e o outro vizinho scrá a quem transmitirá a cxcitação. Cada cadcia horizontal (vertical) está organizada de tal forma que quando uma borda horizontal (vertical) está projetada sobre a grade. as unidades da grade que são relacionadas com as unidades ativadas terminam em uma única cadeia (Rishikesh e Venkatesh. 2001).

Na Figura 2.28 representa-se uma grade de codificação típica e somente cadeias horizontais são mostradas explicitamente. Scja $l \times c$ as dimensões da grade de codilicação, onde $l$ representa o número de linhas e $c$ as colunas. Sejam as unidades pertencentes à coluna de mais à esquerda da grade (representado por $A$ na Figura 2.28) chamadas de conjunto final da grade. As unidades do conjunto final têm as seguintes propriedades:

- Elas são as geradoras das excitações. Elas transmitem a excitação, mas não recebem de nenhuma unidade.

- A direção de transmissão é desde o conjunto final até a saída do codificador (representado por uma seta na Figura 2.28).

- O conjunto final dispara os estímulo simultaneamente.

As outras unidades transmitem a excitação aos seus respectivos vizinhos delas ao longo no sentido de transmissão depois de um tempo constante que é igual a

(a) $T_{p}$, segundos, se não for ativado pelas projeçöes das bordas, $\mathrm{c}$

(b) $T_{n}\left(>T_{p}\right)$ segundos caso contrario. 
Considere o caso $\mathrm{cm}$ que nenhuma das unidades do codificador é ativada pelas projeções das bordas. Nieste caso, o envio do sinal de excitação desde o conjunto final da grade $A$ induz uma varredura da matriz sendo este um valor constante e cada cadcia atingirá a saída simultaneamente. A saída, então scrá um só pulso de $l$ unidade de amplitude, acontecendo em um tempo constante $c * T_{p}$ depois que o conjunto final tenha disparado o sinal.

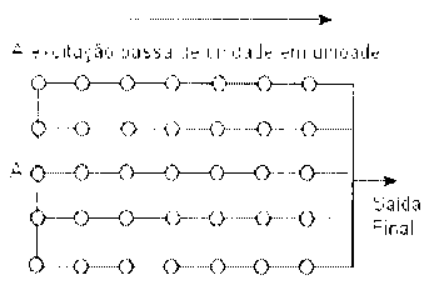

Figura 2.28: Grade de codificação.

De outro lado. no caso em que algumas unidades foram ativadas pelas projeções dos contornos. os períodos de transmissão ao longo das diferentes cadeias serão alternados dependendo no número de unidades ativadas. Consideremos por um instante um caso simples, onde a borda horizontal de comprimento $n<c$ é projetada sobre uma cadeia da grade. Esta ativará $n$ unidades da cadeia, então $n$ unidades da cadeia produzirão uma demora de $T_{a}$ segundos enquanto $\left(e\right.$. n) unidades continuem produzindo uma demora de $T_{p}$ segundos. A saída do codificador é inicialmente um pulso de amplitude $(l-1)$ unidades acontecendo no tempo $c * T_{p}$ segundos depois da excitação desde o conjunto final, seguido pelo sinal de amplitude da unidade acontecendo no tempo $(c-n) * T_{p}+n * T_{a}-\left(* T_{p}+n\left(T_{a}-T_{p}\right)\right.$ segundos depois da excitação desde o conjunto final. Então, é possível notar que o pulso inicial é devido às $(r-1)$ cadeias horizontais não ativadas e aquela com demora (sendo o atraso de $n\left(T_{n}-T_{p}\right)$ ) é o resultado da cadeia horizontal ativada (Rishikesh e Venkatesh, 2001).

\subsubsection{Varreduras perpendiculares}

Não é vantajoso incorporar somente a varredura horizontal na grade de codificação porque pode gerar saídas semelhantes para padrões diferentes. O problema pode ser resolvido usando cadeias verticais, as quais são ativadas por bordas verticais. Essas cadeias são perpendiculares às cadeias horizontais. Então, o codificador tem duas saídas separadas, as quais correspondem às varreduras verticais e horizontais. respectivamente.

Na Figura 2.29 ilustra-se o funcionamento da grade de codificação. A Figura 2.29 (a) é uma típica grade de codificação, onde as unidades ativadas (escuras) correspondem à presença de pontos das bordas; e a Figura 2.29 (c) correspondem aos pulso tanto em sentido horizontal como vertical. Na Figura 2.29 (b) mostram-se as unidades ativadas da grade de codificação de 
uma borda rotacionada e a Figura 2.29) (d) corresponde às sequências de pulsos. Consideráveis diferenças entre as sequiencias na Figura 2.29 (c) e (d) confirmam que a presente grade de codificação não é invariante à rotação dos pontos das bordas (Rishikesh e Venkatesh, 2001).

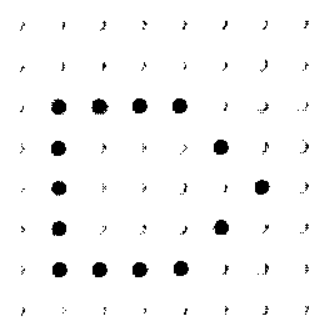

(a)

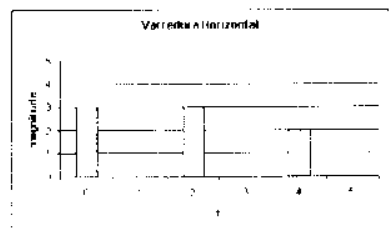

(c)

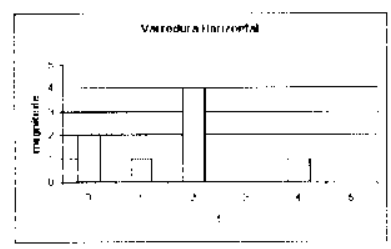

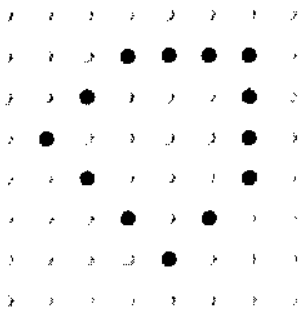

(b)
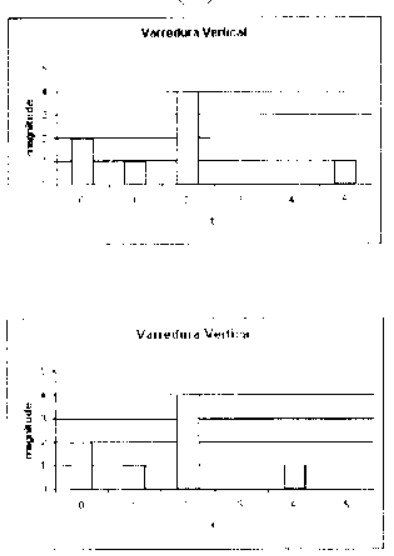

(d)

Figura 2.29: (a) Codificador de grade com unidades ativadas (escuras). (b) Codificador de grade com unidades ativadas (escuras) para um contorno rotacionado. (c) Ilustração da função) do codificador de grade: pulsos correspondentes às varreduras horizontais e verticais de(a). (c) Ilustração da função do codificador de grade: pulsos correspondentes às varreduras horizontais e verticais de (b).

Como podemos ver a grade de codificação é invariante à translação, mas apresenta algumas características não desejáveis pelos seguintes motivos:

1. Não é invariante à rotação c escala.

2. Uma pequena variação na borda de entrada dará como resultado saídas diferentes, isto é. tem tolerância baixa ao ruído.

3. Como a borda é alimentada diretamente sobre o codificador, o tamanho da matriz de codificação também será grande, produzindo um pulso comprido.

Como temos visto, trabalhar com estas técnicas de forma separada não conseguiria se atingir o objetivo. Afim de evitar as desvantagens associadas à grade de codifição de Dodwell. assim 
como com as estratégias de deslocamento desenvolvidas na Seção 2.8.1.1, Rishikesh (Rishikesh e Venkatesh, 2001) propõe uma aplicação da grade de codificação do Dodwell para manipular os deslocamentos depois de ter passado pela CLM. Podemos ver o modelo proposto na Figura 2.30 .

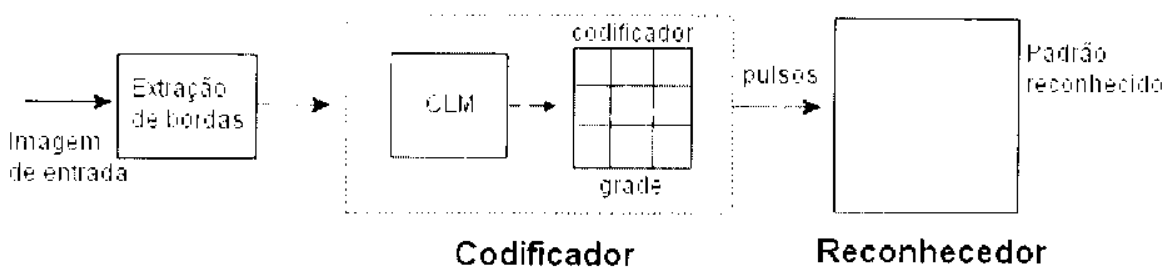

Figura 2.30: Representaçăo do diagrama de blocos do modelo proposto por Rishikesh.

O modelo proposto atinge a invariância da seguinte forma, ao utilizar a técnica CLM é preciso converter as bordas em coordenadas polares, mas antes deve se encontrar o centróide para que seja a origem do mapeamento. Desta forma, está se garantindo que a invariância à translação. Logo, quando as bordas são mapeadas em coordenadas polares, atinge-se a invariâncià à rotaçẫo. No caso de coordenadas polares cuaundo um objeto é rotacionado acontece um deslocamento em forma horizontal, isto é, as partes que vão saindo pela direita irão aparecendo pela esquerda. Portanto, sempre teria-se igual ou similar quantidade de unidades ativadas pelas bordas dentro da grade de codificação. Outra coisa que devemos reparar é que o CLM usa um mapeamento logaritmo, isto quer dizer que o padrão mapeado também seria invariante à escala.

\subsection{Considerações finais}

Neste capítulo foram estudadas as principais técnicas para extração de características invariantes tais como os momentos estatísticos (Hu, Zernike, Fourier-Mellin, Legendre, entre outros), transformadas de Fourier, transformadas de wavelets e redes de pulso acoplado. Entre os momentos estatísticos os momentos de Zernike são os que apresentam um melhor desempenho, permitindo uma melhor extração de características. As redes de pulso acoplado paralelo são eficientes para extração de características invariante de imagens em níveis de cinza por estas ser sincronizadas por cor. mas no caso de imagens binárias as características extraídas são semelhantes para todos os objetos. As redes de pulso acoplado sequiencial permitem obter características invariantes de imagens binárias, mas para aquilo foi sacrificado o paralelismo total que apresentam as redes de pulso acoplado paralelas. Ainda assim conservam paralelismo em linhas e colunas. As redes de pulso acoplado paralelas são as que possuem uma maior tolerância a ruído, no resto de técnicas é limitado. 


\section{Autômatos Celulares}

\subsection{Considerações iniciais}

Veste capítulo, serão abordados os conceitos básicos referentes aos autômatos celulares. Primeiro, serão explicados a nomenclatura, estrutura, regra de evolução, tipos de vizinhança, assim como a classificação dos autômatos celulares segundo Wolfram (Wolfram, 1984). A seguir, será desenvolvida uma descrição do comportamento dinâmico e da capacidade computacional dos mesmos. Serão apresentados exemplos de evoluções dos autômatos celulares, tanto em 1D como em 2D. Por último, será mostrada uma aplicação de autômato celular para extração de bordas de imagens.

\subsection{Introdução}

Os autômatos celulares(ACs) são modelos matemáticos, originalmente introduzidos por von Neumann e Ulan (sob o nome de "espaços celulares") como uma possível idealização dos sistemas biológicos, com o propósito particular de modelar a auto-reprodução biológica. Eles foram utilizados e reintroduzidos para uma grande variedade de propósitos, e referidos através de diferentes nomes como: "autômato mosaico". "estruturas homogêneas", "estruturas celulares", "estruturas mosaico" ou "vetores iterativos" (Wolfram, 1983). 
Os ACs contém uma grande quantidade de componentes simples com interaçóes locais para produzir padrões complexos (Wolfram. 1984). Cada componente, é chamado de célula ou elemento e está conformado por um conjunto finito de cstados, os quais evoluem simultaneamente no tempo de acordo a regras idênticas. O estado de cada elemento é determinado por estados prévios da vizinhança, isto é, dos elementos ao redor do mesmo.

Os ACs podem ser considerados como sistemas dinâmicos discretos e de alta dimensão. Na maioria dos casos a evolução é irreversível. As trajetórias das células no espaço de configuração podem convergir para atratores, os quais contém uma pequena quantidade de combinaçôes dos estados celulares. A evolução destes estados iniciais arbitrários aos atratores, permite um comportamento auto-organizado. onde a estrutura global (padrão) é formada e pode evoluir por períodos longos. A natureza dos atratores determina a forma c extensão dessas estruturas (Wolfram, 1984).

Três características fundamentais dos ACs são:

1. Paralelismo, os estados dos elementos são atualizados simultaneamente.

2. Localidade, o novo estado de uma célula é determinado pelo seu estado anterior e pelo estado dos vizinhos.

3. Homogeneidade, todas as células aplicam as mesmas regras de evolução.

\subsubsection{Notação e formalismo}

Um AC d-dimensional é uma estrutura $\mathrm{A}=\left(\mathbf{Z}^{i}, S, \aleph . \delta\right)$ onde (Bandini et al., 2001):

(a) $\boldsymbol{Z}^{\prime}$ é uma grade de d-tuplas de número inteiros.

(b) S é um conjunto finito de estados.

(c) $N=\left\{\left(a_{1 j}: a_{2 j}, \ldots, a_{d j}\right) / j \in\{1, \ldots n\}\right\}$ é um subconjunto ordenado finito (de tamanho $|N|=n)$ de $\mathbf{Z}^{\prime}$ chamado de vizinhança de $a,$.

(d) $f: S \rightarrow S^{t-1}$ é uma função de transição local ou a regra local de A.

Embora as células possam ser organizadas em qualquer dimensão, ACs unidimensionais e bi-dimensionais são mais estudados e têm maior aplicação prática.

Seja $a_{*}^{(b)}$ o estado da célula $\%$ em um AC unidimensional no tempo $t$, cujo valor está especificado por um número inteiro no intervalo $[0 . \%$ 1 $]$. e é altualizado em passos discretos de acordo 
com a regra $\int$ que depende dos cstados das células dentro da vizinhança pré-definida:

$$
\left.a_{i}^{(t+1)}=f^{\prime} a_{i-r}^{(t)} a_{i, r, 1}^{(t)}, \ldots, a_{i}^{(t)}, \ldots, a_{i+r}^{(t)}\right]
$$

O parâmetro $r \geq 0$ ć o raio da vizinhança. Em cada iteração, uma região de $r$ células em cada direção ć afetada por uma dada célula; depois de $t$ iteraçôes, uma região de $1+2 r t$ células como máximo será afetada pelo valor inicial da célula em referência. Desta forma de evolução, a característica local de cada vizinhança de células é propagada para todos os elementos do $\mathrm{AC}$.

Lima forma mais específica de representar a Equação 3 é

$$
a_{i}^{(t+1)}=f\left[\sum_{j=-r}^{r} \alpha_{j} a_{i+j}^{(t)}\right]
$$

onde $\alpha_{j}$ são constantes inteiras, que representam um peso de influência. Pode ser dado um mesmo valor de pesos para todas as células vizinhas, isso implica que o estado da célula recebe a mesma influência de todos os vizinhos. Caso os valores dos pesos sejam diferentes, a distribuição Gaussiana é mais apropriada, implicando que a célula recebe maior influência dos vizinhos mais próximos e essa influência diminui assim que o raio da vizinhança é incrementado.

No caso das células que são organizadas em uma grade bi-dimensional, a função de transição é definida como:

$$
\begin{aligned}
& a_{i, j}^{(1--1)}=f \mid a_{i-r_{1, j}-r_{2},}^{(1)}, a_{i-r_{1}, j-r_{2}-1}^{(1)}, \ldots, a_{i-r_{1}, j+r_{2}}^{(1)}: \\
& a_{i-r_{3}-1, j-r_{2}}^{(t)}, a_{i-r_{2}+1, j-r_{2}+1}^{(t)}, \ldots, a_{i-r_{1}-1, j-r_{2}}^{(t)}, \\
& \vdots \\
& \left.a_{i+r_{1}, j-r_{2}}^{(\ell)}, a_{i+r_{1}, j-r_{2}+1}^{(t)}, \ldots, a_{i+r_{1}, j+r_{2}}^{(t)}\right]
\end{aligned}
$$

Uma forma mais especifica é

$$
a_{\cdot, j}^{(t-1)}=f\left[\sum_{m}^{n} \sum_{-r_{1}}^{n_{1}} \sum_{-r_{2}}^{r_{2}} \alpha_{m, n} a_{i+m, j+n}^{(t)}\right],
$$

onde $\alpha_{m, n}$ representa o peso de influência da célula $(i+m, j+n)$ na célula $(i, j)$. A região da vizinhança da célula $(i, j)$ é determinada por dois parâmetros $r_{1}$ (extensão horizontal) e $r_{2}$ (extensão vertical). 
Por excmplo, um AC bi-dimensional onde cada célula é acoplada com suas 4 vizinhas mais próximas pode ser definido como:

$$
a_{i, j}^{(t+1)}=f\left[a_{i, j}^{(t)}, a_{i, j ! 1}^{(t)}, a_{i+1, j}^{(t)}, a_{i, j-1}^{(t)}, a_{i-1, j}^{(t)}\right]
$$

Quando a regra totalística é usada, onde a ativação da célula depende do somatório das ativaçôes de seus vizinhos:

$$
a_{i, j}^{(t+1)}=f\left[a_{i, j}^{(\ell)}+a_{i, j+1}^{(t)}+a_{i+1, j}^{(t)}+a_{i, j}^{(t)}+a_{i-1, j}^{(t)} .\right.
$$

Para configurar um $\mathrm{AC}$, precisa-se considerar vários fatores. Os mais importantes são a dimensão $c$ a geometria da grade. o tamanho da vizinhança, condições de fronteira. as condiçôes iniciais, o conjunto de estados e regras de transição.

A geometria da grade define a forma de acoplamento entre as células. Em AC's bi-dimensionais existem três categorias de grades típicas: quadrada, triangular e hexagonal. Na maioria de casos, a quadrada é a mais usada; porque usar as grades triangulares ou hexagonais é a melhor opção somente em algumas ocasiões. Pois estas são difíceis de representar e visualizar, sendo que devem ser mapeadas em uma matriz quadrada de pixels (Viher et al., 1998).

As regras dos ACs podem ser combinadas por composição das funções. A composição de uma função de transição $f$ com ela mesma, denotada $f^{(m)}$, gera padrões correspondentes à evolução em iterações alternas da função $f$.

$\mathrm{Na}$ definição formal de um $\mathrm{AC}$, usualmente precisa-se de grades infinitas em todas as direções. Mas, só podemos simular ACs finitos, os quais necessitam estabelecer as condições de fronteira. Geralmente, dois tipos de condições de fronteira são mais usados: periódicos c absorventes (as células que estão na fronteira não têm vizinhas fora dos limites da grade). No caso de um AC unidimensional com condições de fronteira periódica, o primeiro c o último elemento estão acoplados, formando um ancl. Para uma grade bi-dimensional, isso significa que os elementos correspondentes no extremo superior e no extremo inferior estão conectados. o mesmo acontece com os elementos nos extremos csquerdo e direto, formando uma hola. No caso de condições de fronteira absorvente (finita). não existem conexões entre os elementos nos extremos.

\subsection{Classificação do ACs}

Apesar de ser de simples construção, os ACs são capazes de gerar comportamentos complexos. Os ACs podem ser classificados $\mathrm{em}$ quatro categorias, segundo o comportamento que apresentam durante a evolução (Wolfram, 1984). Os ACs que pertencem à mesma classe exibem 
características similares. Muitos dos detalhes na construção de um AC não são relevantes para determinar o comportamento qualitativo. Então. sistemas físicos e biológicos complexos podem pertencer à mesma classe como um sistema matemático idealizado pelos ACs (Wolfram, 1984).

As quatro classes em que podem se dividir os ACs caracterizam aos atratores na evolução dos $\mathrm{AC}$. Os atratores nas classes 1, 2 e 3 são, a grosso modo, análogos aos pontos estacionários, ciclos limites e a atratores caólicos encontrados em sistemas dinâmicos, respectivamente. Os ACs da classe 4 comportam-se de maneira mais complexa, e supõe-se que são capazes de implementar qualquer algoritmo finito (Wolfram, 1984).

As diferentes classes de ACs representam diferentes níveis de predição dos resultados das evoluções desde um estado inicial particular. Na primeira classe, o resultado da evolução está determinado (com probabilidade 1), independentemente do estado inicial. Na scgunda classe. o estado de uma célula em particular está determinado pelos estados iniciais das células dentro de uma região local depois de um longo período de iterações. Na terceira classe, o estado de uma célula em particular depende dos estados de um crescente número de células iniciais. Estados iniciais randômicos conduzem a um comportamento caótico. Apesar disso, dado o conjunto inicial de estados necessários, o estado de uma célula que pertence à classe 3 pode ser determinado por um algoritmo simples. Por outro lado, na classe 4 dos ACs, o estado de uma célula em particular pode depender de vários estados iniciais de outras células e, aparentemente, só pode ser determinado por um algoritmo equivalente $\mathrm{cm}$ complexidade para poder explicar claramente a simulação da evolução do AC. Para este tipo de AC, não é possível uma predição, o comportamento somente pode ser determinado por uma simulação explícita (Wolfram, 1984).

Esta classificação é empírica e difícil de aplicar. Por exemplo, foi mostrado que o agrupamento de um $\mathrm{AC}$ dado inclusive daqueles que pertencem à classe 1 é indecidível '. Portanto, esta classificação é a base de tentativas de clasșificações mais rigorosas (Bandini et al., 2001).

\subsubsection{Classe 1}

Os ACs da classe 1 evoluem depois de um número finito de iterações. a partir de quase todos os estados iniciais, para um único estado homogêneo, onde todos as células têm o mesmo valor. Esse AC pode ser considerado como aquele que evolui a um simples "ponto estacionário" no espaço; sua evolução perde completamente toda informação do estado inicial. A dimensão do conjunto para tais tipos de atratores são iguais a zero (ver seção 3.4).

\footnotetext{
${ }^{\text {I }}$ im problema $P$ é decidível se, dada uma determinada represcntação deste problema, existe uma Máquina de Turing que sempre pára para qualquer entrada do conjunto de entradas desta representação
} 
As regras para os ACs da classe 1 tomam a função da Equação 3 onde têm os mesmos valores para quase todos os $k^{2 r+1}$ possíveis conjuntos de argumentos (Wolfram, 1984). Isto é, os estados das células evoluem a estados globais homogêneos (cujos valores são uns ou zeros no caso binário). Podemos ver na Figura 3.1, o padrão gerado pelo AC da classe 1, que em poucas iterações os cstados de todas as cćlulas evoluem ao estado zcro (representado pela cor preta).

Algumas configurações iniciais na classe 1 dos ACs podem não evoluir a estados homogềncos, mas podem cntrar em ciclos não triviais, podemos ver na Figura 3.1 o autômato celular da classe 1 . onde as células ativadas (representadas pela cor branca) não evoluem ao ponto estacionário (representado pela cor preto) formando ciclos não triviais até finalmente convergirem em um ponto estacionário. Tais configurações excepcionais decrescem rapidamente com o tamanho $n$, sugerindo que, para ACs infinitos da classe 1 o conjunto de configurações excepcionais é sempre de tamanho zero no conjunto de todas as possíveis configuraçôes (Wolfram, 1984), i.e., se o tamanho $n$ decresce, existe uma menor possibilidade de gerar ciclos, devido a quc existem uma menor quantidade de possíveis sequiências.
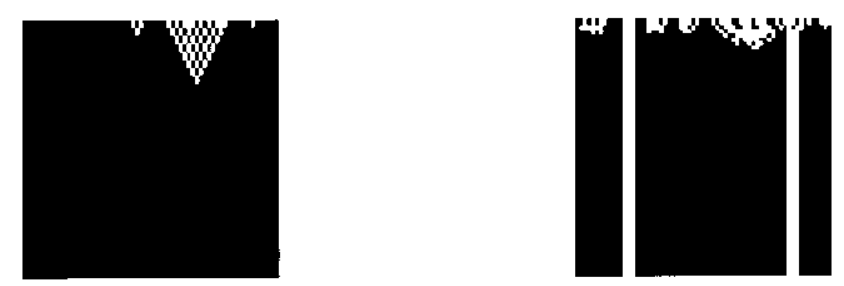

Classe $1: r=1, k \quad 2$, regra 60 Classe $2: r=2 . k:=2$, regra 38
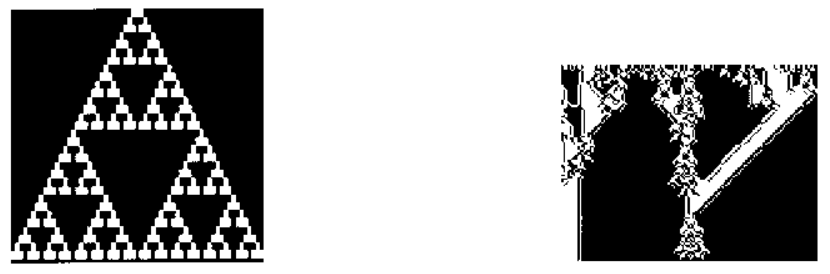

Classe 3: $r=1, k=2$, regra 22 Classe 4: $r=2, k=2$, regra 52

Figura 3.1: Exemplos da classificação de Wolfram, onde $r$ representa o raio e $t$ o número de estados. A classe 1, independentemente da configuração inicial, o AC tende a um estado global espacialmente homogêneo; a classe 2, atinge um estado estável formado por estruturas espaciais periódicas estáveis; a classe 3. têm um comportamento caótico. a maioria de ACs da classe 3 gera padrões fractais e; a classe 4, podem ser geradas cstruturas estacionárias, periódicas ou fractais. As estruturas persistentes podem ser simples, também crescentes e complexas. 


\subsubsection{Classe 2}

Os ACs da classe 2 servem como "filtros", os quais geram estruturas simples, mas não-homogêneas. Freqüientemente, mudanças nos estados iniciais somente afetam os estados finais das células dentro de finitas iterações, tipicamente de ordem $r$ (Wolfram, 1984).

A estrutura gerada pelos $A C s$ da classe 2 também são estacionárias ou periódicas, tipicamente com poucos períodos. As regras ${ }^{2} 38,56,58$ exibidas na Figura 3.2, como as 8, 24, 40 todas aparentemente têm estruturas persistentes estáveis. Exemplos de ACs da classe 2 que produzem estruturas persistentes periódicas, em lugar de estacionárias, incluem o $\mathrm{ACs}$ de $k=2 \mathrm{e}$ r. I com a regra número 108 (Wolfram, 1986), e de $k=3$ e $r \ldots 1$ com a regra 198 (Wolfram, 1984).

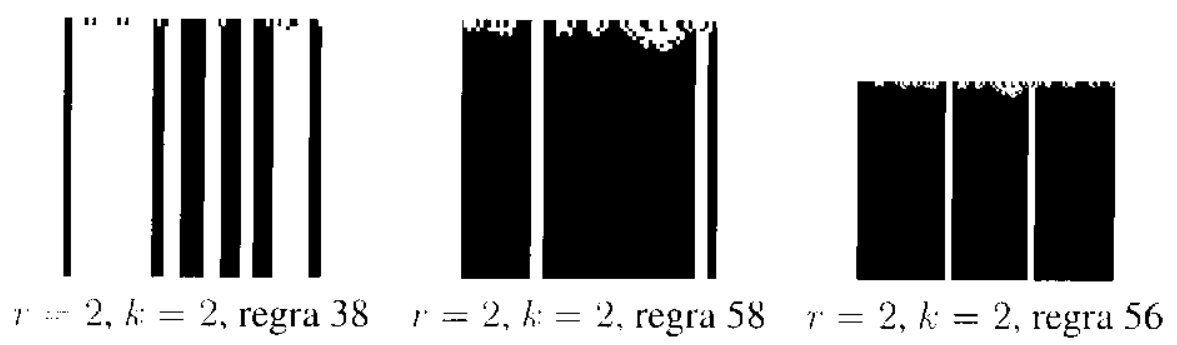

Figura 3.2: ACs da classe 2, atingem um estado estável formado estruturas espaciais periódicas.

\subsubsection{Classe 3}

A cvolução de um $A C$ da classe 3 , de quase todos seus possívcis estados iniciais, conduz a padrões aperiódicos (caóticos). A maioria de ACs da classe 3 gerá padrões fractais. Existem algumas regras que geram padrões irregulares.

Muitas, mas não todas as regras que evolucm a padrões fractais regulares, desde estados iniciais regulares. geram padrões mais regulares que se houvessem sido gerados a partir de estados iniciais desordenados, ver Figura 3.3 (Wolfram, 1984).

\subsubsection{Classe 4}

A Figura 3.4 mostra a evolução dos ACs da classe 4 onde $k=2, r=2$, desde diferentes configurações iniciais aleatórias. Na maioria dos casos, todas as células morrem (atingem valor zero) depois de finitas iterações. Porém, em pouco casos, estruturas estacionárias, periódicas ou fractais que persistem no tempo podem ser formadas. Na Figura 3.4 (a) mostra-se estruturas

\footnotetext{
ZAs regras para $k=2 \mathrm{e} r=1$ estão detinidas $\mathrm{em}$ ht1p://www.stephenwolfram.com/publications/articles/ca/86-caappendix/2/text.html
} 

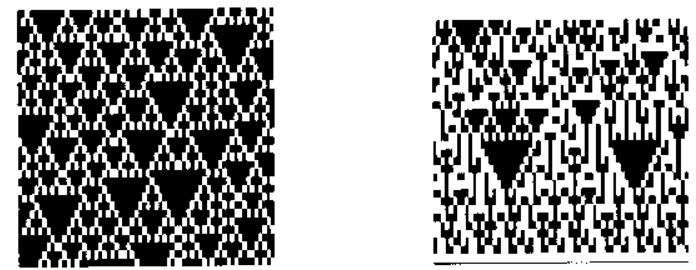

$r-: 1, h:=2$, regra 18

$r=1, k=2$, regra 90
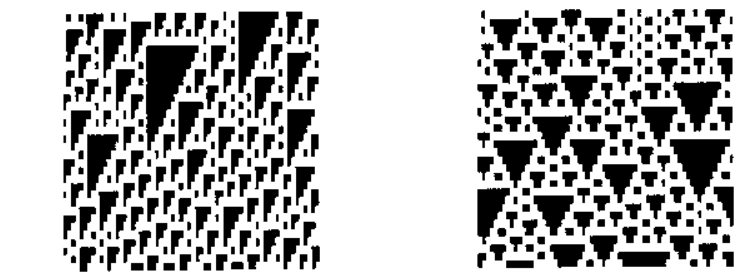

$r=1, k=2$, regra $110 \quad r=1, k=2$, regra 126

Figura 3.3: ACs da classe 3, não apresentam estrutura alguma, tendo um comportamento caótico; isto ocorre por causa de seu comportamento imprevisível.

crescentes que, depois de certo número de itcrações, convergem a um estado "nulo": e em (b) vemos ACs da classe $4 \mathrm{com}$ estruturas persistentes. Estas estruturas podem ser simples, também crescentes e complexas (ver Figura 3.5). Uma importante característica. compartilhada com todos os ACs da classe 4, é a presença de estruturas de propagação em certa quantidade de primeiras iteraçôes. gerando padrões complexos (Wolfram. 1984).

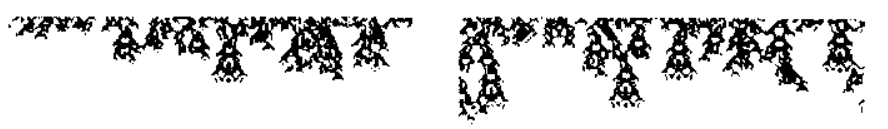

(a)

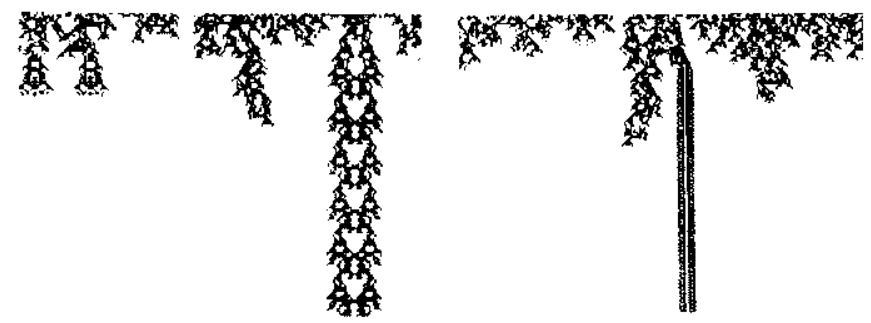

(b)

Figura 3.4: ACs da classe 4, aparecem estruturas complicadas, as vezes localizadas e outras transladando-se pelo espaço celular. Tem-se conjeturado que os ACs desta classe são capazes de processar informação ao estilo das máquinas de Turing. (a) ACs com estruturas crescentes que evoluem a estados "nulos". (b) ACs com cstruturas persistentes (Wolfram, 1984). 


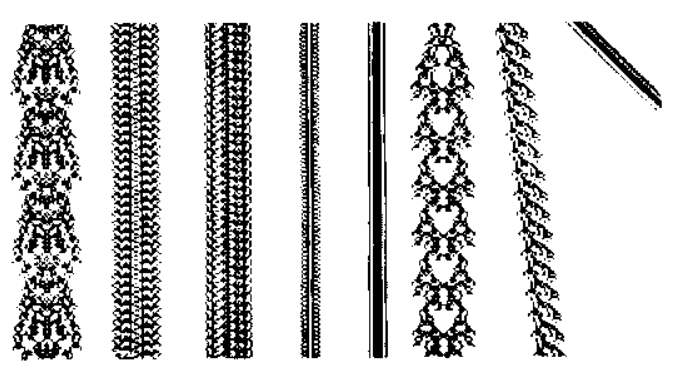

Figura 3.5: Estruturas persistentes encontradas nas evoluções dos ACs da classe 4 descle estados iniciais diferentes de zero (Wolfram, 1984).

Para as classes 1, 2 e 3, as flutuações em medidas estatísticas são progressivamente menores quando aumenta o número de células a ser consideradas. Então, tais sistemas apresentam propriedades definidas no limite do "volume infinito". Para os ACs da classe 4, vê-se que as flutuações não decrescem quando são considerados grandes números de células, e não existe um limite no volume intinito.

\subsection{Caracterização quantitativa de AC}

Esta seção descreverá as medidas estatísticas quantitativas de ordem e do caos nos padrões gerados por ACs. Estas medidas podem ser usadas para distinguir entre as 4 diferentes classes dos ACs.

Considere primeiro as propriedades estatísticas das configurações geradas em um ciclo em particular durante a evolução de um $\mathrm{AC}$, a partir de um estado inicial uniformemente aleatório. A evolução irreversível de um AC gera desvios da alcatoriedade cstatística. Em uma sequiência aleatória, todas as $k^{X}$ possíveis subseqüências ("blocos") de comprimento $X$ podem acontecer com igual probabilidade. Desvios da alcatoriedade implicam probabilidades diferentes para subseqüências diferentes. Com uma probabilidade $p_{i}^{(r)}$ para $h^{X}$ possíveis sequiências dos estados das células em um bloco de comprimento $X$, pode-se definir uma "entropia espacial do sistema" específica (Wolfram, 1984)

$$
s^{(x)}(X)=\frac{1}{X} \log _{k}\left(\sum_{j=1}^{k^{x}} \Theta\left(p_{j}^{(. .)}\right)\right) .
$$

onde $\Theta(p)=1$ para $p>0 \mathrm{c} \Theta(0)=0$, c uma "entropia de medida espacial" específica

$$
s_{\mu}^{(x)}(X)=-\frac{1}{X} \sum_{j=1}^{k x} p_{j}^{(x)} \log _{k} p_{j}^{(x)}
$$


Em ambos casos, o sobrescrito $x \in X$ indica uma sequência espacial (obtida em umal iteração em particular). A "entropia do sistema" Equação 7 é determinada diretamente pelo número total $N^{(x)}(X)$ de comprimento $X$ blocos gerados com probabilidade diferente de zero na evolução de um AC, de acordo com (Wolfram, 1984)

$$
s^{(x)}(X)=\frac{1}{X} \log _{k} N^{(x)}(X)
$$

Na "entropia de medida" Equação 8, cada bloco é pesado com sua probabilidade. tal que o resultado depende explicitamente na medida de probabilidades para diferentes configurações de AC's, como é indicado pelo subscrito $\mu$. A entropia espacial do sistema é chamada de "entropia topológica"; a entropia de medida é também referida como "entropia métrica" (Wolfram. 1984).

Pode-se ver que através das definições das Equações 7 e 8 que

$$
s_{1 /}^{(x)}(X) \leq s^{(x)}(X) \leq 1
$$

A entropia espacial do sistema chega a seu valor máximo $\left(s^{(r)}(X)=1\right)$ somente para sistemas "equidistribuídos", onde todas as probabilidades $p_{i}^{(r)}$ são diferentes de zero e iguais. A entropia de medida espacial chega a seu valor máximo $\left(s_{i}^{(x)}(X) \cdots 1\right)$ se todas as configuraçóes de comprimento $X$ dos estados das células aparecem, i.e., $p_{i}^{(r)} \neq 0$, para todos $;=1,2, \ldots, X^{-k}$. provavelmente com probabilidades diferentes.

Pode ser verificada também, que as equações 10,7 e 8 implicam que

$$
0<s_{n}^{(n)}(X) \leq s^{(x)}(X)
$$

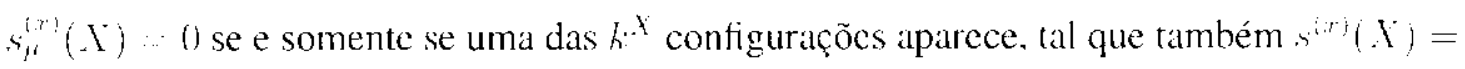
0.

Através das definições das entropias, podemos ver que $s_{(x)}(X)=0$ e $s_{\| \prime}^{(x)}(X)-0$ para ACs da Classe 1, pois somente uma combinação dos estados celulares aparecem no padrão gerado; para ACs da Classe 2. $s^{(x)}(X)$ e $s_{k \prime}^{(x)}(X)$ resultam valores pequenos. pois poucas combinação dos estados celulares aparecem. Para ACs da Classe $3, s^{(x)}(X)$ e $s^{(r)}(X)$ resultam valores relativamente grandes devido à aperiodicidades dos padrões gerados. Entropias $s^{(x)}(X)$ e $s_{\|}(X)$ dos AC's da Classe 4 variam entre os valores das entropias da Classe 1 e classe 3. variam muito dependendo da estrutura de persistência formada.

Considere um conjunto de números no intervalo $[0,1]$. Divida esse intervalo em $t^{h}$ subintervalos de largura $k^{-b}$ e $N(b)$ seja número de subintervalos que contém elementos do conjunto. Para um $b$ grande (subintervalo com largura pequena), este número cresce como $k^{\text {th }}$. O expoente 
d é a dimensão de Kolmogorov do conjunto (Gallager, 1968). Se o conjunto contém todos os números reais dentro do intervalo $[0,1]$, então $N(b)=k^{b}$, e $d=1$. Se o conjunto somente contém um número finito de pontos, então $N(b)$ deve tender a ser constante para um $b$ grande. gerando $d=0$. Por exemplo, o conjunto clássico de Cantor consiste de números reais dentro do intervalo '0.1; , cuja decomposição ternária contém somente os dígitos 0 e 2. Dividindo-o en $3^{\prime \prime}$ subintervalos iguais, fica claro que $2^{b}$ desses subintervalos contém pontos no conjunto. A dimensão do conjunto é $\log _{3} 2$.

A "dimensão do conjunto" $d$ pode ser definida de acordo com

$$
d=\lim _{b \rightarrow \infty} \frac{1}{b} \log _{k} N(b)
$$

onde $N(b)$ é o número de subintervalos que contém elementos do conjunto. Todos os subintervalos săo de igual tamanho, e o número total é de $k^{b}$.

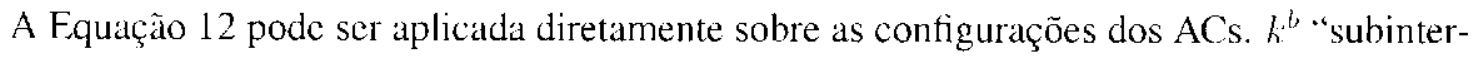
valos" são tomados, consistem das configurações de um AC onde um bloco de $b$ células têm uma seqüência particular de estados. A Equação 9 de entropia do sistema mostra que a dimensão do conjunto está dada por

$$
d^{(r)}=\lim _{x \rightarrow+\infty} s^{(x)}(X)
$$

Uma configuração homogênea, como ACs da Classe 1, dá $d^{(x)}=0$. Similarmente, ACs da Classe 2 apresentam valores de dimensão de conjunto muito baixos. Por outro lado, uma configuração desordenada (ACs da Classe 3), onde aparecem muitas das possíveis combinações dos estados das células con uma probabilidade diferente de zero (ou um conjunto de tais configurações), dá $d^{(x)} \approx 1$. Os valores $d^{(x)}$ para ACs da Classe 4 são maiores que da Classe $2 \mathrm{e}$ menores que da Classe 3, e variam muito, dependendo da estrutura de persistência formada.

Em geral, tanto as entropias, como a dimensão de conjunto, são convenientemente usadas para caracterizar a complexidade dos padrões formados por ACs. Padrões simples (homogêneos) levam a valores de entropias e dimensões pequenos; por outro lado, padrões complexos (irregulares) levam a grandes valores das mesmas.

\subsection{Comportamento dinâmico dos ACs}

Apesar da aparente simplicidade na definição, baseada em regras locais, os ACs podem apresentar um comportamento dinâmico complexo, inclusive no caso dos ACs unidimensionais. 
O estudo da dinâmica dos ACs tem desempenhado uma importante funçäo no desenvolvimento de conceitos e conjeturas no campo de sistemas complexos, particularmente daqueles concernentes com a noção de "margem de caos" (Langton, 1990) e "auto-organização critica" (Bak et al., 1988).

Através do estudo das seções anteriores, observamos que, definindo parâmetros em alguns intervalos de valores, o AC mostra comportamentos ordenados (as classes 1 e 2 de Wolfram). $\mathrm{c}$ do caos (classe 3 ). $\Lambda$ transição entre ordem e caos, correspondente à classe 4 , é chamado de "margem de chaos"(Langton. 1990).

A auto-organização crítica é uma teoria da evolução dos sistemas dinâmicos. que enfatiza a função dos estados críticos, onde a catástrofe ocorre. Estes fenômenos são encontrados na natureza e são caracterizados pela presença de perturbações. Esta teoria aponta a uma grande generalidade e tem gerado um animado debate sobre pesquisas tcóricas de sistemas complexos. Podemos citar como um excmplo, o célebre problema do montículo de areia, o qual foi modelado por Bak e seus colaboladores através de uma simples regra de AC (Bak et al., 1988).

\subsection{Capacidades computacionais dos ACs}

Um AC pode ser considerado como um modelo abstrato de computação, que transforma uma dada configuração finita, representando os dados de entrada, em uma configuração de saída.

As capacidades computacionais dos ACs foram largamente estudadas. Demonstraram que existem ACs que têm as mesmas capacidades das máquinas de Turing. isto é. podem ser usadas como computadores de propósito geral (Bandini et al., 2001).

Especificamente, mostra-se que o conjunto de estruturas persistentes, geradas por qualquer AC da classe 2, corresponde a um conjunto de palavras geradas por uma gramática regular. I Ima gramática regular especifica uma linguagem regular, cujas palavras que pertencem à gramática serão reconhecidas por um autômato finito, representado por um grafo de estados finitos de transição (Wolfram, 1984).

Um AC pode ser visto como um computador, onde o dado representado como configuração inicial é processado por evoluçôes no tempo. A universalidade computacional implica que configurações iniciais adequadas podem especificar algoritmos de procedimentos arbitrários. O sistema pode servir como um computador de propósito geral. capaz de avaliar uma função (computável). Dada uma codificação adequada. o sistema cntão pode $\mathrm{cm}$ principio simular qualquer sistema, c nesse sentido é capaz de simular comportamentos complexos (Wolfram. 1984). 
Se consideramos uma vizinhança de Moore, só são necessários 2 estados para obter a universalidade. Isto foi mostrado por Conway (Berlekamp et al., 1985). O autômato universal do Conway foi apresentado como um jogo de computador, conhecido como "o jogo da vida". A universabilidade também é obtida nos autômatos unidimensionais, como foi demonstrado por Smith (Smith, 1971).

\subsection{Construção de fractais utilizando $\mathrm{AC}$}

A filosotia desta aproximação é a mesma de sempre: regras simples locais para gerar comportamentos complicados globais.

\section{Exemplo 1}

Consideremos as seguintes regras (vizinhança de Moore):

- Lma célulia, nasce e permanece viva se, exatamente, uma das três células de la fila anterior está vivá. Em outro caso morre.

- Se a célula encontra-se na borda inferior do espaço celular, permanece viva indefinidamente.

Assim, do seguinte estado inicial (Figura 3.6):

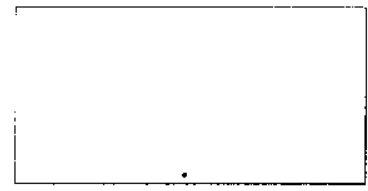

Figura 3.6: Estado inicial
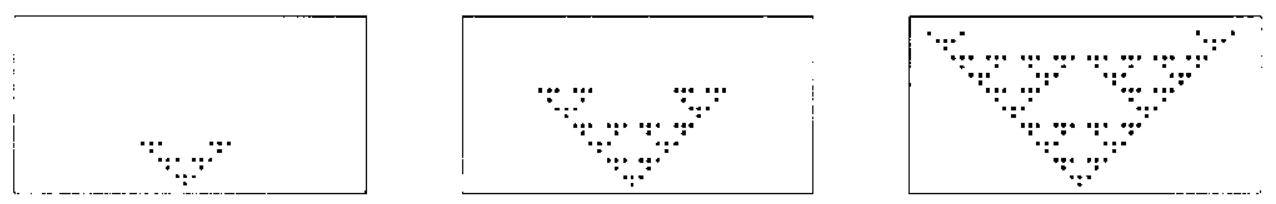

Figura 3.7: Depois de várias iterações a célula vai evoluindo. formando o fractal especificado nas regras do exemplo 1 .

Depois de várias iteraçōes e com um espaço celular maior temos: 


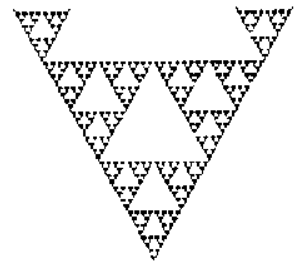

Figura 3.8: Fractal gerado a partir das regras do exemplo 1.

\section{Exemplo 2}

Consideremos agora a vizinhança de von Neumann e com as regras a screm especificadas, a continuação:

- Uma célula permanece viva indefinidamente.

- Se uma célula morta tem a seu redor exatamente uma célula viva a célula volta à vida.

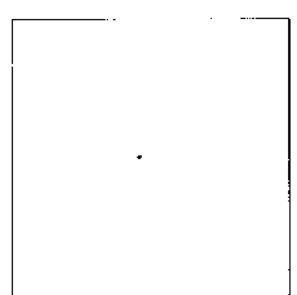

Estado inicial

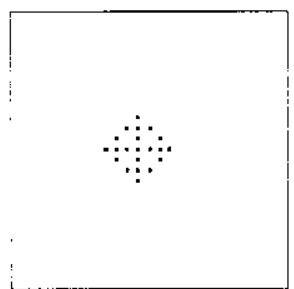

Quarta iteração e consolidação

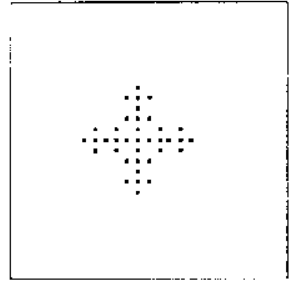

Sexta iteração, nova expansão

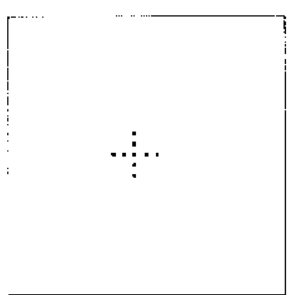

Terceira iteraçũ̂to e fim da expansão

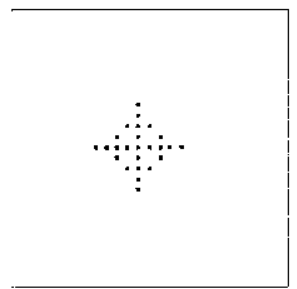

Quinta iteração

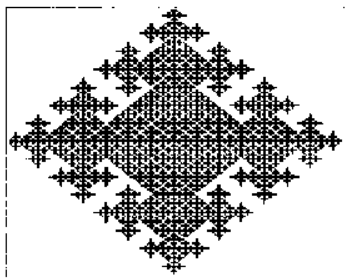

Fractal formado pelas regras

Figura 3.9: Fractal formado pelas regras descritas no Excmplo 2. 
É interessante ver, que neste caso, diferentemente do anterior, o processo de formação não vai criando estruturas semelhantes entre si, porém consiste em um processo de cxpansão-consolidação:

- Na primcira instância o sistema expande-se em todas as direções possíveis, até que as ramas ticam próximas uma das outras.

- Posteriormente as ramas que se aproximam entre si vão formando estruturas com forma de losangos muito compactos. Tal losango começa se expandir pelos quatro vértices e voltamos à fase anterior, ver Figura 3.9.

\subsection{Aplicações dos ACs}

$O$ conccito de $\Lambda C$ data desde o final dos anos 40. Os modelos e aplicações de $A C$ s foram criados, desenvolvidos e usados em diferentes áreas.

Em geral, é possível distinguir duas abordagens na criação de modelos de ACs: forward c backward (Wolfram, 1986). A abordagem forward (teórico) preocupa-se com regras de transição de um dado espaço celular de tal forma que possa estabelecer as propriedades intrínsecas. lais como comportamento dinâmico, formação de padrão, entre outras. A abordagem backward (prática) tenta encontrar uma regra de transição que permite simular adequadamente um dado comportamento desejado de um sistema natural ou artificial (físico, biológico, social, urbano, etc).

Muitas das aplicações atuais derivam dos resultados teóricos. Em muitos casos, um conjunto de regras tem um comportamento vitorioso compatível com o comportamento de um sistema dado, e o comportamento teórico dessas regras deve ser investigado. Vendo o universo das aplicações dos AC.s, isso é possível.

Os ACs podem ser considerados como computadores de processamento massivamente paralclos. Tal que, foram utilizados por exemplo em multiplicadores altamente paralelos (Cole, 1969). Particularmente, os ACs bi-dimensionais foram utilizados para processamento de imagens (Sternberg, 1980), (Viher et al., 1998). Alguns ACs podem ser como computadores de propósito geral, e portanto ser usados como paradigmas gerais para cálculo paralelo (Wolfram, 1983). A localidade e simplicidade permitem uma simulação a um nível molecular (Wolfram, 1983). Além disso, os ACs também são usados em simulação de tráfego (Brockfeld et al., 2001), modelamento dinâmico de vegetação (Aassine c Jai, 2002), modelamento de redes de computadores (Zhiliang et al., 2002) e dinâmica de infecção do vírus HIV (dos Santos e Coutinho, 2001). 


\subsection{Extração de bordas de imagens utilizando AC}

Nesta seção, construímos un AC bi-dimensional para extratir as bordas de imagens binárias e de níveis de cinza. As regras deste modelo são similares às do "jogo da vida".

Regra de transição:

Se tem entre 5 a 7 vizinhos vivos a célula continua vivat senão

se tem menos de 5 vizinhos vivos se tem um só vizinho vivo a célula morre senão a célula mantém seu estado anterior senão a célula morre.

A Figura 3.10 mostra alguns resultados de simulação usando este modelo. Fste método apresenta vantagens de eficiência computacional, simplicidade de construção de modelo e qualidade satisfatória na extração de bordas.
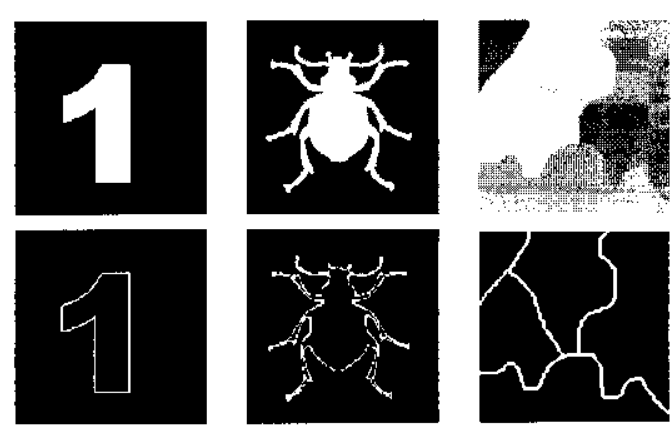

Figura 3.10: Extração de bordas de imagens binárias e em nívcis de cinza.

\subsection{Considerações finais}

Neste capítulo foram vistos conceitos fundamentais de AC. A principal idéia de AC é a geração de padrões complexos a partir de interações locais $\mathrm{cm}$ uma grade com grande quantidade de elementos. Apesar de ter uma estrutura simples. ACs são capazes de demonstrar comportamentos complexos. Baseado no caráter evolutivo e na auto-organização dos ACs, interações locais das células gerando um efeito global, será apresentado no capítulo 5 um sistema celular evolutivo para extração de características invariantes. 


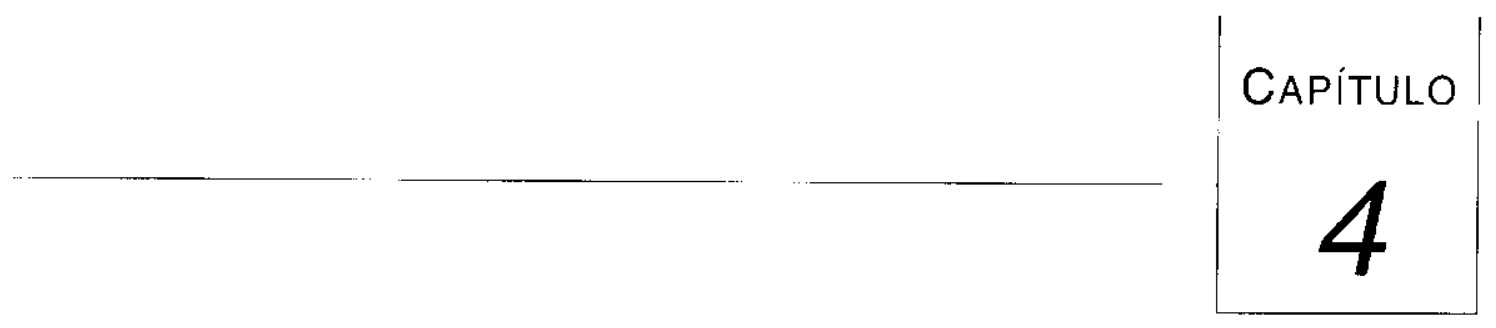

\section{Adaptive Resonance Theory (ART)}

\subsection{Considerações iniciais}

Neste capítulo, apresenta-se o mecanismo de funcionamento da rede neural ART (Adaptive Resonance Theory - Teoria da Ressonância Adaptativa). Especificamente, revisa-se o modelo básico ART1 e o modelo fuzzy ART. O último será usado como classificador de características invariantes neste trabalho.

\subsection{Introdução}

O trabalho, que é considerado como o primeiro na área de Redes Neurais Artificiais (RNAs), foi o apresentado em 1943 por Mc Culloch e Pitts (Haykin, 1999), por serem eles os primeiros em modelar um neurônio computacional, o qual é uma versâo bastante simplificada do neurônio real do cérebro. As tentativas de desenvolvimento de modelos computacionais que possuem algumas características do cérebro continuaram até finais dos anos 50, surgindo uma nova idéia que causou uma grandc expectativa, o conceito nasceu sob o nome de perceptron (Haykin, 1999) e seu criador foi Frank Rosenblatt.

A partir da década 80, as RNAs têm-se convertido em uma das áreas de maior interesse para muitos pesquisadores de diversas disciplinas, tais como matemática, ciência da computação, 
biologia e física, entre outras. Uma RNA é um modelo computacional inspirado em sistemas biológicos, composto por várias unidades de processamento, os quais têm um funcionamento simples e similar entre si. Essas unidades. geralmente são conectadas por canais de comunicação que estão associados a um determinado peso. As unidades fazem operaçôes apenas sobre seus dados locais e todas elas trabalham juntas, gerando comportamentos inteligentes. os quais trazem potenciais soluções a muitos problemas

Uma das características mais importantes das RNAs é a habilidade para aprender de seu ambiente, usando somente dados experimentais, e com isso gerar propriedades matemáticas sobre os dados de entrada. Isso, na maioria dos casos, é feito através de um processo itcrativo de ajustes aplicado aos seus pesos de conexões entre os neurônios, que é chamado de algoritmo de aprendizado. Existem pelo menos três paradigmas de aprendizado:

- Aprendizado Supervisionado - quando é utilizado um agente externo que indica à rede a resposta desejada para o padrão de entrada. O objetivo é ajustar os parâmetros da rede. de forma a encontrar uma ligação entre os pares de entrada e saída fornecidos (de Pádua Braga et al., 1988). Os exemplos mais conhecidos são o algoritmo backpropagation (Rumelhart et al., 1986) e Radial Basis Function (RBF) (Walczak e Massart. 2000), entre outras.

- Aprendizado Não Supervisionado - quando não existe um agente externo indicando a resposta desejada para os padrões de entrada. As redes com este tipo de aprendizado têm a habilidade de formar representações internas para codificar características da entrada e criar novas classes. Este tipo de aprendizado somente é possível quando existe redundância nos dados de entrada. O mapa de Kohonen (Kohonen, 1989) e as redes ART (G. Carpenter, 1987) usam este tipo de aprendizado;

- Aprendizado por Reforço - pode ser visto como um caso particular de aprendizado supervisionado. A única informação de realimentação fornecida à rede é se uma determinada saída esta correta ou não, isto é, não é fornecido à rede a resposta correta para o padrão de entrada. Se uma ação tomada pelo sistema for correta. esta é reforçada; se não for correta, é enfraquecida. Representantes para este tipo de aprendizado são so Mćtodos de Diferença-Temporal (de Pádua Braga et al.. 1988).

\subsection{Familia ART}

As redes ART's foram desenvolvidas por Carpenter e Grossberg (G. Carpenter, 1987), fuzzy ART (G. Carpenter, 1991b), ARTMAP (G. Carpenter. 1991a), fuzzy ARTMAP (G. Carpenter. 1992). 
cntre outras. As redes ARTs são apropriadas para reconhecimento e classificação de padrões, permitindo ao usuário controlar o grau de similaridade entre os padrões que são classificados dentro de um mesmo grupo. As redes ART apresentadas nesta seção, usam o paradigma de aprendizado não supervisionado. Cada vez que um padrão é apresentado, um neurônio que representa uma classe é escolhido e os pesos associados são atualizados para capturar as características dos padrões da mesma classe. Neste sentido, os pesos associados a cada neurônio classificador podem ser considerados como um exemplar ou um filtro para os padrões colocados nessa classe.

Uma das características mais marcantes da ART é que ela consegue escapar do dilema de estabilidade-plasticidade (J.Hertz, et al.. 1991), ou seja, a ART sempre está pronta para reconhecer novos padrões de entrada e não esquece as categorias dos padrões previamente memorizadas, evitando retreinamento para o mesmo problema. Outra característica interessante da ART é a sua alta eficiência de aprendizado (dentro de 10 ciclos em geral) (G. Carpenter, 1987), junto com a característica supracitada, permitindo um treinamento em tempo real (online).

\subsubsection{ART1}

A rede ART1 foi criada por Carpenter e Grossberg (G. Carpenter, 1987); c foi desenvolvida para agrupar padrões binários, permilindo uma grande variação no número de componentes difcrentes de zero. Ela possui um mecanismo de controle do grau de similaridade que é função do parâmetro de vigilância $\rho$. cujo valor pode ser especificado pelo usuário. Ela é um modelo de arquitetura de rede neural onde os algoritmos são implementados em termos de aproximações de equações diferenciais visando uma analogia ao modelo dos neurônios biológicos (de Pádua Braga et al., 1988). Quando um novo padrão de entrada não se enquadra em qualquer grupo já existente, o modelo provoca a formação de um novo grupo, conforme na Figura 4.1.

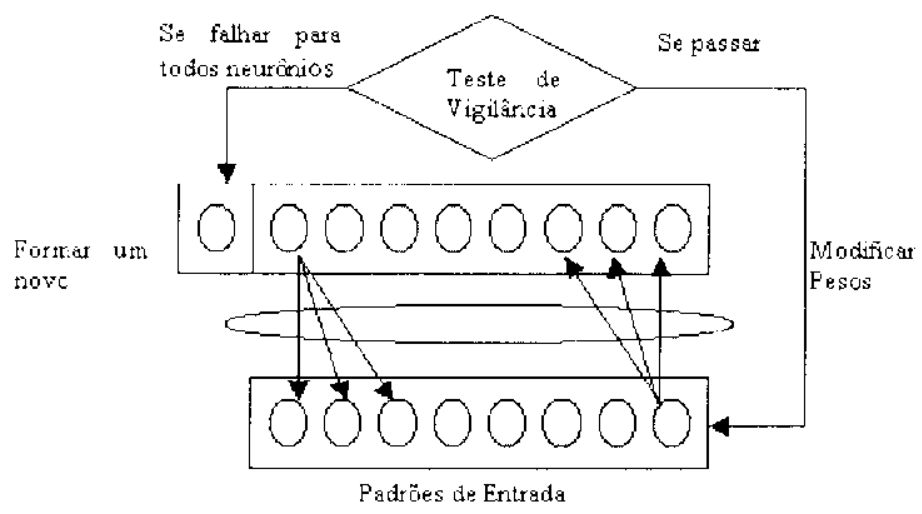

Figura 4.1: Arquitetura simplificada da ART1 . 
A arquitetura básica da ART1 envolve duas camadas de nós. Uma camada de entrada $F_{1}$, que processa os dados de entrada e uma camada de saída $F_{2}$, que agrupa os padrões de treinamento em clusters. Ambas camadas estão conectadas por dois conjuntos de pesos. O primeiro conjunto, representado por conexões bottom-up, b, assume valores reais e vai da camada de entrada para a camada de saída. O segundo conjunto, que contém as conexões top-down. t. assume valores binários e conecta os nós da camada de saída aos nós de entrada. As conexōes descritas acima também são conhecidas como filtros adaptativos por adaptarem dinamicamente seus valores para possibilitar o aprendizado de novos padrões. Para cada camada da rede ART 1 há uma unidade externa de controle. A unidade $C 1$, para a camada de entrada, determina o fluxo de dados nela. Essa unidade assume o valor 1 se uma entrada válida for apresentada à rede, e o valor 0 se algum nó da camada de saída for ativo. A unidade $C 2$, para a camada de saída, tem duas funções (ver Fị̆ura 4.2): determinar o fluxo de dados para a camada de saída. e habilitar ou desabilitar nós da camada de saída. Entre ambas as camadas existe um mecanismo de reset, responsável por verificar a semelhança entre um vetor de entrada e um dado vetor protótipo. Utilizando um limiar de vigilância $\rho$, esse mecanismo de reset determina se um padrão de entrada pode ser incluído nos clusters existentes (ver Figura 4.2).

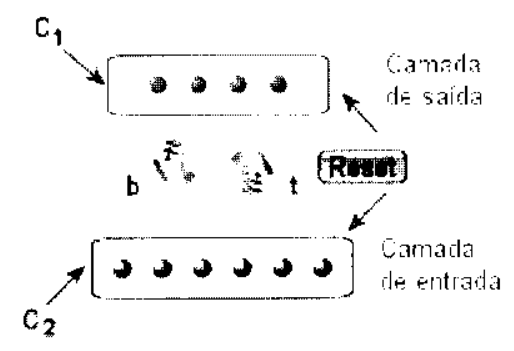

Figura 4.2: Uma outra visão da arquitetura ART1.

Os valores iniciais do vetor de pesos bottom-up (b) são determinados pela Equação 1:

$$
b_{i j}(0)=\frac{1}{1+n} \cdot \forall i . j
$$

onde $n$ é o número de nós de entrada da rede. O limiar de vigilância $(\rho)$ é também inicializado, assumindo um valor dentro do intervalo ()$<\rho<1$. Cada nó da camada de entrada recebe três sinais: um sinal do vetor de entrada, um sinal de feedback da camada de saída e um sinal da unidade de controle $(1$. Um nó da camada de entrada somente scrá ativado se receber pelo menos dois sinais excitatórios, denominada como regra dos dois-terços (2/3). Na lase de reconhecimento, o vetor resultante é comparado com todos os vetores de pesos bottom-rip. b. para encontrar o mais semelhante. Esta comparação é feita calculando o produto interno entre o vetor I resultante c o vetor de pesos bottom-up para cada nó da camada de saída, como se indica na Equação 2. 


$$
y_{j}=\sum_{i} b_{i, j} I_{l}
$$

onde $y_{j}$ é ativação do nó de saída, $j$. definido pelo produto interno entre seu vetor de pesos bottom-up $b_{j}$ e seu vetor de entrada I. O nó da camada de saída com maior valor de ativação é sclecionado como o vencedor e possivel cluster $J$ para armazenar o novo padrão, inibindo os outros neurônios. Quando a regra dos 2/3 é aplicada resulta na ativação ou não de cada nó da camada de entrada. Quando o sinal da unidade de controle $C 1$ é igual a 0 , ocorrc uma operação $\Lambda$ ND entre o vetor protótipo do nó selecionado e o vetor de entrada, produzindo um novo vetor, chamado vetor de comparação. O mecanismo de reset é responsável por testar a similaridade entre o vetor de entrada c o vetor de comparação, cálculo feito na Equação 3

$$
P=\frac{\left|\sum I_{,} b_{i, J}\right|}{\left|\sum I_{i}\right|}
$$

onde |.| é a norma do vetor. Se $P \geq \rho$ incluir o padrão de entrada no cluster e atualizar pesos; caso contrário, inibir o neurônio ganhador e escolher outro ncurônio.

No funcionamento de uma ART 1 há um casamento dos padrões da entrada nos protótipos de padrões já aprendidos pelo sistema. Este casamento, ou leva a um estado de ressonância, o qual procuraremos explicar, e dispara o aprendizado de um outro protótipo de padrão; ou leva a uma busca paralela na memória. Tal busca finaliza quando uma categoria estável é selecionadá e o protótipo pode ser refinado para incorporar novas informações advindas do padrão de entrada. Neste caso, dizemos que atingimos um estado de ressonância. que persiste durante o aprendizado e adaptação à ocorrência. Mas tal busca também pode atingir um nó não treinado, entäo iniciaremos o aprendizado de uma nova calegoria. A maneira pela qual definimos como o casamento irá ocorrer é determinada por um parâmetro chamado vigilância. A vigilância tem maior peso à medida que uma entrada se aproxima de um protótipo para que a ressonância ocorra. O parâmetro de vigilância pode variar de acordo com tentativas de aprendizado na rede ART, o que define vários níveis de generalização. Baixa vigilância permite maior generalização e protótipos mais abstratos que alta vigilância. Com altíssimos níveis de vigilância, aprendizado de protótipos se reduzem ao aprendizado do exemplo dado.

O algoritmo da ARTl é como segue:

\section{Passo 1: Inicialização}

1. Inicialize $N$ com o número total de neurônios na camada de saída;

2. Inicialize o parâmetro de vigilância $\rho$, tal que $(0<\rho \leq 1$;

3. O vetor de pesos top-down, t, é inicializado em 1 ; 
4. Os valores iniciais do vetor de pesos bottom-up são:

$$
b_{i, j}(0)=\frac{1}{1+n}, \forall i, j .
$$

\section{Passo 2: Reconhecimento}

1. Para cada neurônio da camada de saída calcular a entrada de cada neurônio de $F_{2}$

$$
y_{j}=\sum_{i} b_{i, j} I_{i}
$$

2. Um neurônio ganhador I da camada $F_{2}$ é selecionado para representar uma cluster cujo valor da função de seleçăo $y, j$ é maior do que todos os outros neurônios da camada $F$. onde

$$
y=\max \left\{y_{j}: j=1, \ldots n\right\}
$$

Se mais de um $y_{J}$ é máximo. o sistema tem que escolher o cluster com o menor indice $J$.

\section{Passo 3: Comparação}

1. Ocorre uma operação AND entre o vetor protótipo selccionado $b_{i . J}$ e o vetor de entrada I:

$$
P=\frac{\sum I_{i} b_{i},}{\sum I_{i}}
$$

\section{Passo 4: Ressonância ou reset}

1. A ressonância ocorre se a função de seleção do neurônio ganhador da camada $F_{2}$ atinge o critério de vigilância; isto pode ser obscrvado na Equaçâo 7

$$
\frac{\sum I_{i} b_{i, l}}{\sum I_{i}} \geq \rho
$$

Uma vez isso é satisfeito, o processo de aprendizado é efetuado segundo as Equaçöes 8 e

9 (Prado et al., 2000)

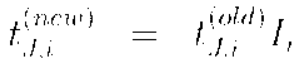

$$
\begin{aligned}
& b_{i, I}^{(\text {nowi })}=\frac{t_{J i}^{(\text {std })} I_{i}}{\frac{1}{2}+\sum_{i=0}^{N-1} t_{J, i}^{(\text {old }} I_{i}}
\end{aligned}
$$


2. O neurônio ganhador é rejcitado se a seguinte condição é satisfeita

$$
\frac{\sum I_{i} b_{i . J}}{\sum I_{i}}<\rho
$$

Logo, o valor da função de seleção é colocado em -1 durante a apresentação desse mesmo padrão de entrada a fim de prevenir que o mesmo neurônio seja selecionado novamente. Neste caso, o processo de seleção é ativado c um novo neurônio ganhador é selecionado pela Equação 6. Este processo continua até que um novo neurônio ganhador selecionado satisfaça a Equação 7.

\subsubsection{Fuzzy ART}

A fuzzy ART foi criada por Carpenter e Grossberg (G. Carpenter, 1991a) em 1991. Esta rede incorpora as características básicas de todos os sistemas ART1, casamento de padrões entre a entrada bottom-up e o vetor protótipo top-down aprendido. Este processo de casamento conduz tanto a um estado de ressonância que focaliza a atenção no processo de aprendizado, e coloca em funcionamento ao protótipo estável aprendido; quanto a uma busca na memória paralela auto-regulada. Se a busca termina na seleção de uma categoria (cluster) estabelecida, então o protótipo da categoria selecionada será refinado incorporando nova informação ao padrão de entrada. Se a busca termina na seleção de um nó prévio não rotulado, uma nova classe é criada.

A fuzzy $\Lambda \mathrm{RT}$ possui a uma estrutura e mecanismo de funcionamento muito semelhante a ART1 e incorpora operações da teoria de conjuntos fuzzy, permitindo a classificação de padrões com valores contínuos. A Tabela 4.1 apresenta um resumo das operadores da ART1 e sua correspondência na fizzy ART.

Na Figura 4.3 é apresentada a arquitetura básica da fuzzy ART. Cada padrão de entrada I é um vetor m-dimensional $\left(I_{1}, I_{2}, I_{3}, \ldots, I_{m}\right)$. A cada cluster the corresponde um vetor $W_{j}:=\left(W_{j, 1}, W_{j, 2}, W_{j, 3, \ldots}, W_{j, n}\right)$ de pesos adaptativos. O número de possíveis clusters $n$ $(j=1,2, \ldots, n)$ é arbitrário. O vetor de pesos da fuzzy ART é o equivalente, em um único vetor, aos vetores de pesos top-down e bottom-up da ART1 (G. Carpenter, 1991 a).

O algoritmo Fuzzy ART (Kim et al., 2001) é como segue:

\section{Passo 1: Inicialização}

1. Inicialmente, todos os neurônios da segunda camada não estão rotulados (uncommitted). e cada vetor de pesos $W_{j}$ é inicializado como segue:

$$
W_{j, 1}(0)-W_{j .2}(0)-\ldots=W_{j, m}^{r}(0)=1
$$




\begin{tabular}{|c|c|c|}
\hline & ART I & Fuz:y ART \\
\hline Seleção da Categoria & $T_{i}-\frac{\mid I \cap W_{i}}{a+\left|W_{i}\right|}$ & $T_{3}=\frac{\mid I \wedge W_{i} !}{a+\left|W_{i}\right|}$ \\
\hline Critério de Semclhança & $\frac{\left|l \cap W_{i}\right|}{\mid I !} \geq \rho$ & $\frac{I \wedge W_{i} \mid}{|I|}>\rho$ \\
\hline Aprendizado Rápido & $W_{j}\left({ }^{n e w}\right)=I \cap W_{i}\left({ }^{n c w}\right)$ & $W_{j}\left({ }^{n e w}\right)=I \wedge W_{i}\left({ }^{n e m}\right)$ \\
\hline & $\cap=$ AND lógico & $\wedge: f u z z y$ AND \\
\hline
\end{tabular}

Tabela 4.1: Analogia entre ART1 e fuzzy ART.

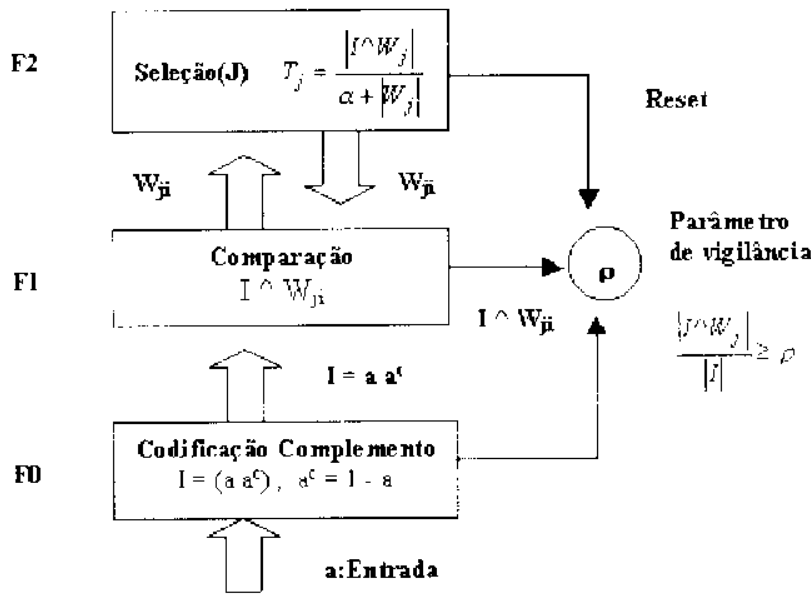

Figura 4.3: Arquitetura da fuzzy ART.

2. Logo. o parâmetro de seleção $\alpha$, a taxa de aprendizado (f, e o parâmetro de vigilância p são iniciados cm:

$$
\alpha>0, \quad 0<\beta<1, \quad 0<\rho<1
$$

\section{Passo 2: Codificação do complemento}

1. Para melhorar a confiabilidade da seleção do cluster ganhador, o vetor de entrada a é dobrado com o seu complemento como se observa na Fquação 12.

$$
I=\left(a, a^{\prime}\right) . \quad a^{r} \cdot 1 \cdots a .
$$

\section{Passo 3: Seleção do cluster}


1. Para cada vetor $I$ e um neurônio j da camada $F 2$, a função de seleção $T_{j}$ é definida por

$$
T_{j}(I) \cdots \frac{\left|I \bigwedge W_{j}\right|}{\alpha+\left|W_{j}\right|}
$$

onde, o operador $\bigwedge\left(j u z z y\right.$ AND) é definido por $(x \wedge y)_{i}=\min \left(x_{i}, y_{i}\right)$ e $|$.$| é definido$ por

$$
|x|=\sum_{i=1}^{m} x_{i}
$$

2. Um neurônio ganhador $J$ da camada $F 2$ é selecionado para representar uma cluster, cujo valor da função de seleção $T_{J}$ é maior do que todos outros neurônios da $F 2$, i.e., selecionado, onde

$$
T_{J}=\max \left\{T_{j}: j=1, \ldots, n\right\}
$$

Se mais de um $T_{J}$ é máximo. o sistema tem que escolher o cluster com o menor índice J. Os nós da camada $F 2$ (saída) são selecionados (committed) na seguinte ordem $j=$ $1,2,3, \ldots, m$.

\section{Passo 4: Ressonância ou Reset}

1. A ressonância ocorre se a função de seleção do neurônio ganhador atinge o critério de vigilância; isto pode ser observado na Equação 16

$$
\frac{I \Lambda W_{J} \mid}{|I|} \geq
$$

Uma vez isso é satisfeito, o processo de aprendizado é efetuado segundo a Equação 17

$$
W_{J}^{(\text {now })}=\beta\left(I \bigwedge W_{J}^{(\text {old })}\right)+(1-\beta) W_{j}^{(\text {old })}
$$

$\mathrm{O}$ aprendizado rápido ocorre quando 3 é igual a 1 . Neste caso, a regra de aprendizado pode ser observado na Equação 18

$$
W_{j}^{(n+w)}=I \bigwedge W_{j}^{(o h)}
$$

2. O neurônio ganhador é rejeitado se a seguinte condição é satisfeita

$$
\frac{I \bigwedge W_{J} \mid}{|I|}<\rho
$$

Logo. o valor da função de seleção é colocado em - 1 durante a apresentação desse mesmo padrâo de entrada, a fim de prevenir que o mesmo neurônio scja selecionado novamente. 
Neste caso, o processo de seleção é ativado e um novo neurônio ganhador é selccionado pela Equação 13. Este processo continua até que o ncurônio ganhador selecionado satisfaça a Equação 16.

Existem duas opções para o algoritmo de aprendizado da fuzzy ART: a opção chamada de "seleção rápida e lenta re-codificação"(fast-commit-slow-recode) e a opção de fuzzificação de entradas. Para uma codificação eficiente de conjuntos de entrada com ruído, o algoritmo frzzy $\Lambda$ RT é usado para combinar o aprendizado rápido no começo com uma baixa taxa de esquecimento. Isto é conhecido como "rápida seleção e lenta re-codificação". Com esta opção. o valor de $\beta=1$ quando $J$ (ganhador) é selecionado pela primeira vez, e $\beta<1$ no caso contrário. A fuzzificação da entrada é para prevenir a proliferação de clusters que poderia acontecer quando uma grande quantidade de entradas corrói a norma do vetor de pesos. O procedimento de normalizaçāo é chamado codificaçãa de complementos.

$\Lambda$ s propriedades de aprendizagem da fuzzy ART já foram analisadas (G. Carpenter. 1991h). $\Lambda$ maioria destas propriedades pertence à rede fuzzy ART quando o parâmetro de seleção (n) é pequeno. O parâmetro de seleção da fuzzy ART inicialmente foi definido no intervalo $(0, \infty)$ (G. Carpenter, 1991a). Muitos trabalhos foram abordados para estudar as propriedades de aprendizado em relação ao parâmetro de seleção, mudando desde um domínio de valores pequenos a um de valores grandes. Entre as pesquisas feitas tem-se o trabalho de Georgiopoulos ct. al. (Georgiopoulos et al., 1996), que demonstra a propriedade de aprendizado "Ordem de Busca (Order of Search)", a qual identifica a ordem de acordo aos neurônios ganhadores na camada de saída (Seleção).

Uma das desvantagens que as redes ARTs apresentam é a dependência da ordem em que os padrões são apresentados, podendo influir no número de clusters (Thomas et al., 1998). Um outro problema é a dificuldade que a família ART apresenta para poder generalizar e tolerância baixa ao ruído.

\subsection{Considerações finais}

Neste capítulo foram apresentados as redes neurais ART1 e fuzzy ART. As redes ARI podem ser vistas como técnicas de clusterização c classificação efetiva, embora apresentem alguns problemas, tendo como uma das vantagens desta rede a alta velocidade de treinamento, além de lidar com o dilema de elasticidade/plasticidade. Alguns resultados usando o modelo fuzz: ART para classificaçăo de padrões invariantes serão apresentados no próximo capitulo. 


$\frac{-5}{5}$

\section{Sistema Celular Evolutivo para extração de características invariantes}

\subsection{Considerações iniciais}

As técnicas tradicionais de extração de características invariantes, tais como momentos, tratam padröes como objetos estáticos. A grande maioria dessas técnicas considera somente características globais dos padrões. Neste capítulo apresentar-se-á um sistema celular evolutivo para extrair características invariantes à rotação. A idéia do modelo proposto por nós no presente trabalho é baseada no Autômato Celular (AC) e considera o processo de cxtração de características como uma evolução de sistemas dinâmicos e combina, de forma natural, as características locais e globais.

Elementos da grade correspondem a componentes de um padrão de entrada. Os elementos interagem com seus vizinhos, propagando características locais para toda as células do sistema. formando uma configuração global. Padrões de entrada similares possucm estruturas locais similares, conseqüentemente, formam configurações similares ao longo da evolução do sistema; por outro lado, para padrões de entrada bem diferentes, espera-se a formação de diferentes configurações do sistema. 


\subsection{Modelo proposto}

Como já foi dito, na construção de um $\mathrm{AC}$. de acordo com cste modelo proposto, também precisamos considerar os seguintes fatores: a dimensão do sistema. a geometria de acoplamento entre as células, a condição de fronteira, a condição inicial e a função de transição.

O modelo é bi-dimensionais e do mesmo tamanho do padrão de entrada. pois trabalha-se com padrões bi-dimensionais (imagens) e deste modo uma relação de correspondência ć estabelecida entre cada pixel da imagem e cada célula do sistema. A condição inicial de cadá célula é configurada com o correspondente valor de pixel normalizado entre 0 e 1 . A condição de frontcira é free-end, ou scja, as células que estão na fronteira são acopladas somente com as células vizinhas interiores.

Neste modelo, cada célula da grade bi-dimensional corresponde a um pixel da imagem de entrada, cujo valor inicial é acertado como o valor de nível de cinza normalizado do pixel correspondente. Cada célula é acoplada com um conjunto de células vizinhas. Ao longo da cvolução do sistema, o estado de cada célula é incrementado devido a interações celulares locais. Quando uma célula atinge seu nível máximo de ativação, o seu estado volta para o cstado inicial. Desta forma, o sistema gera configuraçôes periódicas. O somatório dos estados de todas células ao longo da evolução do sistema apresenta similaridades entre padrões de entrada semelhantes ou rotacionados. O mesmo apresenta diferença entre padrões diversos. Especificamente, o modelo pode ser representado pelas seguintes equações

$$
\begin{aligned}
& x_{i, j}[n+1]=x_{i, j}[n]+\eta \sum_{k, l} u_{i, j, k, l} y_{k, l}[n] \\
& y_{i, j}[n+1]=\left\{\begin{array}{lc}
x_{i, j}[0], & \text { se } x_{i, j}[n+1]>\theta_{i, j} \\
x_{i, j}[n+1], & \text { em outro caso }
\end{array}\right.
\end{aligned}
$$

onde $x_{i, j}[n]$ é o estado interno da célula $\left.(i, j), y_{, j} \mid n\right]$ representa uma saída da célula $(i, j)$. que é propagada para suas células vizinhas. $\theta_{\imath, j}$ representa o nível máximo de ativação da célula (i.j). $\eta$ é um parâmetro para controlar velocidade de crescimento. cujo valor é fixado em 0.05 em todas simulações nesta dissertação. $w_{i, j, k, l}$ é o peso de acoplamento entre as células $(i, j)$ e $(k, l)$. Neste modelo, cada célula é acoplada com três camadas de vizinhos mais próximas. Portanto, $i-3 \leq k \leq i+3$ e $j-3 \leq l \leq j+3$. A matriz de pesos de cada célula satisfaz uma distribuição gaussiana, especilicamente, é representada pela matriz da Figura 5.1.

Na Figura 5.2 mostra-se a evolução das atividades de três diferentes células. Como pode ser visto nesta figura, as células apresentam um comportamento periódico. Tal comportamento permite uma sincronização por scgmentos, os quais têm níveis de cinza similares entre os pixcls. Conseqüientemente, as células. que pertencem a um mesmo bloco correspondente a 


$\left(\begin{array}{ccccccc}0.0101 & 0.0363 & 0.0780 & 0.1007 & 0.0780 & 0.0363 & 0.0101 \\ 0.0363 & 0.1299 & 0.2793 & 0.3604 & 0.2793 & 0.1299 & 0.0363 \\ 0.0780 & 0.2793 & 0.6004 & 0.7748 & 0.6004 & 0.2793 & 0.0780 \\ 0.1007 & 0.3604 & 0.7748 & 1 & 0.7748 & 0.3604 & 0.1007 \\ 0.0780 & 0.2793 & 0.6004 & 0.7748 & 0.6004 & 0.2793 & 0.0780 \\ 0.0363 & 0.1299 & 0.2793 & 0.3604 & 0.2793 & 0.1299 & 0.0363 \\ 0.0101 & 0.0363 & 0.0780 & 0.1007 & 0.0780 & 0.0363 & 0.0101\end{array}\right)$

Figura 5.1: Matriz de pesos para três camadas de vizinhos com distribuição gaussiana.

um segmento da imagem, evoluem seus estados c disparam pulsos ao mesmo tempo, de forma sincronizada.

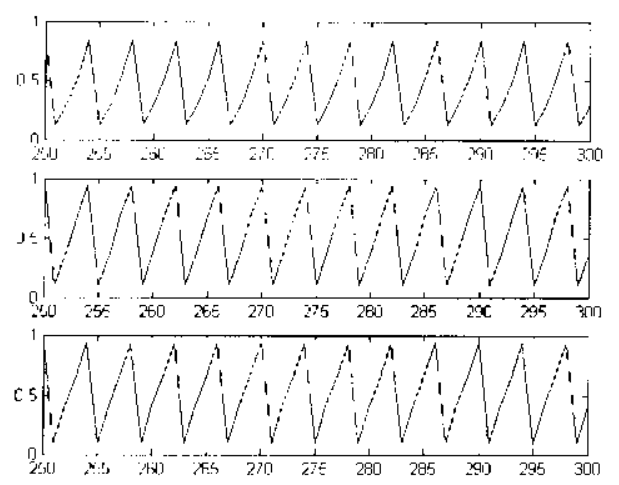

Figura 5.2: Atividade interna das células, pode-se ver que apresentam um comportamento periódico.

Os testes feitos com nosso modelo proposto visa avaliar a qualidade das características invariantes extraídas. Neste primeira ctapa, serão usadas imagens em níveis de cinza. Essas imagens sofreram variações gcométricas como podemos ver na Figura 5.3. Elas são rotacionadas em $37^{\circ} 45^{\circ} \mathrm{e} 90^{\circ}$. Este modelo é totalmente invariante a translações, não fazendo necessário o cálculo do centróide da imagem como era feito nos momentos estatísticos, nas transformadas de wavelets e nas transformadas de Fourier. Devido à forma de acoplamento das células, consegue atingir a invariância à rotação e translação.

Dois vetores são usados para armazenar as características extraídas. Um, chamado de "vetor de estados", contém o somatório dos estados de todas as células de cada iteração e o outro, chamado de "vetor de pulsos". contém o somatório dos pulsos de cada iteração (uma célula, cujo estado interno atinge sua atividade máxima, gera um pulso). Na verdade, o segundo vetor contém a quantidade de células que estão em suas atividades máximas de cada iteraçăo. $O$ número de iterações nas simulaçôes foram de 200 a fim de ver a evolução do sistema. Na Figura 5.4 podemos ver os vetores de estado e o velor de pulsos completos, isto é, com as 200 iterações. Não precisou-se de mais iterações porque o vetor de características apresenta comportamento 


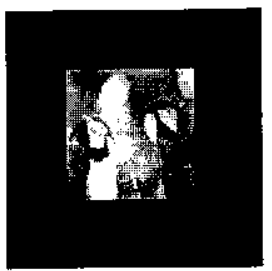

$\left(0^{\circ}\right.$

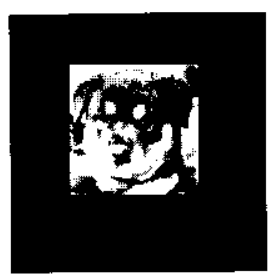

0

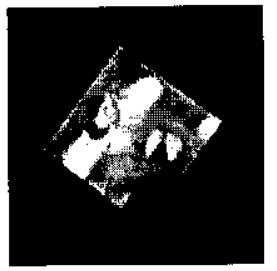

$37^{\circ}$

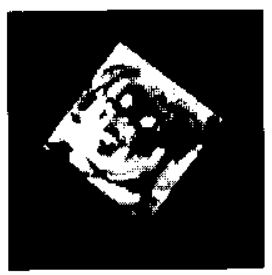

$37^{\circ}$

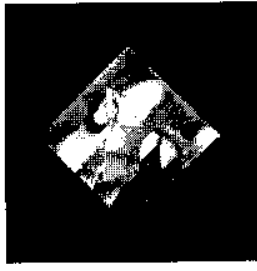

$45^{\circ}$

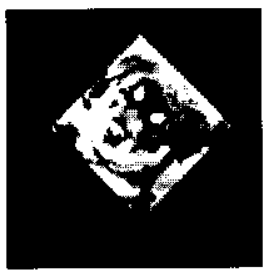

40

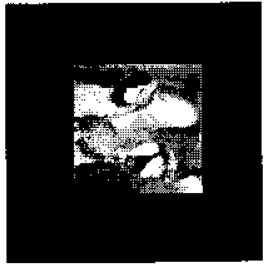

9()$^{\circ}$

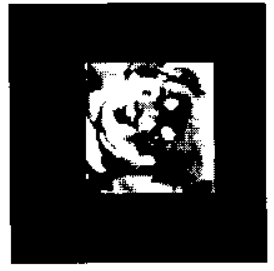

()

Figura 5.3: "Transformações geométricas das imagens "araras" c "cachorro", sendo rotacionadas em ()$^{\circ}, 37^{\circ} .45^{\circ}$ e $90^{\circ}$ respectivamente.

periódico. Isto era esperado devido a que as evoluções das atividades das células são também periódicas.
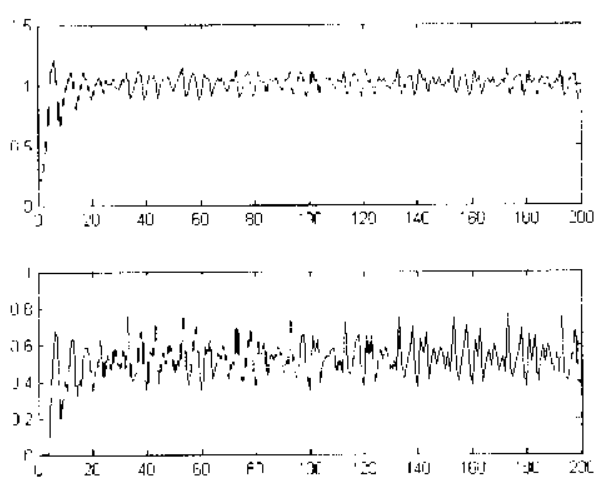

Figura 5.4: Vetores de estado e de pulsos do sistema respectivamente.

A Figura 5.5 (a) mostra 4 vetores de estados, um para cada imagem "araras" da Figura 5.3. Podemos ver que esses vetores são periódicos. O comportamento periódico permite ler uma melhor descrição, devido à sincronização entre as células do mesmo bloco. No caso de rotações de $90^{\circ}$ o vetor de estados é exalamente igual ao vetor de estados gerado para a imagem original (rotação ()$^{\circ}$ ). Esses valores são atingidos graças à forma de acoplamento. No caso de rotaçōes de $37^{\circ}$ e $45^{\circ}$, os vetores de estados aparecem com uma pequena diferença em relação ao vetor de estados da imagem original. Isso acontece devido à característica discreta das imagens digitais. Ou seja, quando uma imagem digital é rotacionada, alguns pixcls são perdidos e novos pixels são introduzidos, a fim de suavizar o desenho da imagem e de que cla continue sendo parecida à original. Mas. como as diferenças são pequenas. os vetores de estados da mesma 
imagem continuam conservando características similares, permitindo quc sejam classificados dentro do mesmo grupo. Podemos ver que se repete a mesma sequiência nos vetores, por serem periódicos, e que esta seqüência é curta, portanto o vetor de características será pequeno, não se precisará de muitos elementos, pois esses valores se repetiriam. Na parte (b) da Figura 5.5 mostra-se os vetores de cstados das imagens "cachorro", e apresenta-se as mesmas características já descritas com os vetores de cstados das imagens "araras". Podemos ver também a grande diferença entre qualquer vetor de cstados da imagem "arara" e qualquer vetor de estados da imagem "cachorro". Pode-se afirmar que o vetor de estados é satisfatório para agrupar as mesmas imagens rotacionadas e diferenciar imagens distintas.

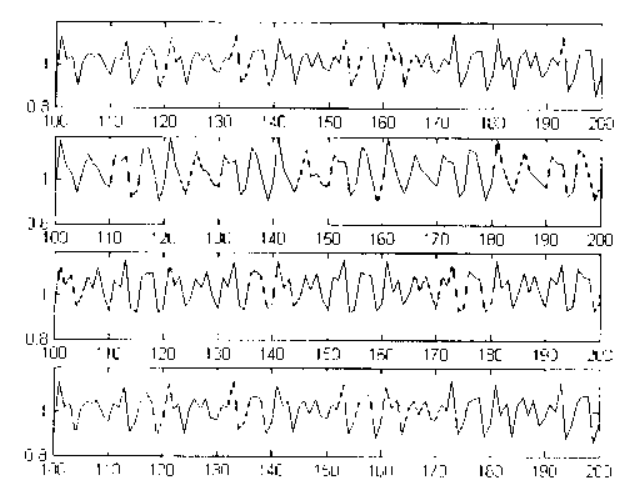

(a)

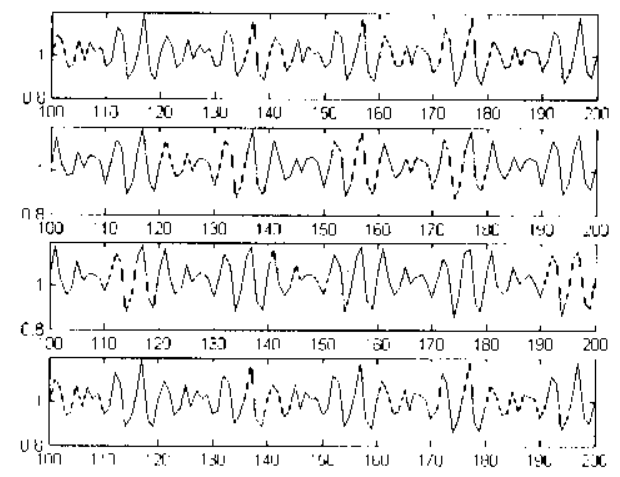

(b)

Figura 5.5: Vetores de estados para a imagem (a) "araras" e (b) "cachorro" com rotações de $0^{\circ}$, $37^{\circ}, 45^{\circ}$ e $90^{\circ}$.

Na Figura 5.6 mostrat-se os vetores de pulsos das imagens "araras" e "cachorro". Neste caso, os vetores de pulsos para as imagens "araras" são similares. O mesmo ocorre para as imagens "cachorro". Então, o vetor de pulsos também é satisfatório para reconhecimento de imagens rotacionadas.

A Figura 5.7 mostra a diferença entre o vetor de estados do padrão sem nenhuma transformação (0 graus) e os vetores do mesmo padrão com rotações de $37^{\circ}, 45^{\circ}$ e $90^{\circ}$, respectivamente. Podemos ver, na parte final deste Capítulo, que o nível de diferença apresentada é aceitável pelo classificador, i.c., esses vetores serão agrupados em uma mesma cluster.

Outra propriedade importante nos autômatos é a formação de padrão, que é o nome que damos quando um padrão é gerado através das funções de transição. Podemos ter essa formaçăo de padrão tanto por atividade das células do sistema, quanto pelos pulsos (saídas) de cada célula em cada iteração. Cada imagem diferente apresentará uma forma de padrão também diferente. Na Figura 5.8 vemos a formação de padrão da imagem "araras" em diferentes tempos de evolução $(5,8,20$ e 50$)$, na primeira linha temos a formação por estados de cada célula do sistema e na segunda linha por pulsos das mesmas (as células que atingiram a ativação 


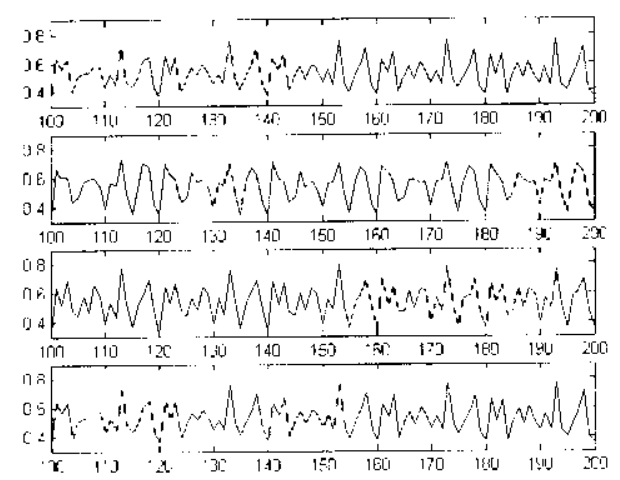

(a)

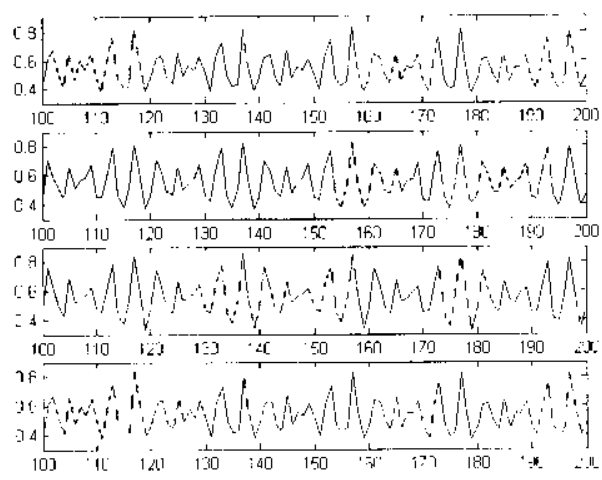

(b)

Figura 5.6: Vctores de pulsos para as imagens (a) "araras" e (b) "cachorro", com rotações de $\left(0^{\circ}, 37^{\circ}, 45^{\circ}\right.$ e $90^{\circ}$.

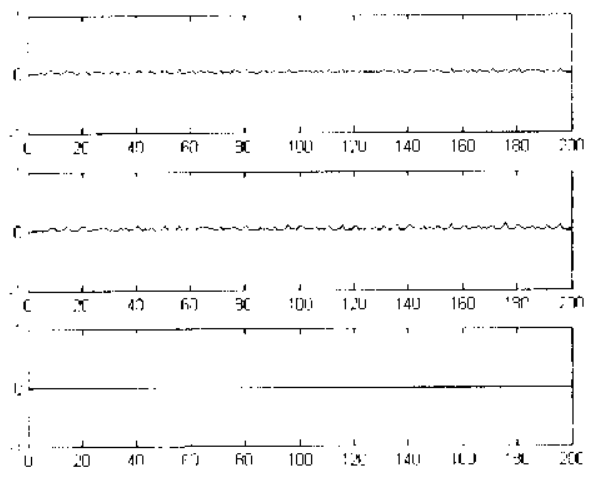

(a)

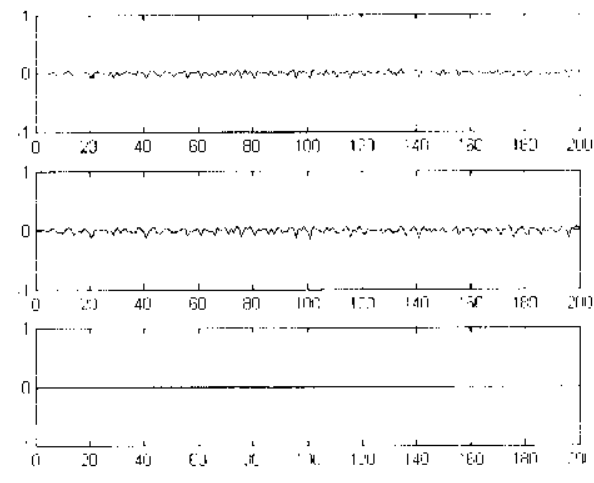

(b)

Figura 5.7: Diferença entre o vetor da imagem "cachorro" original com suas transformações em $37^{\circ}, 45^{\circ}$ e $90^{\circ}$, (a) trata-se dos vetores de estados $\mathrm{e}(\mathrm{b})$ trata-se dos vetores de pulsos.

máxima estão representadas pela cor branca). $\Lambda$ formação de padrão ainda não foi incorporada ao modelo proposto para extração de características invariantes.

I ma boa característica invariante deve ser similar para o mesmo padrão e a mesmo tempo apresentar diferenças razoáveis para padrões distintos. Já vimos que os vetores de estados ou pulsos de diferentes versões rotacionadas da mesma imagem são similares. Agora, precisamos examinar se os vetores de estados ou pulsos de imagens distintas também sâo diferentes. Na Figura 5.10, vemos os vetores de estados de cinco imagens diferentes. sendo que foram usadas as imagens originais da Figura 5.3 e Figura 5.9. A Figura 5.10 mostra claramente as diferenças entre os cinco vetores de estados correspondente às cinco imagens. Na parte (a) vemos os vetores de estados de 200 iterações. (b) mostra uma seção de (a) afim de ver com maior detalhe. 


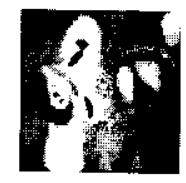

(a)

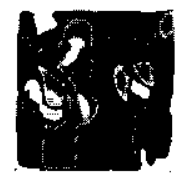

(b)

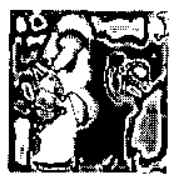

(c)

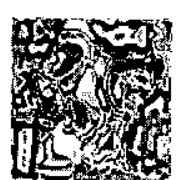

(d)
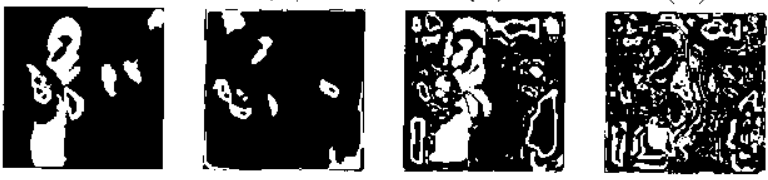

Figura 5.8: A formação de padrão. A primeira linha mostra a formação de padrão por estados celulares e a segunda linha mostra a formação de padrão por pulsos. (a) a formação de padrão depois de 5 iterações, (b) depois de 8 iterações, (c) 20 iterações e (d) 50 iterações.

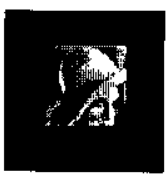

(a)

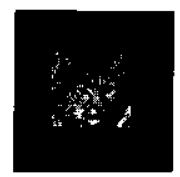

(b)

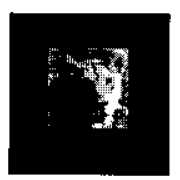

(c)

Figura 5.9: Padrões adicionais usados para testar as técnicas e serem classificados posteriormente, (a) Lenna, (b) lince e (c) leão.

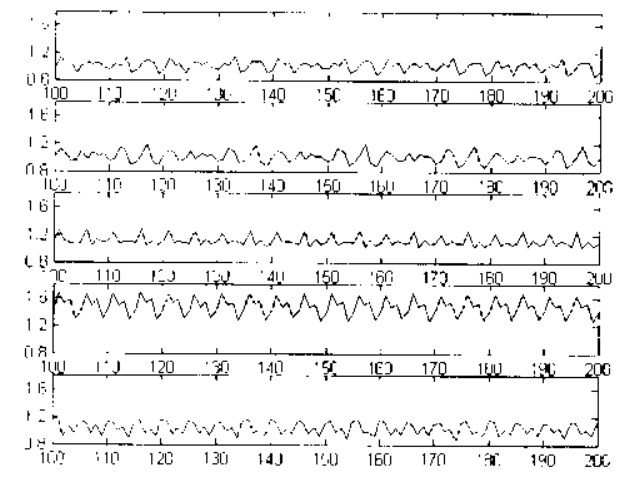

(a)

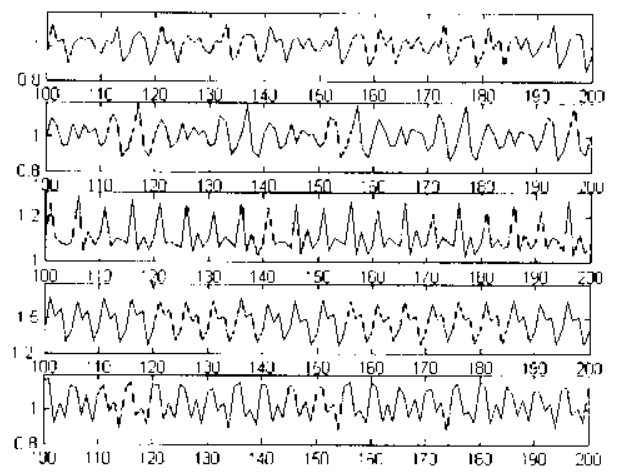

(b)

Figura 5.10: Vetores de estados das imagens originais das Figuras 5.3 e 5.9. (a) Mostra os vetores completos, cada um com 200 iterações e (b) mostra uma seção do vetor.

A Figura 5.11 mostra 4 imagens com diferentes porcentagens de ruído $(5,10,20$ e $30 \%)$, adiciona pixels à imagem em forma aleatória. simulando o efeito de disparar sobre as figuras de um filme em alta velocidade. A distribuição gaussiana é usada para gerar um efeito de mancha mudando o tom do pixel da imagem, onde a porcentagem determina a quantidade de pixels a serem modificados. A Figura 5.12 (a) mostra os vetores de estados para as diferentes imagens da Figura 5.11, sendo que o primeiro vetor de estados é o vetor da imagem "cachorro" livre de ruído (b) mostra a distância entre o vetor de estados sem ruído com os vetores das diferentes versões da mesma com ruídos de 5, 10, 20 e 30\%, respectivamente. Como já era esperado, 
a similaridade entre os vetores de estados da imagem original e da imagem com ruído decai conforme o nível de ruído aumenta. Outra ve $z$, as similaridades são aceitáveis pclo classificador, o que nos leva a concluir que o modelo apresenta certo nível de tolerância ao ruído.

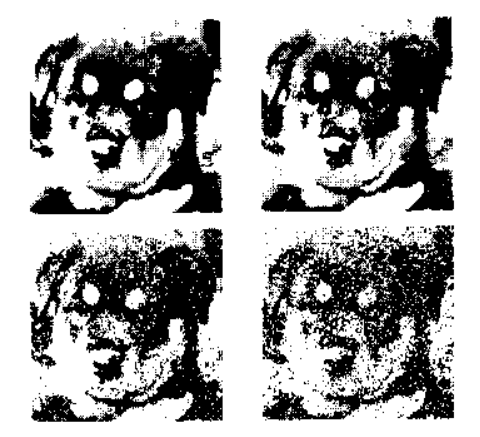

Figura 5.11: Imagens com rú́do. Começando de esquerda para direita e de cima para baixo apresentam-se versões com ruído, tendo uma porcentagem de ruído de 5.10 .20 e $30 \%$.

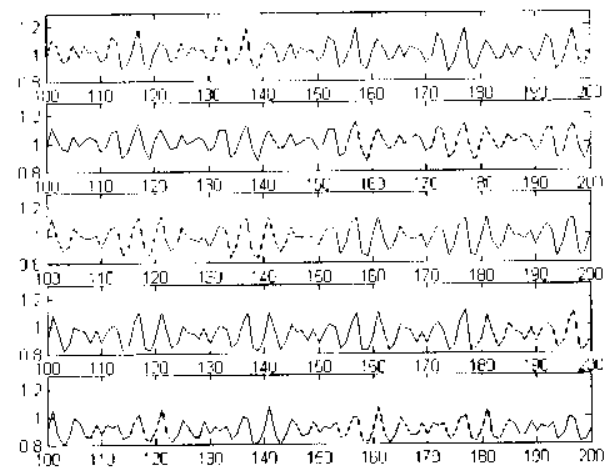

(a)

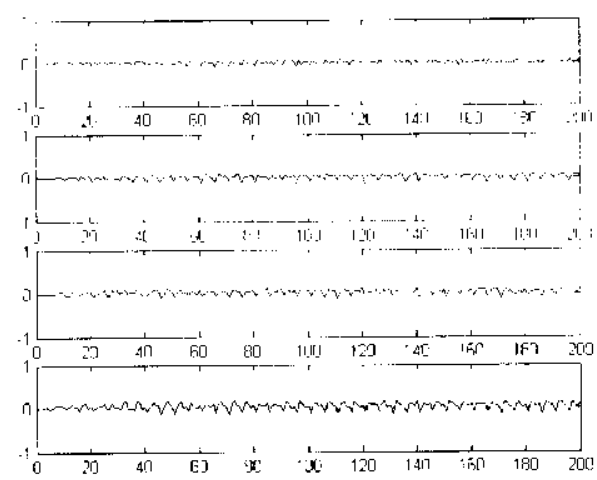

(b)

Figura 5.12: (a) Vetores de estados das imagens com diferentes porcentagens de ruído. (b)Diferença (distância) entre o vetor da imagem original com os vetores com porcentagens de ruído de $5,10,20,30 \%$. As imagens com ruído são aquelas que vemos na Figura 5.11.

En resumo, o modelo apresenta um desempenho satisfatório, no qual as transformações geométricas dos padrões têm valores similares c são diferentes entre padrões de classes distintas.

\subsection{Resultados de classificação}

Nesta seção, resultados de classificação das características invariantes usando a rede neural Fuzzy ART como classificador são apresentados. Uma comparação entre o modelo proposto e outras técnicas, momentos de Hu, momentos de Zernike e rede de pulso acoplado, é feita. 
Usou-se uma base de dados formada por 5 categorias, cada qual contendo 50 versões de uma imagem original, e essas versôes são geradas através de sucessivas rotações da imagem original e/ou inclusão de ruído na mesma (esta pode chegar até uma porcentagem de $40 \%$ de ruído), i.e., cada categoria está formada por imagens rotacionadas e/ou com ruído de uma imagem original. Como a base de dados contém 5 categorias, ela estará formada por 250 padrões no total, os quais devem ser classificados.

Na Tabela 5.1 vemos os valores dos parâmetros da rede fuzzy ART, para o parâmetro de escolha $\alpha$, a taxa de aprendizado $\beta$ e o parâmetro de vigilância $\rho$.

\begin{tabular}{|l|l|c|l|}
\hline & $\begin{array}{l}\text { Parâmetro de } \\
\text { escolha }(\alpha)\end{array}$ & Taxa de aprendizado $(\beta)$ & $\begin{array}{l}\text { Parâmetro de } \\
\text { vigilância }(\rho)\end{array}$ \\
\hline Modelo Proposto (estado) & 40 & 1 & 0.87 \\
Modelo Proposto (pulso) & 40 & 1 & 0.75 \\
Rede de Pulso & 0.001 & 1 & 0.585 \\
Zernike & 0.001 & 1 & 0.53 \\
Hu & 0.001 & 1 & 0.91 \\
\hline
\end{tabular}

Tabcla 5.1: Valores dos parâmetros para a rede fuzzy ART.

Na Tabela 5.2, os resultados da classificação podem ser vistos. No caso dos vetores, a técnica que apresentou melhor desempenho foi a técnica de vetor de pulsos, com precisão de $100 \%$ e quando foi usado o vetor de estados a precisão obtida foi de $96.8 \%$. Ambos os casos foram superiores aos momentos estatísticos e a técnica do vetor de pulsos foi superior à rede de pulso acoplado. Os resultados obtidos das simulações mostram que as duas técnicas (pulso e estados) propostas apresentam desempenho razoável comparado com as outras técnicas. Podemos ver que ao utilizar o vetor de pulsos como conjunto de características, este teve um desempenho melhor que o vetor de estados, isto pode ser devido a que como o vetor de estado contém maior quantidade de informação este pode estar atrapalhando de alguma forma a separação dos grupos. Como as características extraídas por nosso modelo não dependem do classificador, pode ser usado outra técnica para classificá-los.

\begin{tabular}{|c|c|}
\hline Técnica RPI & Precisão de classificação \% \\
\hline Modelo P. (pulso) & $100.0 \%$ \\
\hline Rede de Pulso & $97.2 \%$ \\
\hline Modelo P. (estado) & $96.8 \%$ \\
\hline Momentos de Zernike & $87.6 \%$ \\
\hline Momentos de Hu & $84.0 \%$ \\
\hline \hline
\end{tabular}

Tabela 5.2: Resultado de classificação por diversas técnicas de extração de características invariantes. 


\subsection{Considerações finais}

Neste capitulo foi apresentado um sistema celulares evolutivo para extração de características invariantes à rotação. O desempenho deste modelo foi razoável comparando-o com as outras técnicas de extração de características invariantes. Uma outra vantagem é que o vetor de características invariantes não precisa ser muito longo por ser periódico. Conseqüientemente, a eficiência é aumentada. 


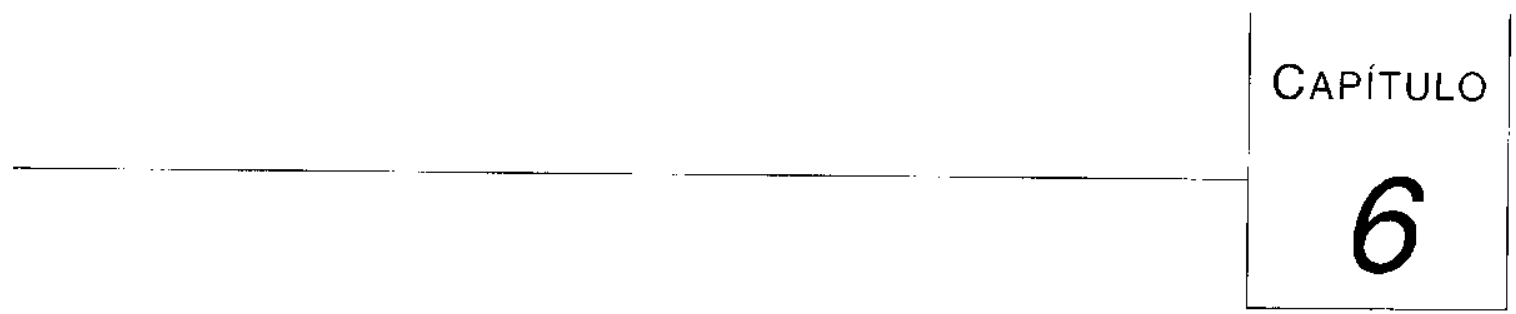

\section{Conclusões e Trabalhos Futuros}

\subsection{Considerações iniciais}

Neste capítulo são apresentadas as conclusões deste trabalho e algumas propostas de trabalhos futuros que podem ser realizados tomando como ponto de partida os modelos propostos nesta Dissertação. Como resultado deste trabalho observa-se que o modelo proposto possui um desempenho aceitável comparado com os métodos tradicionais, mas também apresenta alguns problemas. como a extração de características para imagens binárias.

\subsection{Conclusões}

O reconhecimento de padrôes invariantes, a cada dia, vem se tornando mais e mais importante. O estudo e uso do mesmo podem ser encontrados tanto em nível de pesquisa como na área industrial.

O uso de técnicas de extração de características invariantes como momentos estatísticos, transformada de Fourier, casamento de grafos já foram estudadas amplamente, mas apresentam certos problemas como a pouca tolerância ao ruído, além de exigirem um grande número de iterações conforme a complexidade da técnica é aumentada. Então, surge a necessidade de se 
buscar um novo modelo capaz de realizar cssa atividade de forma simples, conseguindo atingir os mesmos objetivos e com eficiência comparável ou melhor.

Os sistemas celulares evolutivos são uma ferramenta promissora para resolver problemas de reconhecimento de padrões invariantes. Inúmeras aplicações de autômatos celulares que podem ser encontradas na literatura recente demonstram a utilidade e importância da mesma. Através de uma arquitetura simples podemos obter um comportamento complexo.

O modelo proposto nesta Dissertação consiste numa grade bi-dimensional, onde cada célula corresponde ao valor pixel de uma imagem. O valor inicial de cada célula é igual ao valor pixel da imagem. Cada célula está conectada com certa quantidade de vizinhos mais próximos. A vizinhança é dada segundo o raio de acoplamento, neste modelo o raio usado é de 3 . Tem-se escolhido esse raio depois de várias tentativas e por possuir um melhor desempenho. Os pesos das conexöes com os vizinhos tem uma distribuição gaussiana. A atividade das células apresentam um comportamento periódico. Uma da vantagem do modelo proposto é sua eficiência e simplicidade. que foram comprovadas pelos resultados obtidos.

As regras que guiam o nosso modelo durante a execução podem ser facilmente adaptadas a situações reais. Apesar de sua complexidade computacional podem ser perfeitamente adequadas para sistemas de arquitetura paralela. Sendo o comportamento paralelo umas das principais vantagens deste modelo é uma implementação em hardware, portanto um processamento em linha.

$\Lambda$ extração de características invariantes da maioria das técnicas estudadas realiza um processamento global, ignorando estruturas locais de padrões e dificultando um reconhecimento em tempo real. A extração de características invariantes usando somente uma técnica local também apresenta problemas, pois sempre existem diferenças locais entre um padrão original e suas versōes transformadas, exigindo buscas exaustivas para casamento de características locais. Portanto. uma combinação de processamento global e local permitiu ter o melhor desempenho. Esta é exatamente a motivação deste trabalho.

O comportamento periódico das células permite uma melhor extração de características. Atravćs das muitas simulações, observamos que padrões similares devem ter características similares, mas isso não ocorre quando o comportamento das células não é periódico. Ou seja, vetores de estados ou pulsos são totalmente diferentes mesmo para padrões semelhantes quando a atividade das células não são periódicas.

O mecanismo de funcionamento do presente modelo permite $100 \%$ de invariância à translação. pois o vetor de estados ou pulsos somente depende da estrutura do padrão, mas não depende da posição do padrão na grade. 
A rede fuzzy ART foi escolhido como classificador devido as vantagens desta rede: a alta velocidade de treinamento, além de lidar com o dilema de elasticidade/plasticidade, mas também apresenta problemas para generalizar assim como a tolerância baixa ao ruído $c$ a dependência da ordem em que são apresentados os padrões de entrada. As características extraídas não dependem do classificador podendo ser outra técnica de classificação.

Os resultados obtidos para imagens em níveis de cinza foram aceitáveis, mas não acontece o mesmo com imagens binárias, onde os vetores de estados e pulsos resultam ser parecidos para todas as imagens. Portanto, cste modelo visa ser uma tentativa intercssante para extração de características invariantes, merecendo um estudo mais profundo, a fim de que o modelo proposto logre atingir características invariantes razoáveis para imagens binárias.

Em síntese, como resultado do presente trabalho, definiu-se um conjunto de regras de transição de um autômato celular para extração de características invariantes. Os resultados obtidos a indicam como uma lécnica potencial para RPI. Modelo que pode ser implementado em hardware devido a seu desempenho paralelo.

\subsection{Trabalhos futuros}

Finalmente, espera-se que os resultados obtidos despertem o interesse de outros pesquisadores que desenvolvam trabalhos relacionados. Alguns tópicos, onde podem-se visualizar potenciais trabalhos futuros são:

- Detinição de novas regras de transição que possibilitem obter melhor caracterização de forma tal que a distância intra-classe diminua e a distância inter-classe aumente.

- Implementação de um sistema celular evolutivo em nível de hardware, desta maneira o sistema será capaz de processar informação em linha.

- Criar um modelo que, além de extrair características, também seja capaz de classificar os dados como um conjunto único e não dividido em parte onde primeiro é obtido o vetor invariante e depois classificado através de qualquer classificador, seja cstatístico ou neural.

- Analisar e aplicar a formação de padrão para reconhecimento invariante.

- Pode ser usado outro classificador, logrando atingir um melhor desempenho na classificaçâo. 


\section{Referências Bibliográficas}

AAsSiNE, S.; JAI. M. E. Vegetation dynamics modelling: a method for coupling local and space dynamics. Ecological Modelling, , n. 154, p. 237-249, 2002.

Abu-Mostafa. Y. S.; PSALTIS, D. Recognitive aspects of moments invariants. IEEE Trans. Pattern Analysis Machine Intelligence, v. 6, p. 698-706, 1984.

Bak, P.; Tang, C.; Wiesenfeld, K. Self-organized criticality. Phys. Rev. A, , n. 38, p. 364-374. 1988 .

Bandini, S.; Mauri. G.; Serra, R. Cellular automata: From a theorical parallel computacional model to its application to complex systems. Parallel Computing, v. 27, p. 539-553, 2001

BEI,KASIM, S. Pattern recognition with moment invariants- a compararitive study and new results. Pattern Recognition, v. 24, n. 12, p. 1117-1138, 1991.

Bertekkamp, E.; Conway, J.; Gly, R. Winning ways, v. 2. Academic Press, 1985.

BERTHE, K.; YANG, Y. Automatic edge and target extraction base on pulse-coupled neuron network wavelet theory (pennw). Beijing. 2001, p. 504-509.

BOYCE, J. F.; HOSSACK. W. J. Moment invariants for pattern recognition. Pattern Recognition Letter, v. 1, n. 5-6, p. 451-456, 1983.

Brockfeld, E.; Barlovic, R.; Schadschneider, A.; Schreckenberg, M. Optimizing traffic lights in a cellular automaton model for city traffic. Physical Review E, v. 64. 2001 .

Colf, S. N. Real-time computation by $\mathrm{n}$-dimensional iteraive arrays of finite-state machines. IELE Trans. Comput., v. C-18, 1969. 
CoRTIJo, F. Introducción al reconocimiento de formas. Disponivel em http:/www-etsi2.ugr.es/depar/ccia/rf/www/temal_00-01_www/, 2000.

Daubechies, 1. Ten lectures on wavelets, v. 61. Rutgers University and AT and T Bell Laboratories: CBMS-NSF Regional Conference Series in Applied Mathematics, 1992.

ECKHORn, R.; Reitboeck, H.; ARnDT, M.: DiCKE., P. Feature linking via syncronization among distruibed assemblies: Simulations of results from cat visual cortex. Neural Comp. v. 2 , p. $293-307.1990$.

Flusser, J. Pattern recognition by affine moments invariants. Pattern Recognition. v. 26. n. 1, p. $167-174,1993$.

G. Carpenter. S. Grossberg, D. B. R. Artmap: Supervised real-time learning and classification of nonstationary data by a self-organizing neural network. Neural Network, 1991 a.

G. Carpenter, S. GrossberG. D. B. R. Fuzzy art: Fast stable learning and catcgotization of analog patterns by an adaptive resonance system. Neural Network, v. 4, n. 6, p. 759-771. 1991b.

G. Carpenter, S. Grossberg, N. M. J. R. D. B. R. Fuzzy artmap: a neural network architecture or incremental supervised learning of analog multidimensional maps. Neural Network, v. 3, n. 5, p. 698-712, 1992.

G. Carpenter, S. G. A massively parallel architecture for a self-organizing neural pattern recognition machine. Computer Vision, Graphics and Image Processing. v. 37. p. 54-115, 1987.

GALlager, R. Information theory and realiable communications. New York: Wiley, citado em (Wolfram, 1984). 1968.

Georgiopoulos, M.; Fernlund, H.; Bebis. G.: Heilman. G. Order of search in fuzzy art and fuzzy artmap: Effect of the choice parameter. Neural Network. v. 9. n. 5. p. $1541-1559,1996$.

Ghosal. S.; Mehrotra, R. Ortogonal moment operators for subpixel edge detection. I'attern Recognition, v. 26, n. 2, p. 295-306, 1993.

Goshtasby, A. Template matching in rotated images. IEEE Trans. Pantem Analvsis and Machine Intelligence, v. PAMI-7, p. 338-344. 1985.

Grossmann. A.; Morlet. J. Decomposition of hardy function into square integrable wavelets of constant shape. SIAM, Journal of Mathematical Analysis. v. 15. n. 4, p. 723-736. 1984. 
Gutierrez, C.; Beltran, C. Wavelets y análisis multi-resolución de alta frecuencia en la eliminacion de ruido e caracterización de imágenes, 2002.

HAYKIN, S. Neural networks - a comprehensive foundation. Pretice Hall, 1999.

IlEW, P. Orthogonal functions on the unit disk having invariance in form. Deparment of Mathematics, The University of Western Australia, 1996.

HSU, H. Moment preserving edge detection and its application to image data compression. Opt. Eng., v. 32, n. 7. p. 1596-1608, 1993.

HU, M. Pattern recognition by invariant moments. Proc. IRE Transactions on Information Theory, p. 179-187, 1961.

JAIN, A.; DLIN, R.: MAO, J. Statistical pattern recognition: A review. IEEE Transactions on Pattern Analysis and Machine Intelligence, v. 22, n. 1, p. 4-37, 2000.

J.Hertz; Krogh, A.; Palmer, R. Introduction to the theory of neural computation, v. 1. Addison-Wesley, 1991.

JoInson, J. Pulse-coupled neural net: translation, rotation, scale, distortion, and intensity signal invariance for images. Opt. Soc. of America, v. 33, n. 26, p. 6239-6253, 1994.

Kan, C.; SRINaTh, M. Combined features of cubic b-spline wavelet moments and zernike moments for invariant pattern recognition. In: IEEE, ed. International Conference on Information Technology: Coding and Computing., 2001, p. 511-515.

KA.V. C.: SRINATH, M. Invariant character recognition with zernike and orthogonal fourier-mellin moments. Pattern Recogntion, v. 35, p. 143-154, 2002.

KHOTANZAND, A.; LU, J.-H. Classification of invariant image representations using a neural network. IEEE Transactions on Acoustic, Speech, and signal Processing, v. 38 , n. 6 , p. $1028-1038,1990$.

KIM, M.; JANG, D.; YANG, Y. A robust-invariant pattern recognition model using fuzzy art. Pattern Recognition, v. 34, p. 1685-1696, 2001.

KOEKOEK, R.; SWARTTOUW, R. The askey-scheme of hypergeometric orthogonal polynomials and its q-analogue. Rel. Tée., Faculty of Technical Mathematics and Informatics - Delft University of Technology, http://citeseer.nj.nec.com/62223.html, 1998.

Kohonen, T. Self-organizing and associative memory. $3 \mathrm{ed}$. Berlin: Springer-Verlag, 1989. 
LANGTON, C. Computation at the edge of chaos: Phase transitions and emergent computation. Physica D., n. 42, p. 12-37, 1990.

LI, Y. Reforming the theory of invariant moments for pattern recongnition. Pattern Recognition, v. 25, n. 7 , p. $723-730,1992$.

LimA, P. C. Wavelets: Teoria, algoritmos e aplicações. Rel. Téc., Departamento de Matemática ICEX UFMG. 2002.

MAI.I.AT, E. G. A theory for multiresolution signal decomposition: The wavelet representation. IFEE Transaction on Pattern analysis and Machine Intelligence, v. 11, n. 7. p. 674-693. 1989.

MUKUndaN, R.; ONG, S.; LEE, P. Image analysis by tchebichef moments. IELE Transartions on Image Processing, v. 10, n. 9, p. 1357-1364, 2001.

de Pádua braga, A.; de Lleon F. de Carval.ho, A. P.; Ludemir, T. Fundamentos de redes neurais artificias. xi escola brasileira de computaçāo. 1988.

Prado, H.; Hirtle, S.; EngFi. P. Scalable model for extensional and intensional descriptions of unclassified data. IPIDPS Workshop, 2000.

RholmA. M. B. H.; Frigui. H. Self-organization of pulse-coupled oscillators with appplications to clustering. IEEE Trans. on Pattem Analysis and Machine Intelligence, v. 23, n. 2 . p. $180-195,2001$.

RISHIKESH, N.: VENKATESII, Y. Shape recognition using invariant pulse code and a hierarchical, competitive neural network. Pattern Recognition, v. 34, p. 841-853, 2001.

RUMELHART, D.; HINTON, G.; WIIIIAMS. R. Learning representations by back-propagation erros. Nature, , n. 323, p. 533-536, 1986.

dos SAntos, R. Z.; Col\%inho, S. Dynamics of hiv infection: A cellular automala approach. Physical Review Letters, v. 87, n. 16, 2001.

SARKAR, P. A brief history of cellular automata. ACM Computing Surveys. v. 32, n. 1 , p. $80-107,2000$.

SHEN, D.; IP, H. H. Discriminative wavelel shape descriptors for recognition id 2-d patterns. Pattern Recognition. v. 32, p. 151-165, 1999.

SHENG, Y.; SHEN, I. Orthogonal fouricr-mellin moments for invariant pattern recognition. J. Opt. Soc. Am. v. 11, p. 1748-1757, 1994. 
Skol:rikihisf. A.; Prasad, L.; Schelei, B. Neural network for imagem segmentation. Application and Science of Neural Networks, Fuzzy Systems, and Evolutionary Computation III, Procedings of SPIE, v. 4120, p. 28-35, 2000.

Smith, $\Lambda$. Simple computation-universal cellular spaces. $\quad J . \Lambda C M$, v. 18, p. 339-353, 1971.

Sternberg, S. Language and architecture for parallel image processing. Pattern Recognition in Practice, p. 35, edited by E.S. Gelesma and L.N. Kanal (North-Holand, Amsterdam), 1980.

Tliaciliz, M. R. Image analysis via the general theory of moments. J. Opt. Soc. Amer., v. 70, p. $920-930,1980$.

TEH, C.; CHIN, R. On image analysis by the methods of moments. IEEE Transactions on Pattern Analysis and Machine Intelligence, v. 10, n. 4, p. 496-513, 1988.

Thomas, F.; Karl-Friedrich, K.; Torsten, K. Comparative analysis of fuzzy art and art-2a network clustering performance. IEEE Trans. on Neural Networks, v. 9, n. 3, p. 544-559. 1998.

Tzionas, P. A cellular processor for line and corner detection in gray-scale images. Recal-Time Imaging, , n. 6, p. 461-470, 2000.

CNSER, M.; Alddroubi, A.; EdEn, M. On the asymptotic convergence of b-spline wavelets to gabor functions. IEEE Transaction Inform. Theory, v. 38, p. 864-872, 1992.

VHHER, B.; DOBNGKAR, A.; ZAZULA, D. Cellular automata and follicle recognition problem and possibilities of using cellular automata for image recognition purposes. Internacional Journal of Medical Informatics, v. 49, p. 231-241, 1998.

WALCZAK, B.; MASSART, D. Local modelling with radial basis function networks. Chemometrics and Intelligent Laboratory Systems, , n. 50, p. 179-198, 2000.

Waldemark, J.; Becanovic, V.; Lindblad, T.; Lindsey, C. Hybrid neural nelworks for automatic target recognition. Systems, Man, and Cybernetics, 1997. Computational Cybernetics and Simulation., 1997 IEEE International Conference on, v. 4, p. 4096-4021, 1997.

WANG, J. Z. Methodological review - wavelets and imaging informatics: A review of the literature. Journal of Biomedical Infornatics, p. 129-141, 2001.

Disponivel em http: / /www. idealibrary.com

Wata.iabe, S. Pattern recognition: Human and mechanical. New York: Wiley, 1985. 
WHOI-YUL, K.; YONG-SUNG, K. A region-based shape descriptor using zernike moments. Image Communication, v. 16, n. 95-102, 2000.

Wolfram, S. Statistical mechanics of cellular automata. Rev. Mod. Phys., v. 55, p. 601-644. 1983.

Wolfram, S. Universality and complexity in cellular automata. Physica, v, 10D, p. 1-35. 1984.

Wol.fRAM, S. Theory and applications of cellular automata. Singapure, 1986.

XIAODOng. G.: HAIMING, W.; IDAOHENG, Y. Binary image restoration using pulse conpled neural network. Rel. Téc.. Electronics Department, National Laboratory on Machine Perception and Center of Information Scicnce, Beijing, 2000.

YAP. P.; Raveedran, P.; ONG, S. Chebyshev moments as a new set of moments for image reconstruction. Procedings IJCNN 01. Internacional Joint Conference on Neural Networks. p. 2856-2860, 2001.

YONG-SUNG, K.; WhOI-YUL, K. Contend-based trademark retrieval system using visually salient feature. J. Image Vision Comput., v. 16, p. 12-13, 1998.

Zhillang, R.; Zhidong, D.; ZfNgel, S. Cellular automaton modeling of computer network. Computer Physics Communications, , n. 144, p. 243-251, 2002. 